
Integral Fast Reactor Integral Fast Reactor Integral Fast Reactor Integral Fast Reactor Integral Fast Reactor Integral Fast Reactor

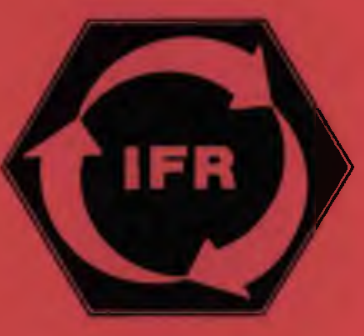

\title{
Analysis of Severe Accident Energetics in Metallic-Fueled, Liquid Metal Cooled Reactors
}

Integral Fast Reactor Integral Fast Reactor Integral Fast Reactor Integral Fast Reactor Integral Fast Reactor Integral Fast Reactor Integral Fast Reactor Integral Fast Reactor Integral Fast Reactor Integral Fast Reactor Integral Fast Reactor Integral Fast Reactor Integral Fast Reactor Integral Fast Reactor Integral Fast Reactor Integral Fast Reactor

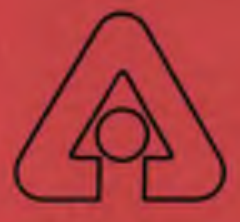

Argonne National Laboratory, Argonne, Illinois 60439 operated by The University of Chicago for the United States Department of Energy under Contract W-31-109-Eng-38

HFR Temmioratmemorandum

Results reported in the IFP TA series of memanta frequently are liminam and subjor rision. Consequently they shoutld not be queted of referenced.

NO ACCESS RESTRICTIONS
This document is not considered OUO-Applied Technology. It was
reviewed for Export Controlled Information and found to be suitable for
unlimited access and reproduction.
This label reflects Applied Technology instructions issued April 13,
2006, by the the Department of Energy Office of Nuclear Energy.
Additional guidance has also been provided by DOE in 2016 and 2018
memos, as well as from NNSA.

by E. E. Morris and A. M. Tentner 
Argonne National Laboratory, with facilities in the states of Illinois and Idaho, is owned by the United States government, and operated by The University of Chicago under the provisions of a contract with the Department of Energy.

\section{DISCLAIMER}

This report was prepared as an account of work sponsored by an agency of the United States Government. Neither the United States Government nor any agency thereof, nor any of their employees, makes any warranty, express or implied, or assumes any legal liability or responsibility for the accuracy, completeness, or usefulness of any information, apparatus, product, or process disclosed, or represents that its use would not infringe privately owned rights. Reference herein to any specific commercial product, process, or service by trade name, trademark, manufacturer, or otherwise, does not necessarily constitute or imply its endorsement, recommendation, or favoring by the United States Government or any agency thereof. The views and opinions of authors expressed herein do not necessarily state or reflect those of the United States Government or any agency thereof. 


\section{DISCLAIMER}

This report was prepared as an account of work sponsored by an agency of the United States Government. Neither the United States Government nor any agency Thereof, nor any of their employees, makes any warranty, express or implied, or assumes any legal liability or responsibility for the accuracy, completeness, or usefulness of any information, apparatus, product, or process disclosed, or represents that its use would not infringe privately owned rights. Reference herein to any specific commercial product, process, or service by trade name, trademark, manufacturer, or otherwise does not necessarily constitute or imply its endorsement, recommendation, or favoring by the United States Government or any agency thereof. The views and opinions of authors expressed herein do not necessarily state or reflect those of the United States Government or any agency thereof. 


\section{DISCLAIMER}

Portions of this document may be illegible in electronic image products. Images are produced from the best available original document. 
ANALYSIS OF SEVERE ACCIDENT ENERGETICS IN METALLIC-FUELED, LIQUID METAL COOLED REACTORS

by

E. E. Morris and A. M. Tentner

Reactor Analysis Division

Argonne National Laboratory

9700 South Cass Avenue

Argonne, I1linois 60439

IFR TECHNICAL MEMORANDUM NO. 235

Results reported in the IER-TM series of memoranda

frequently are preliminary and subject to revision.

Consequently they should not he quated or referenced.

\section{APPLIED TECHNOLOGY}

Any further distribution by any holder of this document op data therein to third parties representing foreign interests, foreign govornments, foreign companies, and foreign subsidiaries or foreign divisions of U.S. companies shall be approved by the Directop for Reactor Systoms, Development, and Technology, Office of Nuclear Energy, U.S. Department of Energy. Further, foreign party release may require DOE approval pursuant to-Federal Regulation 10 CFR-Part 810, andfor may be subject to Section 127 of the Atomic Energy Act. 



\section{TABLE OF CONTENTS}

\section{Page}

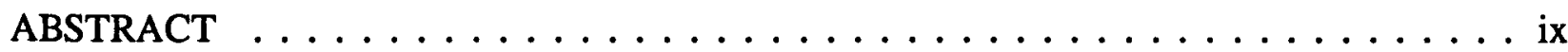

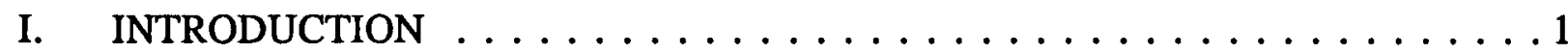

A. Severe Accidents and Passive Safety . . . . . . . . . . . 1

B. Severe Accident Phenomena . . . . . . . . . . . . . 2

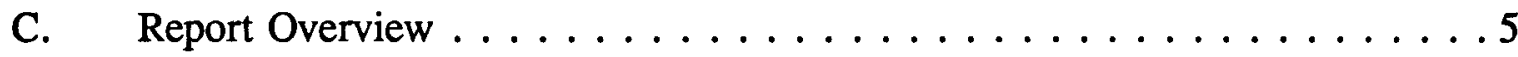

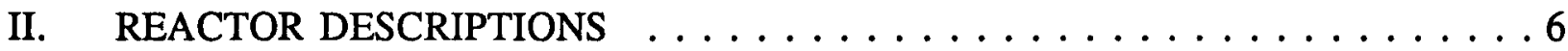

III. SAS4A MODELING AND INPUT ASSUMPTIONS $\ldots \ldots \ldots \ldots \ldots \ldots$

A. Assembly-to-channel Assignments $\ldots \ldots \ldots \ldots \ldots$

B. SAS4A Models and Input Assumptions $\ldots \ldots \ldots \ldots \ldots \ldots$

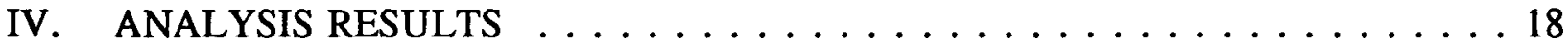

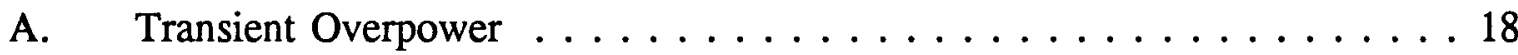

B. Loss of Flow . . . . . . . . . . . . . . . . 21

1. Abrupt Loss of Flow in a 3500-MWt Reactor . . . . . . . . . 22

a. Reference Case . . . . . . . . . . . . . 22

b. Parametric Cases . . . . . . . . . . . . . . . 27

2. Abrupt Loss of Flow in the PRISM Mod B/92 . . . . . . . 36

a. Reference Case . . . . . . . . . . . . 36

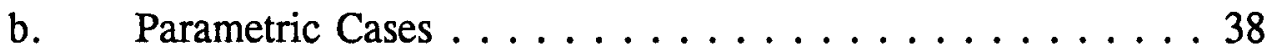

3. Rapid Loss of Flow in the Actinide Burner . . . . . . . . . 41

4. Summary of Abrupt Loss-of-flow Analysis . . . . . . . . . 42

V. PHENOMENOLOGICAL CONSIDERATIONS . . . . . . . . . . . 43

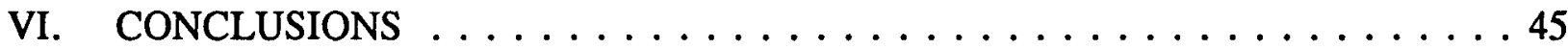

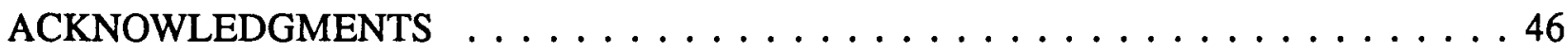

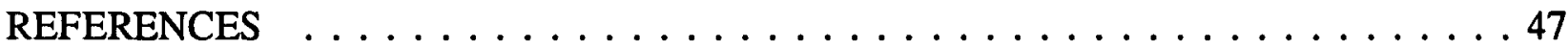




\section{LIST OF FIGURES}

$\underline{\text { Page }}$

1. Plan View of Core for the Actinide Burner $\ldots \ldots \ldots \ldots \ldots \ldots$

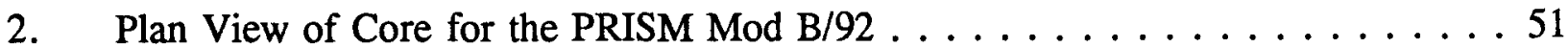

3. Plan View of Core for the $3500-M W t$ Reactor $\ldots \ldots \ldots \ldots \ldots \ldots \ldots$

4. SAS4A Channel Assignments for the Actinide Burner $\ldots \ldots \ldots \ldots \ldots \ldots$

5. Fraction of Actinide Burner Core with Power Greater or Equal to Normalized Power . . . . . . . . . . . . . . . . . 54

6. SAS4A Channel Assignments for the PRISM Mod $\mathrm{B} / 92 \ldots \ldots \ldots \ldots \ldots$

7. Seventy-Eight- and 12-channel Representation of the Fraction of the PRISM Mod B/92 Core with Power Greater than the

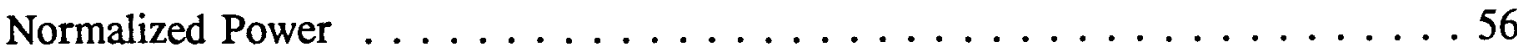

8. SAS4A Channel Assignments for the $3500-$ MWt Reactor $\ldots \ldots \ldots \ldots \ldots$. . . . 57

9. Fifty-Five- and 25-channel Representation of the Fraction of the 3500-MWt Core with Power Greater than the Normalized Power . . . . . . . . . . . . . . . . . . . . . 58

10. Reactor Power During a $0.1 \$ / \mathrm{s}$ Reactivity Insertion in the Actinide Burner . . . . . . . . . . . . . . . . . . . . . . 59

11. Reactivities During a $0.1 \$ / \mathrm{s}$ Reactivity Insertion in the Actinide Burner . . . . . . . . . . . . . . . . . . . . . 59

12. Reactor Power During a $1 \$ / \mathrm{s}$ Reactivity Insertion in the Actinide Burner . . . . . . . . . . . . . . . . . . 60

13. Reactivities During a $1 \$ / \mathrm{s}$ Reactivity Insertion in the Actinide Burner . . . . . . . . . . . . . . . . . . . 60

14. Reactor Power During a $10 \$ / \mathrm{s}$ Reactivity Insertion in the Actinide Burner . . . . . . . . . . . . . . . . . . . . . 61

15. Reactivities During a $10 \$ / \mathrm{s}$ Reactivity Insertion in the Actinide Burner . . . . . . . . . . . . . . . . . . . . . 61

16. Power and Flow During the Reference Transient for the 3500-MWt Reactor . . . . . . . . . . . . . . . . . . . . . . . 62

17. Net and Component Reactivities During the Reference Transient for the $3500-$ MWt Reactor $\ldots \ldots \ldots \ldots \ldots$. . . . . . . . . . 62

18. Representative Temperatures During the Reference Transient for the $3500-M W t$ Reactor $\ldots \ldots \ldots$. . . . . . . . . . . . . 63 


\section{LIST OF FIGURES}

(Contd.)

Page

19. Top and Bottom of the Voided Region During the Reference Transient for the $3500-\mathrm{MWt}$ Reactor . . . . . . . . . . . . . . . . . 63

20. Power and Flow During the Reference Transient for the 3500-MWt Reactor . . . . . . . . . . . . . . . . . . . . . . . . . . . 64

21. Net and Component Reactivities During the Reference Transient for the $3500-$ MWt Reactor . . . . . . . . . . . . . . . . . . . . . . . 64

22. Channel Dependent Fuel Motion Reactivity Feedback During the Reference Transient for the 3500-MWt Reactor . . . . . . . . . . . . . . 65

23. Channel Dependent Fuel Motion Reactivity Feedback During the Reference Transient for the 3500-MWt Reactor . . . . . . . . . . . . . . . . 65

24. Channel Dependent Fuel Motion Reactivity Feedback During the Reference Transient for the $3500-\mathrm{MWt}$ Reactor . . . . . . . . . . . . . . 66

25. Energy Release During the Reference Transient in the 3500-MWt Reactor . . . . . . . . . . . . . . . . . . . . . . . 66

26. Void Pattern at $2.46 \mathrm{~s}$ During the Reference Transient in the 3500-MWt Reactor . . . . . . . . . . . . . . . . . . . . . . . 67

27. Void Pattern at $2.55 \mathrm{~s}$ During the Reference Transient in the 3500-MWt Reactor . . . . . . . . . . . . . . . . . . . . . . . 67

28. Void Pattern at $2.68 \mathrm{~s}$ During the Reference Transient in the 3500-MWt Reactor . . . . . . . . . . . . . . . . . . . . . . . . 68

29. Void Pattern at $2.88 \mathrm{~s}$ During the Reference Transient in the 3500-MWt Reactor . . . . . . . . . . . . . . . . . . . . . . . . . . 68

30. Selected Cladding Temperatures in Channel 1 During the Reference Transient for the $3500-\mathrm{MWt}$ Reactor . . . . . . . . . . . . . . . . . 69

31. Selected Pressure Differences in Channel 1 During the Reference Transient for the 3500-MWt Reactor

32. Cladding Thicknesses in Channel 1 During the Reference Transient for the 3500-MWt Reactor . . . . . . . . . . . . . . . . . . 70

33. Linear Fuel Density as a Function of Time and Axial Position During the Reference Transient in the 3500-MWt Reactor . . . . . . . . . . . . 71

34. Linear Fuel Density as a Function of Time and Axial Position During the Reference Transient in the 3500-MWt Reactor 


\section{LIST OF FIGURES}

(Contd.)

35. Linear Fuel Density as a Function of Time and Axial Position

During the Reference Transient in the 3500-MWt Reactor . . . . . . . . . . . 72

36. Linear Fuel Density as a Function of Time and Axial Position

During the Reference Transient in the 3500-MWt Reactor . . . . . . . . . . 72

37. Comparison of Case 1 with Reference Transient

for the $3500-M W t$ Reactor $\ldots \ldots \ldots \ldots \ldots \ldots$. . . . . . . . . . . . . .

38. Comparison of Case 1 with Reference Transient

for the $3500-\mathrm{MWt}$ Reactor $\ldots \ldots \ldots \ldots \ldots$. . . . . . . . . . . 73

39. Comparison of Case 2 with Reference Transient

for the $3500-$ MWt Reactor . . . . . . . . . . . . . . . . . . . 74

40. Comparison of Case 2 with Reference Transient

for the $3500-\mathrm{MWt}$ Reactor . . . . . . . . . . . . . . . . . . 74

41. Comparison of Case 3 with Reference Transient

for the $3500-\mathrm{MWt}$ Reactor . . . . . . . . . . . . . . . . . . . . . 75

42. Comparison of Case 3 with Reference Transient

for the $3500-M W t$ Reactor . . . . . . . . . . . . . . . . . . . . 75

43. Comparison of Case 4 and Case 5 with Reference

Transient for the $3500-\mathrm{MWt}$ Reactor . . . . . . . . . . . . . . . 76

44. Comparison of Case 4 and Case 5 with Reference

Transient for the $3500-M W t$ Reactor . . . . . . . . . . . . . 76

45. Comparison of Case 4 and Case 5 with Reference

Transient for the 3500-MWt Reactor . . . . . . . . . . . . . . . 77

46. Comparison of Case 4 and Case 5 with Reference

Transient for the $3500-\mathrm{MWt}$ Reactor . . . . . . . . . . . . . . 77

47. Comparison of Case 6 and Case 7 with Reference

Transient for the $3500-\mathrm{MWt}$ Reactor . . . . . . . . . . . . . . . 78

48. Comparison of Case 6 and Case 7 with Reference

Transient for the $3500-\mathrm{MWt}$ Reactor . . . . . . . . . . . . . . . 78

49. Comparison of Case 6 and Case 7 with Reference

Transient for the 3500-MWt Reactor . . . . . . . . . . . . . . . . 79

50. Comparison of Case 6 and Case 7 with Reference

Transient for the 3500-MWt Reactor 


\section{LIST OF FIGURES \\ (Contd.)}

Page

51. Comparison of Case 6 and Case 7 with Reference

Transient for the $3500-\mathrm{MWt}$ Reactor . . . . . . . . . . . . . . . . 80

52. Comparison of Case 4 and Case 8 for the $3500-\mathrm{MWt}$

Reactor .......................... 81

53. Comparison of Case 4 and Case 8 for the 3500-MWt

Reactor ...........................881

54. Comparison of Cases 5, 9, and 10 for the 3500-MWt

Reactor . . . . . . . . . . . . . . . . . . 82

55. Comparison of Cases 5, 9, and 10 for the 3500-MWt

Reactor . . . . . . . . . . . . . . . . . . . 82

56. Comparison of Case 11 and Case 12 with Reference

Transient for the $3500-\mathrm{MWt}$ Reactor $\ldots \ldots \ldots \ldots \ldots$. . . . . . . . 83

57. Comparison of Case 11 and Case 12 with Reference

Transient for the $3500-\mathrm{MWt}$ Reactor . . . . . . . . . . . . . . 83

58. Channel Dependent Fuel Motion Reactivity Feedback for Case $11 \ldots \ldots$. . . . 84

59. Channel Dependent Fuel Motion Reactivity Feedback for Case 11 . . . . . . . 84

60. Comparison of Case 13 with the Reference Transient for the $3500-M W t$ Reactor . . . . . . . . . . . . . . . . . . 85

61. Comparison of Case 13 with the Reference Transient for the $3500-M W t$ Reactor . . . . . . . . . . . . . . . . . . 85

62. Comparison of Case 14 with Case 5 for the $3500-\mathrm{MWt}$

Reactor . . . . . . . . . . . . . . . . . . . 86

63. Comparison of Case 14 with Case 5 for the $3500-\mathrm{MWt}$

Reactor . . . . . . . . . . . . . . . . . . 86

64. Power and Flow During the Reference Transient for the PRISM

Mod B/92 . . . . . . . . . . . . . . . . . . . . . . . . . . . 87

65. Net and Component Reactivities During the Reference Transient

for the PRISM Mod B/92 . . . . . . . . . . . . . . . . . . . 87

66. Channel Dependent Fuel Motion Reactivity Feedback During the

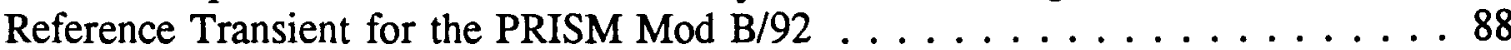

67. Channel Dependent Fuel Motion Reactivity Feedback During the

Reference Transient for the PRISM Mod B/92 . . . . . . . . . . . 888 


\section{LIST OF FIGURES}

(Contd.)

68. Status of the Core at $5.15 \mathrm{~s}$ During the Reference Transient for the PRISM Mod $\mathrm{B} / 92 \ldots \ldots \ldots$. . . . . . . . . . . . . . . . . . .

69. Status of the Core at $5.35 \mathrm{~s}$ During the Reference Transient for the PRISM Mod B/92 . . . . . . . . . . . . . . . . . . . 89

70. Status of the Core at $5.55 \mathrm{~s}$ During the Reference Transient for the PRISM Mod $\mathrm{B} / 92 \ldots \ldots \ldots \ldots \ldots \ldots$

71. Power and Flow During Case 1 for the PRISM Mod B/92 . . . . . . . . 91

72. Net and Component Reactivities During Case 1 for the PRISM Mod $\mathrm{B} / 92 \ldots \ldots \ldots \ldots \ldots$. . . . . . . . . . . . . .

73. Power and Flow During Case 2 for the PRISM Mod B/92 . . . . . . . . 92

74. Net and Component Reactivities During Case 2 for the PRISM Mod $\mathrm{B} / 92 \ldots \ldots \ldots \ldots . \ldots \ldots 2$

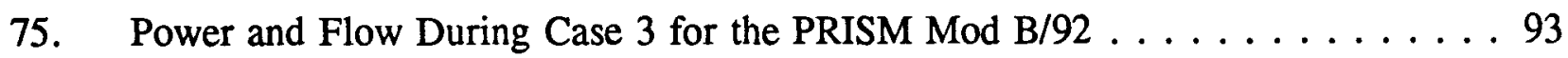

76. Power and Flow During Case 4 for the PRISM Mod B/92 . . . . . . . . . . . 94

77. Net and Component Reactivities During Case 4 for the PRISM Mod $\mathrm{B} / 92 \ldots \ldots \ldots \ldots$. . . . . . . . . . . . . . . . . .

\section{LIST OF TABLES}

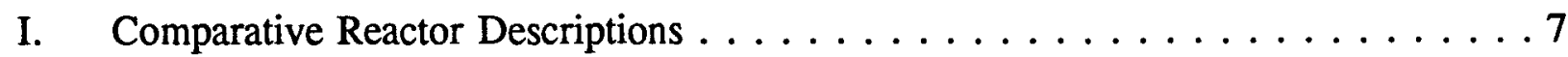

II. Summary of Selected SAS4A Channel Information

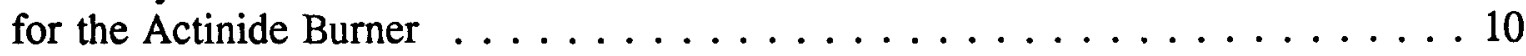

III. Summary of Selected SAS4A Channel Information for the PRISM Mod $\mathrm{B} / 92 \ldots \ldots \ldots \ldots \ldots \ldots$

IV. Summary of Selected SAS4A Channel Information

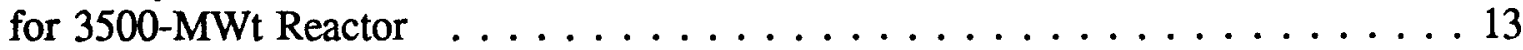

V. Summary Description of Parametric Cases for 3500-MWt Reactor . . . . . . . . . . . . . . . . . . . . . 27

VI. Summary Description of Parametric Cases for PRISM

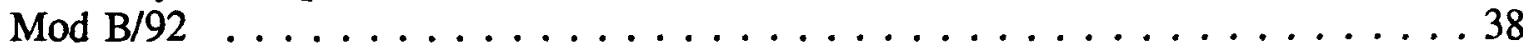




\title{
ANALYSIS OF SEVERE ACCIDENT ENERGETICS IN METALLIC-FUELED, LIQUID METAL COOLED REACTORS
}

by

\author{
E. E. Morris and A. M. Tentner
}

\begin{abstract}
The energetics potential of severe accidents is investigated for metallicfueled reactors using the SAS4A accident analysis code. The accident initiators considered are transient overpower and loss of flow, each with failure to scram. Extensive analysis of the response of metallic-fueled reactors to double fault initiators such as loss of flow, loss of heat sink, or transient overpower with failure to scram shows that the reactors passively adjust their power to match the available heat rejection capability without boiling coolant or melting fuel. The analysis considered here assumes some extremely unlikely additional contribution to the accident such as an essentially unlimited reactivity insertion in the case of the transient-overpower sequence, or failure of the flow-coastdown device in the case of a loss-of-flow sequence. When the reactivity insertion rates are high enough, either due to control rod motion or due to coolant voiding, the low melting point of metallic fuel allows fuel to disperse within intact cladding prior to cladding failure. Negative reactivity feedback from this in-pin fuel motion counters the positive reactivity insertion and prevents a rapid and large release of energy. The SAS4A analysis shows that extensive core melting and disruption can be expected, but that the energy release will not be large enough to threaten rupture of the reactor vessel. Metallic fuel acts as an additional safety device which acts to counter large or rapid reactivity insertions either from inadvertent control rod motion or coolant boiling and voiding.
\end{abstract}




\section{INTRODUCTION}

The SAS4A accident analysis code[1] has been used to investigate the energetics potential of severe accidents in metallic-fueled reactors. The accidents investigated are transient-overpower (TOP) and loss-of-flow (LOF) sequences with failure to scram. Calculations for the TOP sequence assume a linear reactivity insertion rate with essentially no limit on the amount of reactivity that can be inserted, while the calculations for the LOF sequence assume that the primary coolant pumps stop abruptly, leading to a very rapid reduction in flow. These initiators are extremely unlikely events, but could perhaps be caused by a very large earthquake which causes the reactor core to move rapidly away from the control rods or which causes the coolant pump rotors to seize. The calculations show that extensive core melting and disruption could be expected, but that the amount of energy released during the reactivity excursion would not be sufficient to pose an immediate threat to the reactor vessel and would not pose a threat to persons in the vicinity of the reactor.

\section{A. Severe Accidents and Passive Safety}

Extensive analysis of the response of metallic-fueled reactors to double fault initiators such as loss of flow, loss of heat sink, or transient overpower with failure to scram have shown that the reactors passively adjust their power to match the available heat rejection capability without boiling coolant or melting fuel.[2-4] In order to initiate coolant boiling and subsequent fuel melting and relocation, at least one additional fault must be assumed. For example, in the case of the TOP, many control rods must move at the same time and/or the rod-stop device must fail so that an essentially unlimited amount of reactivity is added, or perhaps a catastrophic earthquake causes the core support structure to give way, allowing the core to fall away from the control rods. In the case of the LOF, one must assume that the flow coastdown device fails or that the pump rotors seize. Catastrophic pump failure might be caused by a very large earthquake. In any event, such multiple fault initiators must have extremely low probability of occurring. 
This report is the first assessment of the energetics potential in metallic cores of the TOP accident for initiators that lead to fuel melting and subsequent relocation; however, Sevy[5] has performed scoping analyses of the LOF accident involving a sudden loss of flow in metallic cores with coolant void worths up to about $10 \$$. His analysis developed an accident scenario in which coolant boiling and subsequent voiding pushes the reactivity to a level near, but below prompt critical and the power to a few tens times nominal. By this time, considerable fuel melting has occurred, but cladding remains intact. Since fuel melting in many fuel subassemblies extends all the way to the top of the active fuel pin, fission gas, trapped in the fuel porosity, is able to push fuel upward into the fission-gas plenum. This in-pin fuel motion causes a significant reduction in the reactivity, and quickly brings the power to a level a few times nominal power. Continued deposition of energy in the fuel eventually leads to cladding failures above, but fairly close, to the axial midplane. A modest increase in reactivity caused by the motion of fuel within the cladding toward the failure point is insufficient to push the reactivity close to prompt critical, and subsequent dispersion of the fuel through the coolant channels leads to neutronic shutdown, thus terminating the initiating phase of the transient. His calculated fuel temperatures were well below the levels required to produce significant fuel vapor pressures, and he concluded that the transient posed no immediate threat to the reactor vessel. The SAS4A analyses contained in this report confirm the basic scenario proposed by Sevy and support his conclusion that the initiating phase of sudden-loss-of-flow accidents does not produce an energetics challenge to the reactor vessel.

\section{B. Severe Accident Phenomena}

Severe accidents initiated by inadvertent reactivity insertions or loss of coolant flow have been investigated over many years for oxide fueled cores. TOP analysis for the Clinch River Breeder Reactor is reported in Ref. 6 for reactivity insertion rates up to $0.1 \$ / s$. Note that 0.1 $\$ / \mathrm{s}$ was four times the design maximum control rod withdrawal rate. The analysis showed that the event was relatively benign, with limited core damage and fuel in a coolable geometry at the end of the initiation phase of the accident. The analysis predicted cladding failures near the top of the core and removal of the fuel ejected from the fuel pins by the flowing sodium. 
Similar results were obtained for beginning and end of equilibrium of equilibrium cycle cores. It was concluded that different results could be expected only if cladding failures were presumed to occur near the core axial-midplane or if higher reactivity insertion rates were considered.

Because of the benign nature of the TOP accident, most subsequent analysis for oxidefueled cores focused on the LOF accident sequence. Analyses for this accident are reported in Refs. 6, 7, and 8 for the Clinch River Breeder Reactor and in Refs. 9 and 10 for a large pooltype reactor. Reference 6 identifies the basic accident sequence for a core designed with a 2.5 to $3 \$$ void worth. Following the initiation of flow reduction, the net reactivity and the reactor power decline because of the dominance of Doppler and fuel axial expansion reactivity feedback. The initiation of coolant boiling drives the reactivity upward so that at the time when fuel pin disruptions begin to occur, the net reactivity is in the 0.7 to $0.9 \$$ range and the power is on the order of 10 times nominal. Following this, assuming that cladding does not move very much prior to the breakup of the fuel, and assuming a significant amount of fission gas has been released to the fuel grain boundaries, one or two mild power excursions occur, caused by the initial fuel relocation and continued coolant voiding. The fuel relocation then becomes essentially dispersive, and neutronic shutdown is achieved.

Two major uncertainties in the calculation were in the amount of fission gas immediately available to influence fuel motion and the amount of clad motion (cladding melts before the fuel) that might occur prior to the time when fuel motion begins. In cases where significant clad motion occurs or in which there was an inadequate amount of fission gas immediately available to drive fuel motion, then either the positive feedback caused by the movement of cladding toward the core boundary or positive feedback due to the compaction of fuel following fuel pin breakup could drive the net reactivity close to, and in some cases beyond, prompt critical and the associated power excursion could cause cladding failures in lower powered subassemblies prior to any significant voiding in these subassemblies. Because of the high power level, the cladding failures tended to be close to the axial midplane. The ejection of molten fuel and the resulting fuel/coolant interaction caused rapid voiding of a high void-worth 
region of the core causing the net reactivity and the power to escalate even more. In addition, if the failure site was localized, the motion of molten fuel within the fuel pin could also contribute positive reactivity driving the net reactivity and power even higher. In these cases a hydrodynamic disassembly followed and neutronic shutdown depended on the production of significant levels of fuel vapor pressure.

When an accident proceeds to the point of coolant voiding and fuel melting, reactors with metallic fuel have a significant advantage over reactors with oxide fuel. The analysis for oxide-fueled reactors shows that when coolant voiding and fuel melting occur, the timing and nature of fuel relocation provides the key to accident termination without an energy release sufficient to generate the high fuel vapor pressures which have the potential to challenge the primary containment of the reactor. In a well-designed core, the reactivity effect of fuel relocation is an order of magnitude greater than the effect of moving any other material, including the control rods. One of the uncertainties in the calculations is the timing and extent of reactivity feedback from the motion of cladding. Significant relocation of cladding prior to fuel motion has the potential to drive the net reactivity close or even over prompt critical with the result that even a small amount of compactive fuel motion could drive the reactor into an energetic transient. The fuel in the metal cores melts before the cladding. This provides an opportunity for fuel, even with only modest burnups, to move within the cladding into the fission gas plenum above the fuel, thus driving the net reactivity away from prompt critical. When cladding does fail, some positive reactivity feedback from fuel motion can be tolerated without having the reactivity go above prompt critical and without the reactor power reaching levels sufficient to release damaging amounts of energy. In fact, when the reactor power moves into the range approximately an order of magnitude above nominal, the in-pin fuel motion is more likely to occur before cladding failures. This greatly reduces the likelihood of severe accident energetics in metallic cores.

If primary system integrity were to be threatened as a result of a severe accident, the threat would most likely result from the acceleration of a large mass of liquid sodium into the vessel wall, probably the head. Two mechanisms, acting separately or in combination could 
conceivably cause the acceleration. The first would be for enough energy to be deposited in fuel to create a large, rapidly expanding bubble of fuel vapor. The second would be for a large amount of energy to be transferred from fuel into sodium, thus creating a rapidly expanding bubble of sodium vapor. In general, this second mechanism implies intimate mixing of fuel and sodium to create large heat transfer areas between the two materials. Conditions for the intimate mixing are most easily envisioned in the case of a high-ramp-rate TOP where large amounts of energy might be deposited in the fuel before any significant voiding occurs. In the calculations described in Sect. IV, results for the TOP indicate that cladding failures occur before enough energy is deposited in the fuel for such an energetic fuel-coolant interaction to occur. In the LOF calculations, coolant is substantially voided before cladding fails. Thus, intimate mixing of fuel and coolant seems unlikely. Furthermore, because of the dispersal of fuel within the cladding prior to failure, and the rapid dispersal of fuel in the coolant channel following failure, the amounts of energy deposited in the fuel are not nearly high enough to create an expanding bubble of fuel vapor.

\section{C. $\quad$ Report Overview}

Severe accident calculations have been carried out for three reactor cores. The first is a $1575-\mathrm{MWt}$, low-void-worth core designed for actinide burning,[11,12] the second is the PRISM Mod B/92, 840-MWt core,[13,14] and the third is a large, pool-type, 3500-MWt reactor.[15] These reactors are described in more detail in Sect. II. The SAS4A models of these reactors are described in Sect. III. In addition, Sect. III describes the accident initiators and SAS4A input required to simulate them, and a brief overview of the SAS4A models used in the analysis.

Section IV presents the results of the analysis. All the TOP analysis was performed for the low-void-worth actinide burner, but because of the nature of the results obtained, similar results can be expected for the other two reactors. LOF calculations were performed for all three reactors, but abrupt LOF calculations of the type implied by pump seizure were performed 
only for the PRISM Mod B/92 and the large, pool-type reactor. All of the LOF calculations assume higher flow reduction rates than would be anticipated for normally functioning pumps.

Section V discusses analysis uncertainties and Sect. VI presents the conclusions of this study. Analysis results indicate that an energetic threat to primary system integrity as a result of a severe accident in a metallic-fueled reactor is very unlikely. Considerable fuel melting and core disruption can be expected, but because the fuel melts before the cladding, in-pin relocation of fuel provides sufficient negative feedback to counter positive reactivity feedback from either coolant voiding or inadvertent control rod motion.

\section{REACTOR DESCRIPTIONS}

Table I shows some of the more important characteristics of the three reactors considered in the analysis in Sect. IV. The table draws information from Refs. 11 through 15. Figures 1,2, and 3 show plan views of the respective core layouts. The three reactors represent a broad range in power levels, with the power increasing by about a factor of two in going from the PRISM to the actinide burner and by another factor of two in going from the actinide burner to the 3500-MWt design. Because of the short core height, the actinide burner has more fuel assemblies than the 3500-MWt reactor, and the radial dimensions of the core are nearly as large. Except for length, the fuel assembly design for the actinide burner is very similar to that for the 3500-MWt reactor. The actinide burner has the highest linear power of the three designs.

In spite of the fact that the powers differ by more than a factor of four, Table I shows that the void worths for the PRISM and the 3500-MWt reactor are rather similar. In fact, when the internal blanket void worths are taken into account, the PRISM actually has a total void worth more than $1 \$$ greater than the 3500-MWt core. Voiding of internal blankets plays somewhat larger role in the rapid-loss-of-flow transients for the PRISM than for the 3500-MWt reactor. Because of this, in the LOF calculations presented in Sect. IV the voiding reactivity 
TABLE I. Comparative Reactor Descriptions

\begin{tabular}{|l|c|c|c|}
\hline & $\begin{array}{c}\text { Low-Void-Worth } \\
\text { Actinide Burner }\end{array}$ & $\begin{array}{c}\text { PRISM } \\
\text { Mod B/92 }\end{array}$ & $3500 \mathrm{MWt}$ \\
\hline \hline Core Power, MWt & 1575 & 840 & 3500 \\
\hline Core Height, in. & 18 & 42 & 36 \\
\hline Assembly Pitch, in. & 6.150 & 5.801 & 6.131 \\
\hline Assembly Outer Flat-to-Flat, in. & 6.028 & 5.626 & 5.931 \\
\hline Assembly Wall Thickness, in. & 0.122 & 0.175 & 0.150 \\
\hline Driver Fuel Composition & U-25Pu-10Zr & U-23Pu-10Zr & U-15Pu-10Zr \\
\hline Number of Driver Assemblies & 420 & 126 & 396 \\
\hline Number of Blanket Assemblies & -- & 60 & 163 \\
\hline Driver Pins per Assembly & 271 & 217 & 271 \\
\hline Blanket Pins per Assembly & -- & 127 & 169 \\
\hline Wire Wrap Pitch, in. & 12 & 8 & 12 \\
\hline Driver Pin Outside Diameter, in. & 0.285 & 0.293 & 0.285 \\
\hline Driver Cladding Thickness, in. & 0.022 & 0.022 & 0.022 \\
\hline Driver Wire Wrap Diameter, in. & 0.049 & 0.056 & 0.049 \\
\hline Driver Smear Density, \% T.D. & 75 & 75 & 75 \\
\hline Blanket Pin Outside Diameter, in. & -- & 0.428 & 0.392 \\
\hline Blanket Cladding Thickness, in. & -- & 0.022 & 0.022 \\
\hline Blanket Wire Wrap Diameter, in. & -- & 0.030 & 0.034 \\
\hline Blanket Smear Density, \% T.D. & -- & 85 & 85 \\
\hline Fission Gas Plenum Length, in. & 39 & 64 & 52 \\
\hline Coolant Outlet Temperature, ${ }^{\circ} \mathrm{C}$ & 510 & 499 & 510 \\
\hline Coolant Temperature Rise, ${ }^{\circ} \mathrm{C}$ & 166 & 139 & 153 \\
\hline & & & \\
\hline
\end{tabular}


TABLE I. (Contd.)

\begin{tabular}{|l|c|c|c|}
\hline & $\begin{array}{c}\text { Low-Void-Worth } \\
\text { Actinide Burner }\end{array}$ & $\begin{array}{c}\text { PRISM } \\
\text { Mod B/92 }\end{array}$ & 3500 MWt \\
\hline \hline Primary Control Rods & 24 & 9 & 24 \\
\hline Secondary Control Rods & 6 & -- & 12 \\
\hline Driver Linear Power, kW/ft* & 14.1 & 8.49 & 12.6 \\
\hline Driver Sodium Void Reactivity, \$* & 0.16 & 4.41 & 4.98 \\
\hline Blanket Sodium Void Reactivity, \$* & -- & 3.95 & 2.31 \\
\hline Driver Doppler Coefficient** & 0.88 & 1.32 & 1.93 \\
\hline Blanket Doppler Coefficient** & -- & 1.84 & 1.73 \\
\hline Delayed Neutron Fraction* & 0.00347 & 0.00338 & 0.00352 \\
\hline Prompt Neutron Lifetime, $10^{-7} \mathrm{~s}^{*}$ & 2.47 & 3.07 & 3.20 \\
\hline
\end{tabular}

* End of Equilibrium Cycle.

** $-10^{-3} T d k / d T$, End of Equilibrium Cycle with Sodium In.

feedback levels off near $5 \$$ for both reactors. A table found in Ref. 11 shows that in the actinide burner, the void worth in the core is $2.85 \$$ and that the void worth for the region above the core is $-2.7 \$$. For rapid-loss-of-flow calculations, the results show that voiding occurs mostly in the core so that the impact of the large difference in the total void worth is not as great as might be expected.

The core layouts shown in Figs. 1 through 3 exhibit a number of differences. Both the PRISM and the 3500-MWt reactor were designed to have breeding ratios of unity or greater, and are of heterogeneous design. Breeding is not a priority in the actinide burner, and except for the "island" of reflector and/or absorber assemblies near the center of the core, the core is homogeneous in design. To provide a mechanism to mitigate the effects of the positive sodium density worth during loss-of-flow accidents, the PRISM design includes six gas expansion modules (GEMs). These assemblies are filled with sodium with a compressed-gas cover. During a loss of flow, the gas expands, pushing out the sodium and introducing negative 
sodium void reactivity feedback. To mitigate the larger burnup reactivity swing implied by the homogeneous core design, the actinide burner includes 18 exchange assemblies. At the beginning of a burn cycle, these assemblies contain natural $\mathrm{B}_{4} \mathrm{C}$, but midway through the cycle, they are replaced by steel reflectors.

Because of the differences in the core layouts, the reactor missions, and the power levels, comparison of rapid loss-of-flow results between the actinide burner and corresponding results for either the PRISM or the 3500-MWt reactor do not provide a satisfactory basis for addressing the impact of the sodium void worth on accident energetics. A more systematic assessment of this issue is in progress.[16]

\section{SAS4A MODELING AND INPUT ASSUMPTIONS}

The original SAS4A models for each of the reactors described in Sect. II were threechannel models constructed by Wigeland et al.[3,4,17] Each channel represents a group of assemblies which for purpose of analysis are assumed to be identical. SAS4A performs a detailed thermal-hydraulic analysis for a surrogate fuel pin from each assembly group. All fuel pins within the assembly group are assumed to behave like the surrogate pin for that group. Wigeland used the three-channel models to investigate the passive safety characteristics of the reactors. For TOP analysis, the actinide burner model was expanded to 10 channels, and the LOF calculations for the PRISM and the 3500-MWt reactor utilized 12-channel and 25-channel models, respectively. The assembly-to-channel assignments are described in the next subsection. The specific SAS4A models used in the analysis along with the more important input assumptions are described in a second subsection.

\section{A. Assembly-to-channel Assignments}

Axial power shapes and reactivity worth distributions were calculated for 10 distinct assembly groups in the actinide burner.[12] Figure 4 shows these assembly groups (channels) 
TABLE II. Summary of Selected SAS4A Channel Information for the Actinide Burner

\begin{tabular}{|c|c|c|c|c|}
\hline $\begin{array}{c}\text { Channel } \\
\text { Number }\end{array}$ & $\begin{array}{c}\text { Assembly*** } \\
\text { Type }\end{array}$ & $\begin{array}{c}\text { Number of } \\
\text { Assemblies }\end{array}$ & $\begin{array}{c}\text { Assembly* } \\
\text { Power }\end{array}$ & $\begin{array}{c}\text { Outlet** } \\
\text { Temperature, K }\end{array}$ \\
\hline 1 & F & 6 & 1.262 & 823 \\
2 & F & 18 & 1.250 & 811 \\
3 & F & 48 & 1.223 & 807 \\
4 & F & 72 & 1.161 & 806 \\
5 & F & 24 & 1.204 & 804 \\
6 & F & 24 & 1.102 & 781 \\
7 & F & 90 & 1.020 & 783 \\
8 & F & 60 & 0.851 & 770 \\
9 & F & 24 & 0.727 & 772 \\
10 & F & 54 & 0.592 & 743 \\
\hline
\end{tabular}

* Normalized to average assembly power of unity.

** Inlet temperature is $616 \mathrm{~K}$.

*** Fuel (F).

on a one-sixth sector of the core map shown in Fig. 1. The one-sixth sector contains 70 distinct fuel assemblies. The TOP analysis for the actinide burner used a SAS4A core model which incorporated all 10 channels shown in Fig. 1. Because of the relatively small number of channels compared to the number of distinct fuel assemblies, there is the possibility that for some severe accident analysis, coherent behavior of relatively large portions of the core may aggravate the accident consequences. Table II lists the assembly type, number of assemblies, assembly power, and outlet temperature for each of the 10 channels. Figure 5 shows the assembly power as a function of the fraction of the core having a power equal or greater than the given power.

Neutronics calculations produced axial power shapes and reactivity worth distributions for each of 78 distinct fuel, internal blanket, and radial blanket assemblies in a one-third sector of the PRISM Mod B/92 core.[13] Figure 6 shows a one-third sector of the map in Fig. 2, and 
TABLE III. Summary of Selected SAS4A Channel Information for the PRISM Mod B/92

\begin{tabular}{|c|c|c|c|c|}
\hline $\begin{array}{c}\text { Channel } \\
\text { Number }\end{array}$ & $\begin{array}{c}\text { Assembly*** } \\
\text { Type }\end{array}$ & $\begin{array}{c}\text { Number of } \\
\text { Assemblies }\end{array}$ & $\begin{array}{c}\text { Assembly* } \\
\text { Power }\end{array}$ & $\begin{array}{c}\text { Outlet** } \\
\text { Temperature, K }\end{array}$ \\
\hline 1 & F & 3 & 1.576 & 797 \\
2 & F & 15 & 1.548 & 794 \\
3 & F & 12 & 1.450 & 788 \\
4 & F & 12 & 1.447 & 784 \\
5 & F & 6 & 1.450 & 778 \\
6 & F & 12 & 1.347 & 773 \\
7 & F & 18 & 1.331 & 770 \\
8 & F & 12 & 1.251 & 767 \\
9 & F & 36 & 1.136 & 759 \\
10 & IB & 12 & 1.038 & 787 \\
11 & IB & 48 & 0.672 & 790 \\
12 & RB & 48 & 0.455 & 775 \\
\hline
\end{tabular}

* Normalized to average assembly power of unity.

** Inlet temperature is $633 \mathrm{~K}$.

*** Fuel (F), internal blanket (IB), and radial blanket (RB).

shows the assembly-to-channel assignments for the 12-channel SAS4A model. Table III lists the assembly type, number of assemblies, assembly power, and outlet temperature for each of the 12 channels. The assembly powers for the individual fuel assemblies are compared with the assembly powers of the 12-channel model in Fig. 7. The powers are plotted as a function of the fraction of the driver assemblies with powers greater than or equal to a specified power. The figure shows that the 12-channel model provides a good representation of the assembly powers, particularly in the driver assemblies (core fraction less than 0.54 ).

For the 3500-MWt reactor, the neutronics calculations produced axial power shapes and reactivity worth distributions for each of 63 distinct fuel, internal blanket, and radial blanket assemblies in a one-twelfth sector of the core.[15] The assemblies were divided into 10 flow 
orifice zones.[18] J. E. Cahalan[19] expanded the three-channel model developed in Ref. 4 into a 25-channel SAS4A core model which includes only the fuel and internal blanket assemblies. The channel assignments are shown in Fig. 8 for a one-sixth sector of the core layout given in Fig. 3. Table IV lists the assembly type, number of assemblies, assembly power, and outlet temperature for each of the 25 channels. Figure 9 shows a comparison of the assembly power distribution for the 25-channel model with the original 55-assembly fuel and internal blanket power distribution. The 25-channel model provides a very good representation of the assembly powers.

\section{B. SAS4A Models and Input Assumptions}

The balance-of-plant models for the PRISM and 3500-MWt reactor are described in Refs. 3 and 4. The balance of plant model for the actinide burner is essentially the same as for the 3500-MWt reactor.[17] The primary and secondary loop flows along with some dimensions were changed to accommodate the difference in reactor power and differences in the physical dimensions of the core.

The reactivity insertion used to drive the TOP calculations was simulated using tabular input of an external reactivity vs time. The reactivity table starts at location 29 in block 12 of the SAS4A input file, and the corresponding times start at location 49 in the same block. The reactivity was inserted at a constant rate until some maximum was reached and held constant thereafter.

The LOF transients were simulated differently depending on which reactor was being analyzed. Both the actinide burner and the 3500-MWt reactor had primary and secondary coolant flow driven by mechanical pumps. These pumps were simulated using the homologous pump model in PRIMAR-4. For the actinide burner, several flow reduction rates were considered. These were achieved by setting the motor torque to zero at the initial time and adjusting the pump inertia to achieve the desired flow halving time. The pump motor torque was set in input locations starting at location 1959 in block 18 of the SAS4A input file, and the 
TABLE IV. Summary of Selected SAS4A Channel Information for 3500-MWt Reactor

\begin{tabular}{|c|c|c|c|c|}
\hline $\begin{array}{l}\text { Channel } \\
\text { Number }\end{array}$ & $\begin{array}{c}\text { Assembly*** } \\
\text { Type }\end{array}$ & $\begin{array}{l}\text { Number of } \\
\text { Assemblies }\end{array}$ & $\begin{array}{l}\text { Assembly* } \\
\text { Power }\end{array}$ & $\begin{array}{c}\text { Outlet** } \\
\text { Temperature, } \mathrm{K}\end{array}$ \\
\hline 1 & $\mathrm{~F}$ & 6 & 1.437 & 827 \\
\hline 2 & $\mathrm{~F}$ & 12 & 1.429 & 823 \\
\hline 3 & $\mathrm{~F}$ & 12 & 1.419 & 822 \\
\hline 4 & $\mathrm{~F}$ & 12 & 1.404 & 820 \\
\hline 5 & $\mathrm{~F}$ & 12 & 1.389 & 828 \\
\hline 6 & F & 12 & 1.377 & 819 \\
\hline 7 & $\mathrm{~F}$ & 12 & 1.357 & 816 \\
\hline 8 & F & 12 & 1.336 & 813 \\
\hline 9 & $\mathrm{~F}$ & 18 & 1.317 & 808 \\
\hline 10 & $\mathrm{~F}$ & 6 & 1.312 & 831 \\
\hline 11 & F & 12 & 1.305 & 819 \\
\hline 12 & $\mathrm{~F}$ & 12 & 1.298 & 808 \\
\hline 13 & F & 18 & 1.271 & 825 \\
\hline 14 & $\mathrm{~F}$ & 18 & 1.251 & 799 \\
\hline 15 & $\mathrm{~F}$ & 12 & 1.236 & 806 \\
\hline 16 & $\mathrm{~F}$ & 18 & 1.163 & 795 \\
\hline 17 & $\mathrm{~F}$ & 12 & 1.173 & 800 \\
\hline 18 & $\mathrm{~F}$ & 12 & 1.157 & 807 \\
\hline 19 & $\mathrm{~F}$ & 24 & 1.121 & 792 \\
\hline 20 & $\mathrm{~F}$ & 24 & 1.063 & 783 \\
\hline 21 & $\mathrm{~F}$ & 36 & 0.991 & 782 \\
\hline 22 & $\mathrm{~F}$ & 18 & 0.912 & 770 \\
\hline 23 & $\mathrm{~F}$ & 66 & 0.761 & 772 \\
\hline 24 & IB & 60 & 0.761 & 771 \\
\hline 25 & IB & 103 & 0.597 & 766 \\
\hline
\end{tabular}

* Normalized to average assembly power of unity.

** Inlet temperature is $630 \mathrm{~K}$.

*** Fuel (F) and internal blanket (IB). 
pump inertia is set starting at location 1899, also in block 18. The LOF transients considered for the 3500-MWt reactor assumed that the pump rotors seized at the initial time. This was achieved by setting input locations for the primary pumps equal to unity starting at location 430 in block 3 of the SAS4A input file. In addition, the initial main time step size, location 11 of block 13, was set to $4 \mathrm{~ms}$. For the PRISM, electromagnetic pumps, driven by a synchronous machine, are used. The model for this pump was selected by setting input locations starting at location 418 equal to -2 in block 3 of the SAS4A input file. The flow reduction rate was modified by changing the inertia of the synchronous machine. This inertia is found in locations starting at location 1899 of block 18 in the SAS4A input file.

Coolant boiling and subsequent voiding plays a relatively minor role in the TOP analysis described in Sect. IV, but is a significant source of positive reactivity feedback in the LOF transients. Because some of the LOF transients require the SAS4A boiling module to run for long periods of time, input location 178 of block 64 was set to a value larger than any time step in the problem being run. This caused an acceleration term to be dropped from the momentum equation for sodium vapor and reduced the likelihood that the boiling module would require very small time steps and correspondingly long computation times. A test problem run with and without this input assumption showed that the LOF results were effected relatively little, so the assumptions was used in many of the LOF calculations reported in Sect. IV.

The time and location of cladding failure is calculated using the DEFORM-5 fuel pin mechanics module. Use of this model was achieved by setting input locations 86 and 122 of block 51, respectively, to 8 and 1 in the SAS4A input file. The module uses the failure life fraction[20-22] to evaluate the impact of pressure loading due to fission gases within the fuel pin and the formation of eutectic due to the interaction of fuel and cladding at in inner surface of the cladding. The rate of eutectic penetration of cladding is estimated using a correlation originally proposed by Bauer.[23] Fission gas, prior to the time of initial fuel melting can be treated in two ways. The first, obtained by setting location 282 of block 51 equal to 0 , assumes that fission gas moves freely between the fuel porosity and the fission-gas plenum and maintains a uniform axial pressure loading on the cladding. The second is obtained by setting 
location 282 equal to 1 . In this case, free movement of fission gas is assumed during steadystate operation, but migration to the gas plenum is not permitted during the transient. Gas flow calculations by Gesh and Kramer[24] show that the time scale for gas migration is long compared to the duration of the LOF transients, so most of the LOF calculations were carried out using the second option.

Following the initiation of fuel melting, a cavity containing molten fuel and fission gas forms within the fuel pin. The PINACLE fuel motion model calculates the dynamics of this fuel gas mixture up to the time of cladding failure. Regardless of which fission gas option is in effect prior to fuel melting, gas migration within the fuel is not allowed once PINACLE initiates. PINACLE provides the pressure distribution used by DEFORM-5 to predict cladding failure. Because of the high thermal conductivity of metallic fuel, the position of the molten fuel cavity is biased toward the top of the fuel, and if fuel heating rates are high enough, melting may reach the top of the fuel prior to cladding failure. When this happens, PINACLE models the ejection of fuel from the molten cavity into the fission gas plenum. Two conditions must be satisfied for the calculation of fuel ejection to be initiated. First, the molten cavity must extend into the top computational node of the active fuel, and second, the fuel temperature at the interface between the active fuel and the gas plenum must reach the fuel solidus temperature.

Three input parameters control when PINACLE will allow the molten cavity to form and the first of the three controls when the cavity can extend into the top axial computational node of the fuel. The first is the fraction of the heat of fusion which must be achieved for the fuel to be considered molten, the second is the areal melt fraction which must be reached by fuel in the central node of the initially formed cavity, and the third is the fraction of the areal melt fraction required for the central node which must be satisfied by the adjacent axial nodes. These three input parameters are set in location 1169 of block 13 and locations 22 and 23 of block 64, respectively, in the SAS4A input file. For most of the calculations reported in Sect. IV, the values were, respectively, $0.4,0.2$, and 0.5 . Because fuel melting begins along grain boundaries, it is expected that metallic fuel will become mobile as soon as its temperature 
reaches solidus,[25] and it would probably be justified to reduce the value assigned to the fraction of the heat of fusion required for fuel mobility. This will be done in some of the parametric calculations for the LOF.

The temperature at the interface between the active fuel and the gas plenum depends on two-dimensional heat transfer processes which are not modeled explicitly by PINACLE. Fuel pins are fabricated with about $25 \%$ porosity and the thermal bond between the pin and the cladding is established by filling the gap with sodium. After a relatively small amount of burnup, radial swelling of the fuel forces much of the bond sodium from the gap and into the lower part of the fission-gas plenum. The bond sodium in the bottom of the gas plenum is modeled as an axial blanket, and PINACLE estimates the interface temperature as a weighted average of the centerline temperature in the top axial node of the fuel and the centerline temperature of the bottom axial node of the sodium "blanket." The weight is determined by setting input location 1295 in block 13 of the SAS4A input file. When this input is set to unity, the interface temperature is estimated to be equal to the centerline temperature in the top node of the fuel and when it is set to zero, the interface temperature is estimated to be the centerline temperature in the bottom node of the sodium "blanket." Analysis of TREAT test M7,[26] found the a value of 0.5 most appropriate for two of the pins, but the value of unity more appropriate for the third pin. The value of 0.5 is used in the TOP analysis in Sect IV.A. Because of the higher heating rates and the greater difference between the pressure in the molten fuel cavity and the pressure in the fission-gas plenum, a value of unity seems more appropriate for LOF transients and is used for most of the transients described in Sect. IV.B. This is discussed further in Sect. IV.B.1.b and Sect. V.

For transients in which the reactor power rises into the range from several times to a few tens times nominal prior to cladding failure, the time of the initiation of the ejection of fuel to the fission-gas plenum (rapid in-pin motion), relative to the time of cladding failure is a key issue in determining whether or not sufficient energy is released to pose a threat to the integrity of the reactor vessel. The values suggested in the preceding paragraphs for locations 1169 and 
1295 in block 13 appear to be conservative in the sense that an earlier initiation of rapid in-pin motion than these parameters predict seems likely.

An additional issue related to rapid in-pin motion is the behavior of fuel after it enters the gas plenum. The PINACLE model assumes that the fuel forms a pool in the bottom of the plenum, pushing the bond sodium upward and compressing the plenum gas. Fuel in the pool may plate-out on the cladding, and depending on the choice for input location 487 in block 51 of the SAS4A input file, if the pressure in the plenum subsequently exceeds the pressure in the molten cavity, the fuel may reenter the core. If the pressure difference between the molten cavity and the fission-gas plenum is large enough when rapid in-pin motion begins, the reentry may cause the mass of fuel in the plenum to oscillate and may produce some oscillations in the fuel motion reactivity feedback. The SAS4A input description recommends that the viscosity of fuel at the solidus (location 1209 in block 13) be assigned a value 200 times greater than the viscosity above the liquidus (location 1162 in block 13). If this is done, then selection of a smaller value for the fraction of the heat of fusion required for fuel to become mobile tends to mitigate the oscillations. This mitigation is particularly apparent in calculations currently in progress,[16] but is also observed in some of the LOF calculations reported in Sect. IV. If reentry of fuel is not allowed, the oscillatory behavior does not occur. For most of the LOF calculations reported in Sect. IV, the decision to allow or not allow reentry did not seem to have a significant impact on the energy release during the transient.

Following cladding failure, the fuel motion calculation both within the cladding and in the coolant channel are taken over by the LEVITATE fuel motion module. In addition, LEVITATE takes over the coolant dynamics calculation in the SAS4A channel where the cladding failure occurs and determines whether or not cladding should fail at other axial nodes in addition to the one where the initial failure occurs. The DEFORM-5 module ceases to function in channels where cladding failure has occurred. If cladding failure occurs after the initiation of rapid in-pin motion in the PINACLE calculation, LEVITATE does not include the fuel removed to the gas plenum in its calculation of in-pin motion. The removal of this 
inconsistency has been identified[27] as one of the issues to be addressed in the future development of SAS4A metallic fuel modeling capability.

\section{ANALYSIS RESULTS}

Most of the severe accident analysis described in this section focuses on the LOF accident. This emphasis was chosen because the LOF was judged to have the greatest chance of producing a sufficiently large energy release to cause serious damage to the reactor vessel. As noted in Sect. I.C, TOP analysis was performed only for the actinide burner. The results of this analysis are described in Sect. IV.A below. Because of the benign nature of the results and the limited role played by coolant voiding, the judgement was reached that similar results could be expected for the PRISM and the 3500-MWt reactor. A limited amount of recent TOP analysis for the PRISM Mod B/93[16] and an example problem included in Ref. 1 for the 3500MWt reactor support this judgement.

\section{A. Transient Overpower}

TOP calculations for the actinide burner were performed for linear reactivity insertion rates of $0.1,1$, and $10 \$ / \mathrm{s}$. In each case, the maximum reactivity was limited to a total insertion of $7.8 \$$, but in each case, the transient terminated before this limit was reached. $7.8 \$$ is comparable to the total worth of all the control rods in the reactor at the beginning of cycle. The power and reactivities for the $0.1 \$ / \mathrm{s}$ case are shown in Figs. 10 and 11 . Figure 10 shows that the power increases at a nearly constant rate for about the first $12 \mathrm{~s}$, reaching a level about three times nominal at the end of the time interval. A combination of reactivity feedbacks, dominated by core radial expansion, causes the net reactivity to level off at about $0.25 \$$ after about the first $5 \mathrm{~s}$. At about $12.1 \mathrm{~s}$, rapid in-pin fuel motion is initiated by the PINACLE module in channel 1 , but the pressure difference between the molten cavity and the gas plenum and the amount of molten fuel ejected from the cavity are both small enough so that the reactivity impact of this event is relatively slight. Rapid in-pin motion initiates in channels 2 
through 5 in the time interval between 12 and $16 \mathrm{~s}$, but for each channel, the reactivity impact is small. These channels, together with channel 1 , represent about $40 \%$ of the core. Coolant boiling in channel 1 initiates just after $16 \mathrm{~s}$ and cladding fails in this channel at about $16.5 \mathrm{~s}$. The cladding failure occurs very near the top of the active fuel and the resulting reactivity feedback remains negative throughout the remainder of the calculation. The calculation was terminated about $300 \mathrm{~ms}$ after cladding failure in channel 1. At the time of termination, the net reactivity was $-0.41 \$$ and the fuel motion reactivity $-0.77 \$$. These values are relatively small, but the net and fuel motion reactivities were decreasing at rates of -1 and $-0.92 \$ / \mathrm{s}$, respectively. The power level has dropped from a peak of about 3.3 to about 1.9 times nominal. Since the reactivity insertion is continuing, additional cladding failures and subsequent fuel motion can be expected, but no mechanism has been identified that would cause the power level to increase to levels sufficient to cause a large and rapid energy release. Cladding failures and subsequent dispersive fuel motion in about $11 \%$ of the core would be sufficient to introduce enough negative reactivity to overcome the maximum reactivity insertion of $7.8 \$$.

Results for a reactivity insertion rate of $1 \$ / \mathrm{s}$ are shown in Figs. 12 and 13. This ramp rate is large enough so that longer term reactivity feedbacks such as core radial expansion do not have time to act. As a result, the net reactivity deviates from the imposed reactivity only slightly as a result of negative Doppler and axial expansion reactivity feedbacks. The reactivity reaches a level of about $0.82 \$$ and the power about 13.9 times nominal when rapid in-pin fuel motion initiates essentially simultaneously in channels $1,2,3$, and 5 at about $1.1 \mathrm{~s}$. These channels represent between 30 and $35 \%$ of the core. The rapid in-pin motion introduces more than a dollar of negative reactivity and brings the reactor subcritical and the power down to about two times nominal. Coolant boiling begins in channel 1 just before $1.2 \mathrm{~s}$, and boiling soon initiates also in channels 2, 3, and 5. Rapid in-pin motion initiates in channels 4 and 6, representing an additional 10 to $15 \%$ of the core, and causes an additional decrease in the fuel motion reactivity feedback and in the net reactivity. Following this, the reactivity insertion drives the net reactivity back positive. The net reactivity and the power continue to increase until cladding failure occurs in channel 1 at about $2.46 \mathrm{~s}$. At this point, the power has increased to about three times nominal and the net reactivity is $0.4 \$$. The failure occurs at a level about 
$30 \%$ of the fuel pin length from the top of the active core, and because of the lower failure site, the postfailure fuel motion introduces some positive reactivity. The positive reactivity is not sufficient to overcome the negative feedback from the in-pin fuel motion in other channels and the total fuel motion feedback remains practically constant until fuel begins to disperse through the coolant channels in channel 1. The calculation was terminated about $500 \mathrm{~ms}$ after the cladding failure. As in the $0.1 \$ / \mathrm{s}$ case, additional cladding failures and additional rapid in-pin fuel motion can be expected, but no mechanism has been identified which is likely to cause a rapid and large power increase.

Figures 14 and 15 show the reactor power, the net reactivity, and the reactivity feedbacks resulting from a reactivity insertion rate of $10 \$ / \mathrm{s}$. Both the net reactivity and the power increase rapidly under the high reactivity insertion rate, but Doppler and axial expansion reactivity feedbacks prevent the net reactivity from reaching prompt critical. The net reactivity stops and remains near 0.97 \$ until the PINACLE model calculates a small negative reactivity due to the redistribution of fuel within the molten cavities of fuel pins in several channels. This causes a brief reduction in power, but both the power and the net reactivity begin to increase again until rapid in-pin motion starts in channels $1,2,3,5$, and 6 . These channels all initiate fuel motion within about a $5 \mathrm{~ms}$ time interval following $0.133 \mathrm{~s}$. The relocation of fuel to the gas plenum causes a rapid reduction in the net reactivity to a level of about $-2 \$$ and brings the power back to about nominal. Boiling begins in channel 1 at about $0.26 \mathrm{~s}$ and is quickly followed by boiling in several other channels. The continuing reactivity insertion drives the reactor super critical again at about $0.4 \mathrm{~s}$, and the resulting power increase causes rapid in-pin motion to initiate in channel 4 at about $0.48 \mathrm{~s}$ followed by a reduction in both power and reactivity. Within a brief time, the net reactivity and power again increase until rapid in-pin motion begins in channel 7 at about $0.59 \mathrm{~s}$. Following another brief reduction in power and net reactivity, both begin to increase again until cladding failure occurs in channel 1 at about $0.65 \mathrm{~s}$. The failure occurs at a point about $37 \%$ of the fuel pin length from the top of the core, and because the failure site is so close to the axial midplane, the subsequent fuel motion reactivity feedback is positive, adding about $0.06 \$$. The imposed ramp rate causes the power and reactivity to continue to increase until rapid in-pin motion begins in channel 8 . This 
channel, representing about $15 \%$ of the core causes enough negative fuel motion reactivity feedback drive the reactivity toward subcriticality even though cladding failure occurs in channel 2 at a point about $30 \%$ of the pin length below the top of the core. When the calculation is terminated just after $0.7 \mathrm{~s}$, the imposed reactivity insertion has reached $7.13 \$$ and the net reactivity has dropped to almost $-0.5 \$$ and is decreasing at a rate of about $-84 \$ / \mathrm{s}$.

References 28 and 29 describe several TREAT tests which subjected metallic fuel to transient overpower conditions. In particular, tests M5, M6, and M7 subjected ternary fuel similar to that identified in Table I to overpower conditions close to those observed in the 0.1 $\$ / \mathrm{s}$ case described earlier in this section. The tests showed significant in-pin fuel relocation prior to cladding failure for fuel pins with axial peak burnups ranging from 0.8 up to 9.8 atom $\%$. Following cladding failures near the top of the fuel pins, essentially the entire molten fuel inventory moved into the coolant channels and dispersed, thus confirming the scenario described in the foregoing analysis.

All of the reactivity insertion rates considered in the foregoing analysis are larger than are normally considered in TOP analyses. Indeed, to achieve an insertion rate of $10 \$ / \mathrm{s}$, one must postulate an extremely low-probability event such as failure of the core support structures so that the core essentially falls away from the control rods. In spite of the extreme nature of the TOP initiators, the results indicate relatively benign accident consequences in which there is significant core damage but no rapid release of energy and no immediate threat to the reactor vessel. Examination of the reactivity feedbacks in Figs. 11, 13, and 15 shows that coolant reactivity feedback plays a minor role in all transients. Thus, similar results can be anticipated for comparable TOP transients in reactors having a broad range of void worth reactivities.

\section{B. Loss of Flow}

LOF calculations have been performed for all three of the reactors described in Sect. II. Because the analysis has been more extensive for the PRISM and the 3500-MWt reactor, 
detailed results will be presented for these two reactors and only a brief description of the analysis for the actinide burner will be given.

\section{Abrupt Loss of Flow in a 3500-MWt Reactor}

Analysis for the 3500-MWt reactor was carried out by first defining a reference case and then comparing several parametric cases with the reference case. In each parametric case, one or more of the input assumptions used in the reference case was changed.

\section{a. $\quad$ Reference Case}

In the reference calculation, the fission gas and fill gas (location 27 of block 63 of the SAS4A input file) were set to provide a pin pressure of $1.44 \mathrm{MPa}$ at a reference temperature of $300 \mathrm{~K}$. Since the fill gas alone provides a pressure of $0.1 \mathrm{MPa}$, this pressure corresponds to a core-wide average burnup of about 6.5 atom \%. Location 1169 of block 13 was set to 0.4 , and locations 22 and 23 of block 65 were set to 0.2 and 0.5 , respectively, so that the PINACLE fuel motion module would initiate when the fuel reached $40 \%$ of its heat of fusion over an areal fraction of $20 \%$ in the peak axial node and $10 \%$ in the two adjacent nodes. Fission gas was allowed to migrate so as to maintain a uniform axial pin pressure during steady state, but migration was not permitted once the transient started. Rapid in-pin motion was allowed to begin as soon as the molten fuel cavity reached the top axial computational node of the fuel pin.

Figures 16 and 17 show the first $2.4 \mathrm{~s}$ of the reference transient. Following seizure of the pump rotors, flow falls rapidly (flow halving time of $160 \mathrm{~ms}$ ), but the gravitational head of cold coolant between the heat exchanger and the inlet plenum prevents the coolant flow from dropping all the way to zero. The resulting coolant heat-up produces positive reactivity feedback and leads to a gradual increase in the reactor power. The initiation of coolant boiling just before $2.2 \mathrm{~s}$ causes flow reversal at the inlet of several fuel assemblies, and the rapid introduction of the voiding reactivity feedback causes the power to rise sharply. 
Representative temperatures from the fuel assemblies with the highest power (channel 1) are shown in Fig. 18. Except for the inlet temperature, the temperatures are from the first axial node above the core midplane. The initial growth of the voided region is shown for the highest powered fuel assemblies in Fig. 19. The top and bottom of the core are located at about 1.02 and $0.1 \mathrm{~m}$, respectively. The figure shows that voiding begins between 0.1 and $0.15 \mathrm{~m}$ above the axial midplane, and that the voiding is preferentially toward the top of the core. Voiding initiates in channels 1 through 13 , representing $39 \%$ of the core, between 2.18 and $2.43 \mathrm{~s}$.

Figures 20 and 21 show the power and reactivities for the remainder of the reference transient. The PINACLE fuel motion module forms molten cavities in channels 1 through 22 , representing $83 \%$ of the fuel assemblies, between 2.435 and 2.47 s. Rapid in-pin motion initiates in 8 channels, representing $23 \%$ of the core, in a $7 \mathrm{~ms}$ time period starting at $2.462 \mathrm{~s}$. The net reactivity is $0.95 \$$ and the power level has reached 36 times nominal when the rapid in-pin motion begins. The plots in Figs. 22, 23, and 24 show the fuel motion reactivity feedback from channels 1 through 15 . The rapid in-pin motion contributes more than $3 \$$ of negative fuel motion reactivity within about $40 \mathrm{~ms}$. Following this initial negative reactivity insertion, some of the fuel reenters the core and, in combination with the continuing increase in the coolant voiding reactivity, drives the net reactivity to about $0.6 \$$. At about 2.57 $\mathrm{s}$, more fuel is ejected from the core, helped by the initiation of rapid in-pin motion in channels 7,8 , and 11 , representing 36 additional fuel assemblies. Cladding failures occur in channels 1 through 7 and in channels 9,14 , and 15 between 2.89 and $3.10 \mathrm{~s}$. These channels represent $32 \%$ of the fuel assemblies. Each failure occurs within about $0.16 \mathrm{~m}$ of the core midplane and contributes positive fuel motion reactivity feedback for about $30 \mathrm{~ms}$ following failure. There is enough temporal separation of the failures to prevent the positive feedbacks from driving the reactor near prompt critical, and when the calculation is stopped, the fuel motion reactivity has driven the reactor subcritical and the power level is approaching 0.4 times nominal. Additional fuel melting and cladding failures can be expected, but they are not likely to add greatly to the energy deposited. Peak fuel temperatures at the end of the calculation are well below $2000 \mathrm{~K}$. 
Figure 25 shows the total energy in full power seconds (fps) as a function of time. Not all this energy contributes to the heating of fuel; some is carried off by the coolant or heats the cladding. The plot shows that about $2.5 \mathrm{fps}$ are deposited somewhere in the reactor up to the time when coolant boiling begins and that an additional $2.7 \mathrm{fps}$ are added after coolant boiling initiation. The energy deposition is still rising, but is beginning to level off when the calculation terminates.

The "snap shots" in Figs. 26 through 29 show the extent of core voiding at four different times during the reference transient. The area of the region labeled "void" is proportional to the core void volume. The assemblies are grouped in order of ascending channel number. Thus, the first six assemblies represent channel 1 , the next 12 , channel 2 , and so on. The snap shot at $2.46 \mathrm{~s}$ indicates the voiding pattern at the time when rapid in-pin motion begins, and that at $2.88 \mathrm{~s}$ shows that pattern just before the first cladding failure. The times 2.55 and $2.68 \mathrm{~s}$ are arbitrarily selected intermediate times. The figures show that voiding does not initiate in the internal blanket assemblies. The physical picture of the reactor core at the time of cladding failure is of fully flooded blanket assemblies sitting in regions with fully or substantially voided fuel assemblies.

Among the factors which influence the time of cladding failure are the cladding temperature and heating rate, the pressure difference between the inside of the fuel pin and the coolant channel, and the thinning of the cladding due to eutectic formation at the fuel/cladding interface. Figure 30 shows the cladding temperature as a function of axial position just prior to the power peak in Fig. 20 (2.41 s), just prior to cladding failure in a highpowered fuel assembly (channel 1 at $2.89 \mathrm{~s})$ and at an intermediate time $(2.70 \mathrm{~s})$. The curves show that the cladding temperature has its maximum value near the axial elevation where the cladding fails. The curves also indicate an average heating rate of about $500 \mathrm{~K} / \mathrm{s}$ over the time period just prior to cladding failure. The database on which the life fraction correlation is based contains heating rates up to a few hundred K/s.[20-22] 
The plot in Fig. 31 shows the pressure difference between the inside of the fuel pin and the adjacent coolant channel for a high-powered fuel assembly (channel 1) at the same three times considered in the cladding temperature plots. The pressure shows a significant variation with axial position prior to the initiation of rapid in-pin fuel motion. Following the start of rapid in-pin fuel relocation, the pressure difference decreases and becomes axially uniform. The higher pressure at the bottom of the fuel pin reflects the fact that fuel in this part of the pin is not yet mobile.

Figure 32 shows the effect of eutectic formation on the cladding thickness. The times for the plotted results are the same as considered for the cladding temperature plots in Fig. 30. Not surprisingly, the cladding thickness has its minimum at about the same axial location where the temperature has its maximum, the position where the life fraction criterion predicts cladding failure. The application of the life fraction correlation to a situation where a pressurized cladding tube is both heating and changing wall thickness because of eutectic formation has not been verified, and is a source of uncertainty in the reference calculation.

The plots in Figs. 33 and 34 show two views of the surface generated by the axial distribution of the linear fuel density in the highest-powered fuel assemblies (channel 1) as it evolves in time. The large bulge which develops prior to $2.52 \mathrm{~s}$ along the upper axial edge of the surface indicates the movement of fuel into the fission gas plenum as a result of rapid in-pin fuel motion. From the viewpoint used in Fig. 34, one sees that the growth of the bulge is accompanied by a reduction in the linear fuel density which sweeps axially downward through the core. The initial movement of fuel from the core to the fission gas plenum leads to a sign change in the pressure difference between the core and the fission gas plenum, and some of the fuel returns to the core. Fuel alternately moves back and forth between the core and the fission gas plenum a couple of times before the establishment of a stable situation in which fuel is gradually ejected to the plenum. The gradual ejection continues up until the time of cladding failure and the initiation of the LEVITATE fuel motion model. The LEVITATE model currently does not allow fuel in the fission gas plenum to return to the core. 
The calculated motion of fuel moving alternately to and from the fission gas plenum is certainly open to question and, if physically real, potentially troublesome from a reactivity standpoint. Such behavior has not been indicated in TREAT simulations of transient overpower conditions, but the pressure difference between the molten cavity and the fission-gas plenum is much larger under rapid LOF conditions. It is possible that some fuel might freeze on the walls of the fission gas plenum and thus not be able to return to the core. The low eutectic threshold temperature for plutonium and iron may prevent freezing however. The fuel might also freeze as a result of mixing with the bond sodium in the bottom of the gas plenum, but this is not currently modeled by PINACLE. Higher friction or viscosity for the moving fuel within the cladding or in the molten cavity might also mitigate or eliminate the oscillatory motion. However, higher friction would probably reduce the amount and rate of fuel motion to the plenum and could lead to a broader initial power excursion. Some of the parametric calculations described in Sect. IV.A.1.b will use the option in SAS4A which precludes the return of fuel to the core from the plenum.

Figures 35 and 36 show a $50 \mathrm{~ms}$ portion of the surface shown in Figs. 33 and 34 which includes the initial part of the LEVITATE fuel motion calculation. As the LEVITATE calculation begins, the plots show fuel mass beginning to pile up near the failure site just above the axial midplane, and an associated reduction in the fuel mass above and below the failure site. During the time interval immediately after LEVITATE initiation, the fuel mass in the fission gas plenum does not change, but later in the calculation, as Figs. 33 and 34 clearly show, the fuel mass in this region changes due to the movement of fuel upward through the coolant channel. The fuel motion plots show that while there is a slight preference for movement of fuel toward the upper edge of the core, a significant amount of fuel is beginning to move into the region below the core when the calculation terminates. 


\section{b. $\quad$ Parametric Cases}

Several parametric cases were considered to assess sensitivity of the calculated results to changes in the input parameters used in the reference case. Table $\mathrm{V}$ provides summary descriptions of the cases considered.

TABLE V. Summary Description of Parametric Cases for 3500-MWt Reactor (Description Indicates Change from Reference Transient)

\begin{tabular}{|c|c|}
\hline Case & Description \\
\hline 1 & Use thermal conductivity for $100 \%$ theoretical density fuel. \\
\hline 2 & Allow fuel to become mobile when its temperature reaches solidus. \\
\hline 3 & Form PINACLE cavity when areal melt fraction reaches 0.01 . \\
\hline 4 & Reduce burnup to 1 atom $\%$. \\
\hline 5 & Increase burnup to 15 atom $\%$. \\
\hline 6 & Allow fission gas migration until PINACLE initiation. \\
\hline 7 & $\begin{array}{l}\text { Same as Case } 6 \text { except that fuel cannot reenter the core after ejection to the } \\
\text { fission gas plenum. }\end{array}$ \\
\hline 8 & Case 4 with fission gas migration until PINACLE initiation. \\
\hline 9 & Case 5 with fission gas migration until PINACLE initiation. \\
\hline 10 & Case 9 with fuel becoming mobile when it reaches a melt fraction of 0.1 . \\
\hline 11 & $\begin{array}{l}\text { Initiate fuel ejection to the fission gas plenum when the average centerline } \\
\text { temperature in the top fuel node and the bottom node of the upper axial } \\
\text { blanket reaches the fuel solidus temperature. }\end{array}$ \\
\hline 12 & $\begin{array}{l}\text { Same as Case } 11 \text { except that fuel cannot reenter the core after ejection to the } \\
\text { fission gas plenum. }\end{array}$ \\
\hline 13 & Fail cladding when life fraction reaches 0.325 . \\
\hline 14 & $\begin{array}{l}\text { Same as Case } 5 \text { except fail cladding when life fraction reaches } 0.325 \text { and } \\
\text { assume fuel becomes mobile when it reaches a melt fraction of } 0.1 \text { and } \\
\text { freezes below a melt fraction of } 0.07 \text {. }\end{array}$ \\
\hline
\end{tabular}


The thermal conductivity used for the fuel in the reference calculation is taken from a table on page B-24 in Ref. 4 . The fuel is assumed to have $25 \%$ porosity with $25 \%$ of the porosity logged with sodium. In parametric Case 1, entries in the thermal conductivity table were increased by nearly $40 \%$ to correspond to $100 \%$ theoretical density fuel. The plots in Figs. 37 and 38 compare the power and net reactivity for Case 1 with the reference calculation for the time period after $2.4 \mathrm{~s}$. The differences between the two cases are mainly caused by a slight shift in the timing of various events. Voiding initiation is delayed in Case 1 by about $24 \mathrm{~ms}$ relative to the reference case because of a lower inventory of stored heat in the fuel pins. The delay in voiding initiation delays the initial power excursion and the onset of fuel relocation by nearly $30 \mathrm{~ms}$. The overall consequences of the accident are essentially the same as in the reference calculation, indicating that the accident sequence is insensitive to the value of the thermal conductivity.

The reference calculation assumes that fuel becomes mobile when it absorbs $40 \%$ of its heat of fusion. Because fuel melting initiates along the grain boundaries,[25] one can argue that the fuel becomes mobile when its temperature reaches the fuel solidus. Case 2 repeats the reference transient with location 1169 of block 13 in the SAS4A input file set to 0.0 . This change means that rapid in-pin fuel motion begins very close to the time when the centerline temperature of the top axial fuel node reaches solidus, and thus represents about the earliest time in the calculated transient when fuel relocation can be initiated with current models. Figures 39 and 40 compare the power and net reactivity for Case 2 with the reference transient. The earlier initiation of rapid in-pin fuel motion terminates the initial power increase about $4 \mathrm{~ms}$ earlier than in the reference transient and reduces the peak power by about a factor of two. The total energy release during the transient is reduced relative to the reference transient by about $0.5 \mathrm{fps}$. This calculation indicates relatively low sensitivity to the fraction of the heat of fusion required for the fuel to become mobile in the reference case; however, the higher burnup cases considered below have higher sensitivity to this parameter.

Because fuel relocation in Case 2 begins when the fuel temperature is much closer to the fuel solidus temperature than in the reference case, the oscillation caused 
by reentry is essentially absent in Case 2 . In Sect. III.B, it was noted that the fuel viscosity at the fuel solidus was set to a value 200 times greater than the value at liquidus. The higher viscosity of the fuel that initially relocates to the fission-gas plenum following the initiation of rapid in-pin motion apparently damps the oscillatory behavior. The increased damping reduces the amount of fuel that initially moves to the gas plenum, and this reduction, in combination with the initiation of rapid in-pin motion in somewhat fewer assemblies increases the reactivity minimum that occurs just after $2.48 \mathrm{~s}$. The difference in the minima in the net reactivity between Case 2 and the reference case is clearly evident in Fig. 40. The increase in the net reactivity that occurs following the minimum is due to the continued increase in the voiding reactivity feedback.

The choice of an areal melt fraction of 0.2 for the initiation of the PINACLE in-pin fuel motion model in the reference transient is arbitrary. In Case 3, the required areal melt fraction, (location 22 of block 65 in the SAS4A input file) was changed to the value 0.01 . This change allows fuel to shift in the molten cavity earlier than in the reference transient, but since the reactivity effects of this motion should be small, and because the conditions for the initiation of fuel ejection to the fission gas plenum are not affected, the overall transient should not change. Case 3 is compared with the reference transient in Figs. 41 and 42 . As expected, the two transients are practically indistinguishable from one another.

Cases 4 and 5 explore sensitivity to the burnup. In Case 4 , the sum of the partial pressures of fill and fission gases was set to $0.306 \mathrm{MPa}$, corresponding to a burnup of about 1 atom $\%$, and in Case 5 , the sum was set to $3.19 \mathrm{MPa}$, corresponding to a burnup of about 15 atom $\%$. One atom $\%$ is about the burnup at which the steady-state axial expansion of the fuel stops and gas release begins.[30] At this burnup, the fuel has expanded radially out to the cladding. Fifteen atom $\%$ burnup is representative of a high-burnup situation. Axial variation of the burnup is not taken into account and as in the reference case all fuel assemblies are assumed to have the same burnup. 
The plots in Figs. 43 and 44 compare the powers and net reactivities computed in Cases 4 and 5 with the values from the reference transient. Figure 45 compares the fuel relocation reactivity feedbacks for the three cases, and Fig. 46 compares the time evolution of the total energy release. The results show that the effect of changing the burnup is to change the time scale of the accident following the initiation of rapid in-pin fuel motion. All three cases initiate rapid in-pin fuel motion within $2 \mathrm{~ms}$ of one another; however, the pressure difference between the fuel pin cavity and the fission gas plenum is smaller in the lowburnup case, and a more gradual introduction of fuel relocation reactivity feedback results. This leads to greater energy deposition during the first power excursion as indicated in Fig. 46. It also results in the initiation of rapid in-pin fuel motion in about $40 \%$ of the fuel assemblies before the local minimum in the fuel motion reactivity feedback at about $2.55 \mathrm{~s}$. In both the reference transient and in Case 5, rapid in-pin fuel motion begins in only about half as many fuel assemblies before the local minimum in the fuel motion reactivity feedback. The larger energy release in the first power excursion and the initiation of rapid in-pin fuel motion in more fuel assemblies cause Case 4 to have a deeper minimum in the fuel motion reactivity feedback than in the higher burnup cases.

Cladding failures must occur to provide sufficient negative reactivity feedback to completely offset the positive void reactivity. The lower fission gas pressure in the low-burnup case causes a longer time interval between the initiation of rapid in-pin fuel motion and the first cladding failure. The corresponding time intervals are $933 \mathrm{~ms}$ in the low-burnup case and $34 \mathrm{~ms}$ for the high-burnup case. The interval in the reference transient is $430 \mathrm{~ms}$. The longer time interval along with similar power levels following the initial power excursion cause the larger energy release in the low-burnup case. Both Cases 4 and 5 end with peak fuel temperatures less than $2000 \mathrm{~K}$ and the energy release poses no threat to the reactor vessel.

One additional feature of the comparison of Cases 4 and 5 with the reference transient is that in both the low-burnup and the reference transients rapid in-pin fuel motion initiates in approximately $40 \%$ of the fuel assemblies prior to the first cladding failure. In the high-burnup case, rapid in-pin fuel motion initiates in only about half as many fuel 
assemblies prior to cladding failure. By the time the transients end, cladding failures occur in approximately $14 \%, 32 \%$, and $50 \%$ of the fuel assemblies, respectively, in the low-burnup, reference, and high-burnup cases. Because of the smaller number of fuel assemblies initiating rapid in-pin fuel motion and the relatively short delay time between fuel ejection and cladding failure in the high-burnup case, this case will be the most sensitive to the criteria used to initiate rapid in-pin fuel motion and cladding failure.

Case 6 differs from the reference transient in that fission gas migration continues up until the time when fuel melting begins and a cavity of molten fuel and fission gas forms. This reduces by nearly a factor of two the amount of gas in the central parts of the fuel pin at the time when rapid in-pin fuel motion initiates and has the related consequence that a significantly smaller amount of fuel must be ejected to equilibrate the pressure in the molten cavity with the pressure in the fission gas plenum. The plots in Figs. 47 and 48 compare power and net reactivity for Case 6 with the reference case. The coolant reactivity feedbacks for the two cases are compared in Fig. 49 and the fuel relocation feedbacks are compared in Fig. 50. Figure 51 shows the energy release. The reduced amount of fission gas in the fuel pin causes a larger amount of energy to be deposited in the initial power excursion and this in turn leads to a slightly larger voiding rate following the excursion. More importantly, the lower gas concentration results in less negative fuel motion reactivity feedback from the channels where rapid in-pin fuel motion first occurs, and during the subsequent fuel reentry, the feedback reaches a local maximum that is about 0.7 or $0.8 \$$ higher than in the reference transient. The combination of the higher voiding rate and the larger local maximum causes the net reactivity to over shoot prompt critical by about $0.08 \$$ and causes a second power excursion which deposits more than 2 fps of additional energy. The second power excursion terminates when several more channels initiate rapid in-pin fuel motion and produce large negative fuel relocation feedback. Cladding failures begin to occur just after $2.57 \mathrm{~s}$, but the positive fuel motion feedback is not sufficient to overcome the negative feedback caused by the rapid in-pin fuel motion, and the reactor remains subcritical. 
Fission gas migration subsequent to pump seizure causes the reactivity to exceed prompt critical briefly in Case 6. The reentry of fuel following ejection to the fission-gas plenum causes prompt criticality to be reached earlier in the transient, but suppression of reentry does not prevent prompt criticality. This is confirmed by Case 7 which repeats Case 6 using the SAS4A option which prevents reentry. The results from this case are compared with Case 6 and the reference transient in Figs. 47 through 51. Following the initiation of rapid in-pin fuel motion in about $44 \%$ of the fuel assemblies during the initial power excursion, the fuel motion reactivity feedback levels off near $-2.25 \$$. The coolant voiding reactivity feedback gradually pushes the net reactivity back into the 0.3 to $0.6 \$$ range. Rapid in-pin fuel motion initiates in several additional fuel assemblies starting around $2.57 \mathrm{~s}$, but the continued increase of voiding reactivity feedback offsets the resulting negative reactivity feedback, and the net reactivity levels off until cladding failures begin around $2.76 \mathrm{~s}$. The positive fuel relocation feedback following cladding failure drives the net reactivity over prompt critical leading to a second major power excursion just before $2.8 \mathrm{~s}$. The energy release during this power excursion is not as large as during the second excursion in Case 6, but enough energy is released prior to the second excursion for the energy release during the entire transient to exceed that in Case 6. Both Cases 6 and 7 have energy releases larger than in the reference transient, producing peak fuel temperatures in the neighborhood of $2500 \mathrm{~K}$. These temperatures are well below the temperature required to produce significant fuel vapor pressure $(\sim 3500 \mathrm{~K})$ and do not pose an immediate threat to the reactor vessel.

Case 8 repeats the low-burnup case, Case 4 , with gas migration permitted up until the time of fuel melting and the formation of a cavity with molten fuel and fission gas. The plots in Figs. 52 and 53 compare the powers and reactivities for the two cases. The comparison is similar to that for Case 6 and the reference transient. The lower gas content in Case 8 causes a larger energy deposition during the initial power excursion. Because of the smaller negative fuel motion reactivity feedback from rapid in-pin fuel motion, when the fuel reenters from the gas plenum, the fuel motion feedback achieves a higher local maximum than in Case 4 and the net reactivity goes about $0.07 \$$ over prompt critical, causing second power excursion. The second power excursion causes the initiation of rapid in-pin fuel motion in 
additional fuel assemblies and the resulting negative reactivity feedback drives the reactor subcritical. Cladding failures begin when the reactor is deeply subcritical and the resulting positive feedback is not sufficient to bring the reactor back to critical. Temperatures at the end of Case 8 are higher than in Case 4, but not high enough to produce significant fuel vapor pressures.

Case 9 repeats the high-burnup case, Case 5, with gas migration permitted. The case is similar to Case 8 in that more energy is released during the initial power excursion than in Case 5. Rapid in-pin fuel motion initiates in $35 \%$ to $40 \%$ of the fuel assemblies during the initial power excursion, and the subsequent reentry of fuel in these channels leads to a super-prompt-critical power excursion during which rapid in-pin fuel motion initiates in several more fuel assemblies. In part because of the higher pin pressure, cladding failures occur in the 54 highest powered fuel assemblies during this second power transient. Coincident with the positive reactivity feedback caused by the reentry of ejected fuel in the second group of channels, more cladding failures occur leading to still more positive feedback. The result is a third, super-prompt-critical power excursion which produces fuel temperatures substantially above that required to produce significant fuel vapor pressures.

When rapid in-pin fuel motion began in Case 9, fuel melting across the full radius had occurred over a substantial length of the fuel pin. Given the substantial pressure difference between the fuel pin cavity and the fission gas plenum, it is likely that rapid in-pin fuel motion should have started at least by the time melting had spread across the full radius. Sevy[31] has suggested that significant upward movement of fuel might begin even before fuel melts across the full radius of the pin. In Case 10, Case 9 was repeated with the melt fraction required for fuel to become mobile decreased from 0.4 to 0.1 . This change caused rapid in-pin fuel motion to begin just after fuel had melted across the full radius of the pin, reduced the energy deposition during the first power excursion, delayed initial cladding failure by about 110 ms relative to Case 9, and resulted in a nonenergetic transient. The plots in Figs. 54 and 55 compare Cases 9 and 10 with Case 5. 
In Case 11, rapid in-pin fuel motion initiates when the average of the centerline temperature in the top fuel node and the temperature of the bond sodium in the bottom of the gas plenum reaches the fuel solidus temperature. Setting location 1295 of block 13 in the SAS4A input file equal to 0.5 achieves this result. The plots in Figs. 56 and 57 compare Case 11 with the reference transient. The energy release during the initial power excursion increases substantially because of the delay in the start of rapid in-pin fuel motion and causes cladding failures in several fuel assemblies without prior rapid in-pin fuel motion in these assemblies. In addition, the first cladding failures in several fuel assemblies coincide with the reentry of fuel in other assemblies where rapid in-pin fuel motion is in progress. The resulting power excursion causes cladding failure in all the remaining fuel assemblies and produces fuel temperatures in excess of that required to generate significant fuel vapor pressures. The rearrangement of the event sequence can be seen by comparing the fuel motion reactivity plots for the first 10 channels in Case 11, shown in Figs. 58 and 59 with the corresponding plots, Figs. 22 and 23, for the reference transient.

In Case 12, Case 11 was repeated using the SAS4A option which prevents fuel from reentering the core after ejection to the fission gas plenum. The power and net reactivity for this case are compared with the reference transient and with Case 11 in Figs. 56 and 57. As in Case 11, the large energy release during the first power excursion causes rapid in-pin fuel motion to produce a larger amount of negative reactivity feedback than in the reference transient even though fewer fuel assemblies are involved. Prevention of fuel reentry locks in this large negative feedback so that the subsequent cladding failures occur at low power and do not produce enough positive feedback to carry the net reactivity back to critical. This happens in spite of the fact that cladding failures occur in several fuel assemblies where rapid in-pin fuel motion has not previously occurred.

As discussed in Sect. III.B, the temperature at the interface between the fuel and the bond sodium in the bottom of the fission gas plenum is estimated as the weighted average of the centerline temperature at the top of the fuel and the centerline temperature at the bottom of the sodium. This procedure is used pending future development of a more detailed 
treatment of the temperature fields near the interface. If one regards the interface as the boundary between a semi-infinite medium of fuel and a semi-infinite medium of sodium with each medium initially at uniform but distinct temperatures, then using the analytical solution given on page 88 of Carslaw and Jaeger[32] for the transient temperature as a function of distance from the boundary, one finds that the contact temperature is the weighted average of the fuel temperature and the sodium temperature and that the weighting factor is essentially the same as the weighting factor used to estimate the interface temperature in Cases 11 and 12 . The power history in Fig. 20 shows that in the $50 \mathrm{~ms}$ time period just prior to the initiation of rapid in-pin fuel motion, the power increases by nearly an order of magnitude. If one assumes that all the energy during the $50 \mathrm{~ms}$ time interval is deposited at the beginning of the time interval, then using Carslaw and Jaeger's solution, one finds that the difference between the fuel temperature and the initial sodium temperature at the end of the interval is $99 \%$ of the difference at the beginning of the interval only $2.5 \mathrm{~mm}$ from the interface. The fact that the distance is small suggests that during the rapid heating part of the transient the impact of axial conduction of heat across the interface is small and justifies in part the use of unity for the weighting factor as was done in the reference transient.

A final set of parametric calculations examines the sensitivity to the failure life fraction correlation used for predicting cladding failures. An analysis conducted by Derollepot[33] indicates that the life fraction at failure is log-normally distributed with a mean very close to unity and standard deviation such that $-2 \sigma$ corresponds to a life fraction of 0.325 . In Case 13, the reference transient was repeated with the extreme assumption that all cladding fails when its life fraction reaches 0.325 . Minor code changes in SAS4A subroutines FAILUR and LEIF were required to run this case. The plots in Figs. 60 and 61 compare the power and net reactivity for Case 13 with the reference transient. The plots show that the cases are identical up to the time of the initial cladding failure in Case 13. Cladding failed about $35 \mathrm{~ms}$ earlier than in the reference transient, but this change did not significantly alter the energy release. 
Case 14 repeats the high-burnup case, Case 5, with the cladding failure criterion reduced to a life fraction of 0.325 as in Case 13 and with the criterion for fuel mobility reduced to a value of 0.1 . In addition, location 1161 in block 13 of the SAS4A input file was reduced to the value 0.07 to produce a fuel freezing calculation (should freezing occur) consistent with the reduced mobility criterion. (Changing only the life fraction criterion led to the generation of significant fuel vapor pressures.) The change in the mobility criterion causes rapid in-pin fuel motion to initiate at about the time when the entire radius of the fuel pin reached the fuel solidus temperature at some axial location. The plots in Figs. 62 and 63 compare Case 14 with Case 5. The two cases are very similar in terms of the energy released during the transients. Case 14 illustrates once more the importance of the criterion for the initiation of rapid in-pin fuel motion.

\section{Abrupt Loss of Flow in the PRISM Mod B/92}

As for the 3500-MWt reactor, the analysis for the PRISM included a reference case and several parametric cases. Since the analysis for the PRISM basically confirms the results obtained for the larger reactor, fewer cases will be presented for this reactor.

\section{a. $\quad$ Reference Case}

The reference transient for the PRISM assumes a burnup of 10 atom \% and does not permit fuel reentry after ejection to the fission gas plenum. One of the parametric cases to be considered in the next section shows that the reference transient is insensitive to whether or not fuel reentry is assumed. A flow halving time of $180 \mathrm{~ms}$, very similar to that for the 3500-MWt reactor, is achieved by adjusting the moment of inertia for the synchronous machine used to drive the electromagnetic pumps. Reactivity feedback from the GEMs is neglected.

The plots in Figs. 64 and 65 show the power history, the net reactivity, and the reactivity feedback components for the reference transient. Fuel motion reactivity 
feedbacks from the SAS4A channels representing driver fuel assemblies are shown in Figs. 66 and 67. The plots cover the time period following $5 \mathrm{~s}$ after transient initiation. Coolant boiling and voiding in the transient begin in the highest powered fuel assemblies at $4.4 \mathrm{~s}$. Even though the flow reduction rate is similar, the initiation time is later than in the cases for the $3500-\mathrm{MWt}$ reactor because of the lower linear power rating for the PRISM (see Table I). As in the cases for the larger reactor, the rapid introduction of voiding reactivity feedback drives a rapid power increase which terminates with a peak of 32 times nominal at $5.14 \mathrm{~s}$ when rapid in-pin fuel relocation begins in the highest powered fuel assemblies. Rapid in-pin fuel motion initiates in $14 \%$ of the fuel assemblies in the $14 \mathrm{~ms}$ time interval starting at $5.14 \mathrm{~s}$, and the resulting negative reactivity feedback drives the net reactivity below $-4 \$$. The first cladding failures occur in fuel assemblies where rapid in-pin fuel motion has not initiated about $190 \mathrm{~ms}$ after the initiation of rapid in-pin fuel motion in the highest powered assemblies. At the time of cladding failure, the power is about 0.4 times nominal and the net reactivity is still substantially subcritical $(-3.3 \$)$. The cladding failure occurs about $0.14 \mathrm{~m}$ above the core midplane, but even though the reactivity feedback immediately following failure is positive, the reactor remains subcritical. Cladding failures in the highest powered fuel assemblies occur approximately $600 \mathrm{~ms}$ after the initiation of rapid in-pin fuel relocation. The dispersive nature of the fuel motion, once fuel enters the coolant channels drives the reactor more deeply subcritical so that when the calculation terminates, the net reactivity has dropped to $-4.89 \$$ and is continuing to decrease, and the power is down to 0.24 times nominal.

Figures 68,69 , and 70 show the state of the core at three times during the fuel motion phase of the calculation. In Fig. 68, state of the core is shown after rapid in-pin fuel motion has begun in the fuel assemblies represented by channel 1, but just before the initiation of rapid in-pin fuel relocation in channel 2. Figure 69 shows the core just after cladding failure in channel 3. It shows considerable in-pin fuel relocation in channels 1 and 2 , but no rapid in-pin fuel relocation elsewhere in the core. Figure 70 shows the core state after cladding failures have occurred in channels 3,4 , and 5, but before the net reactivity reaches its postfailure maximum of about $-2.14 \$$. When the calculation terminated, the energy release had 
reached nearly 7 fps and the peak fuel temperature was less than $1600 \mathrm{~K}$. The overall character of the transient is very similar to the reference transient for the $3500-\mathrm{MWt}$ reactor.

\section{b. $\quad$ Parametric Cases}

Table VI provides summary descriptions of the parametric cases considered for the PRISM. While not identical, these cases tend to parallel the parametric cases for the 3500-MWt reactor.

The first parametric case, Case 1, repeats the reference case with the burnup reduced by a factor of 2 to 5 atom $\%$. The power and reactivities for this case are shown in Figs. 71 and 72. The sequence of events is very similar to that for the reference case. Reactivity feedback from rapid in-pin fuel relocation drives the reactor subcritical following the initial power excursion, and the net reactivity remains negative throughout the remainder of the transient. The positive reactivity feedback immediately following cladding failures, and the

TABLE VI. Summary Description of Parametric Cases for PRISM Mod B/92 (Description Indicates Change from Reference Transient)

\begin{tabular}{|c|l|}
\hline Case & \\
\hline 1 & Reduce burnup to 5 atom \%. \\
2 & Increase burnup to 15 atom \%. \\
3 & Case 2 with fuel becoming mobile when it reaches a melt fraction of 0.1. \\
4 & Allow fuel to reenter the core after ejection to the fission gas plenum. \\
5 & $\begin{array}{l}\text { Initiate fuel ejection to the fission gas plenum when the average centerline } \\
\text { temperature in the top fuel node and the bottom node of the upper axial } \\
\text { blanket reaches the fuel solidus temperature. }\end{array}$ \\
6 & Allow fission gas migration until PINACLE initiation. \\
\hline
\end{tabular}


continued introduction of positive feedback due to coolant voiding causes the net reactivity to reach a maximum of about $-0.1 \$$ before reactivity feedback from the dispersal of fuel through the coolant channels begins to drive the net reactivity downward.

In Case 2, the burnup was increased to 15 atom \%. In this case, the event sequence changed significantly from that observed in the reference case. Figures 73 and 74 show the power and reactivity. Cladding failures occur before satisfaction of the criterion for the initiation of rapid in-pin fuel motion in the highest powered fuel assemblies. These assemblies represent $14 \%$ of the core. The cladding failures are slightly closer to the axial midplane than the cladding failures in the reference case, and the subsequent positive fuel motion feedback drives the reactor over prompt critical. The resulting power excursion causes rapid in-pin fuel motion to begin in all the remaining fuel assemblies. The rapid in-pin motion introduces small amounts of negative feedback, but in all but the 36 lowest powered fuel assemblies, it is soon followed by cladding failures. The 36 low-power fuel assemblies are essentially unvoided, and the high reactor power causes rapid in-pin motion reactivity feedback from these assemblies to drive the reactor sub-prompt-critical. Negative reactivity feedback from these fuel assemblies is soon augmented by negative feedback due to the dispersive fuel motion in the coolant channels, and the calculation ends with the net reactivity at about $-5.5 \$$ and decreasing rapidly.

In spite of the super-prompt-critical power excursion, fuel temperatures in Case 2 remained below the temperature required to generate significant fuel vapor pressures, and the energy release, while larger than in the reference case, would not pose a threat to the reactor vessel. Rapid in-pin fuel motion played the key role in preventing an energetic excursion which might have threatened the reactor vessel.

Because the criterion currently used to initiate rapid in-pin fuel motion does not depend explicitly on the difference between the pressure in the cavity of molten fuel and fission gas and the pressure in the fission gas plenum, and because fuel had melted across the full radius along a significant axial extent of the fuel pin by the time of cladding failure, 
Case 2 was repeated with the criterion for fuel mobility set at $10 \%$ of the heat of fusion rather than $40 \%$. The reactor power for this case, Case 3, is shown in Fig. 75. The change in the fuel mobility criterion allows rapid in-pin fuel motion to initiate in the highest powered fuel assemblies prior to cladding failure and, except for the fact that the peak power during the initial power excursion is only 23 times nominal, the transient looks very much like the reference transient.

In Case 4, the reference transient was repeated with fuel reentry permitted after ejection into the fission gas plenum. Figures 76 and 77 show the power and the reactivities for Case 4 . The results look very similar to those of the reference case, except that the net reactivity is higher after the initial insertion of negative reactivity feedback by the rapid in-pin fuel motion. At the time of the initial cladding failures, the net reactivity is $-2 \$$, as compared with $-3.3 \$$ in the reference case. The net reactivity reaches a maximum of $0.01 \$$ following cladding failures in several fuel assemblies, but then rapidly becomes negative as a result of the dispersion of fuel through the coolant channels.

Two additional cases for the PRISM will be discussed briefly. In Case 5 , the initiation of rapid in-pin motion was delayed by requiring that the average of the centerline temperature at the top of the fuel and the temperature at the bottom of the sodium equal the fuel solidus temperature. This is comparable to Case 11 for the 3500-MWt reactor. The delay in the initiation of rapid in-pin fuel motion was too large in this case, and cladding failures occurred in all fuel assemblies without prior rapid in-pin fuel motion. Significant fuel vapor pressures were generated. Note that substantial fuel vapor pressures were also generated in Case 11 for the 3500-MWt reactor.

In Case 6, fission gas present in the fuel at the beginning of the reference transient was allowed to continue relocation to the fission gas plenum up until the time of fuel melting and the formation of a cavity of molten fuel and fission gas. In this case the fission gas relocation was sufficient to maintain a uniform axial pressure distribution in the fuel pin up to the time of cavity formation. Rapid in-pin fuel motion occurred before cladding failures 
in this case, but introduced only a small amount of negative reactivity feedback because of the reduced amount of fission gas. The continuing voiding pushed the net reactivity sufficiently close to prompt critical so that postfailure positive fuel motion reactivity feedback drove the reactor super-prompt-critical. The resulting power excursion produced significant fuel vapor pressures. This case is similar to Cases 6 through 9 for the 3500-MWt reactor. Case 9 produced significant fuel vapor pressures. The lower burnup cases, Cases 6, 7, and 8 did not generate fuel vapor pressures, but all three cases did produce mild prompt-critical power excursions.

\section{3. $\quad$ Rapid Loss of Flow in the Actinide Burner}

Initial scoping analysis using a three-channel model for the actinide burner considered flow halving times ranging from $150 \mathrm{~ms}$ up to $2.5 \mathrm{~s}$. The analysis for a $300 \mathrm{~ms}$ halving time was repeated using the 10-channel described in Sect. III.A, and the results for this case provide an adequate basis for summarizing the response of the reactor to a rapid LOF. All fuel assemblies were assigned a burnup of 10 atom\%. Because the flow reduction was fairly abrupt, initial coolant voiding initiated well below the top of the core. As noted in Sect. II, the void worth in this region is positive, and the initial effect of the voiding was to drive the reactivity upward. Because the core void reactivity worth is more that $1.5 \$$ smaller than the driver fuel void worth reactivities in either the PRISM or the 3500-MWt reactor, the net reactivity reached only about $0.74 \$$ and the power only about four times nominal when initial cladding failures occurred. The power level remained fairly low and the flow reduction was slower than in the cases considered above for the PRISM and the 3500-MWt reactor, so the cladding failures were high enough in the core for the subsequent fuel motion reactivity feedback to be negative. However, the void reactivity continued to dominate for a brief period after failure, and the power reached about 6.5 times nominal before the fuel motion reactivity feedback drove the reactor subcritical. As the calculation continued, the coolant voiding began to spread into the region above the core where the void worth is negative. By the time the calculation terminated, the coolant voiding reactivity had fallen from a peak of about $1.5 \$$ to about $1.1 \$$, the net reactivity had dropped to $-1.6 \$$, and fuel motion reactivity feedback was 
decreasing at a rate of nearly $-10 \$ / \mathrm{s}$. Cladding failures occurred in about $17 \%$ of the fuel assemblies. Because the power levels remained fairly low throughout the transient, rapid in-pin motion did not occur in any fuel assemblies.

\section{Summary of Abrupt Loss-of-flow Analysis}

The foregoing analyses show that the sudden loss-of-flow accident can be expected to cause considerable core damage, but that the resulting energy release will pose little or no threat to the primary core containment. This conclusion holds for a broad range of burnups and is relatively insensitive to the cladding failure criterion. For reactors with moderate to high void worth reactivities, the relatively coherent voiding of the core can drive the reactivity near prompt critical, but Doppler and fuel axial expansion feedback will prevent the reactivity from reaching prompt critical. The reactivity insertion rate due to voiding can approach the $10 \$ / \mathrm{s}$ to $15 \$ / \mathrm{s}$ range. The high overpower that develops will cause rapid in-pin fuel motion, and the associated negative reactivity feedback will reduce the reactivity back near or below critical, thus bringing the power into the range of nominal or, at most, a few times nominal. Because of the brief period of high overpower and the fact that the voiding initiates near the core axial midplane, subsequent cladding failures will be predisposed to occur near the midplane. Because of the prior rapid in-pin motion, the resulting positive feedback that briefly occurs before fuel dispersal through the coolant channels gets underway will not drive the reactor prompt critical. In addition, because the power is relatively low when cladding failure occurs, there will be more temporal incoherence of the failures than might otherwise be the case. As fuel disperses through the coolant channels, neutronic shutdown occurs.

For reactors with lower sodium void worth reactivities, the results for the actinide burner indicate that initial voiding will take place primarily in the core where the positive worth will drive the reactivity upward. However, the lower void worth means that the void worth reactivity insertion rate will be lower, and voiding may not push the reactor very close to prompt critical. As a result, the fuel heating rates will be lower, and cladding failures may occur before the onset of rapid in-pin motion. The fact that the power level is lower may cause 
more temporal incoherence in the failures, and the fact that the net reactivity is well below prompt critical makes it unlikely that postfailure, positive reactivity feedback would drive the reactor over prompt critical. Should the reactivity get too high, the resulting increase in fuel heating rates would be likely to cause rapid in-pin motion in some of the lower powered fuel assemblies, thus limiting the power increase and the resulting energy deposition.

\section{PHENOMENOLOGICAL CONSIDERATIONS}

Two primary phenomenological considerations hold the key to a nonenergetic outcome for the initiating phase, particularly for the sudden-loss-of-flow accident. The first is the initiation of fuel relocation to the fission gas plenum, and the second the absence of significant fission gas relocation within the fuel pin during the transient. A third consideration, the return of fuel to the core after ejection to the plenum, may be important if either of the first two considerations cannot be resolved favorably. Theoretical calculations by Gesh and Kramer[24] provide firm support for the absence of fission gas relocation. Additional sophistication in the modeling of the interface between the top of the fuel and the fission gas plenum may provide additional insight into the first and third considerations, but experimental support is highly desirable for the ultimate resolution of these issues.

Most of the calculations described in Sect. IV initiated fuel relocation to the fission gas plenum when both the centerline temperature of the top axial node in the fuel reached the fuel solidus temperature and the molten cavity extended into the top axial computational node for the fuel. If fuel was assumed to remain immobile until it absorbed $40 \%$ of the heat of fusion, then the extension of the cavity to the top computational node was the controlling criterion. At the time when this criterion was satisfied, the fuel temperature had reached solidus across the full radial extent over a significant axial length of the fuel pin. For the LOF accident, Sevy[31] has postulated that the relatively large pressure difference between the fuel pin cavity and the fission gas plenum, particularly at the higher burnups, would probably initiate fuel displacement to the fission gas plenum even before fuel has melted all the way out to the 
cladding. An earlier initiation of fuel relocation was simulated in a couple of cases by reducing the fraction of the heat of fusion required for the fuel to become mobile. One of these cases showed that the earlier initiation had the potential to make the higher burnup cases less sensitive to the timing of cladding failures. Experimental support for the modeling of the initiation of rapid in-pin fuel relocation is highly desirable.

Fission gas migration during the transient was not allowed in most of the cases described in Sect. IV. The LOF cases where gas migration was permitted up until the initiation of fuel melting and cavity formation produced significantly higher fuel temperatures than cases where migration was not permitted. This result obtained at all burnups, showing that the issue is not only the total amount of fission gas in the fuel pin, but also the relative amounts of gas in the pin and gas plenum. Smaller amounts in the pin relative to the plenum require smaller displacements of fuel to bring the cavity pressure into equilibrium with the pressure in the plenum. This in turn means that there is less negative feedback to offset the positive feedback that follows cladding failures. Calculations by Gesh and Kramer[24] show that gas is not able to relocate within the fuel pin on the time scale of a few seconds, indicating that the modeling assumption of no gas migration is reasonable.

The return of fuel to the active core following ejection to the fission gas plenum has the potential to cause oscillations in the fuel motion reactivity feedback, particularly following high overpower conditions. Cladding failures coincident with the return of fuel to the core can augment the already increasing feedback and lead to very high overpower conditions. As discussed in Sect. III.B, modeling of this fuel motion is not consistent because the LEVITATE fuel motion model does not keep track of fuel that has been displaced from the core by PINACLE, thus possibly underestimating the fuel motion feedback following cladding failure. Parametric LOF calculations for both the PRISM and the 3500-MWt indicate that the accident consequences are insensitive to the possible reentry of fuel after ejection provided there is sufficient time between the initiation of ejection to the gas plenum and the first cladding failures, and so long as gas migration within the fuel does not occur during the transient. It should further be noted that in three of the parametric cases for the 3500-MWt reactor, the fuel 
was assumed to become mobile when the fuel reached $10 \%$ or less of its heat of fusion. This had the effect of increasing the viscosity of the fuel when rapid in-pin motion began, and essentially eliminated the tendency for the fuel to reenter the core after ejection. If the lower mobility limit is reasonable, as seems likely, and if the viscosity used in the calculation is reasonable, the question of allowing or not allowing fuel reentry may become moot.

\section{CONCLUSIONS}

An essential part of the scenario for both high-reactivity-insertion-rate transientoverpower and sudden-loss-of-flow accidents is that enough fuel relocates to the fission gas plenum so that when cladding failures occur, the resulting positive feedback will not drive the reactor into an energetic power excursion. The fact that cladding failures occurred significantly later than the initiation of rapid in-pin motion in the extreme case of a $10 \$ / \mathrm{s}$ reactivity insertion, as describe in Sect. VI.A, indicates that this requirement is met relatively easily in the TOP accident. Continued coolant flow removes heat from the cladding and tends to delay failures relative to the melting of fuel. In the LOF analysis described in Sect. IV.B, the criterion used for the initiation of rapid in-pin fuel motion seems to be conservative since, as discussed in Sect. IV.B.1.b and Sect. V, a less restrictive criterion seems justifiable. Thus, the requirement for sufficient fuel relocation to the fission gas plenum prior to cladding failure seems readily met in this case also. The sequence of events in the reference transient for the 3500-MWt reactor is representative of what would be expected in all abrupt loss-of-flow transients. Peak fuel temperatures were much less than $2000 \mathrm{~K}$ and considerably less than the temperature required to produce significant fuel vapor pressure. In the parametric cases, several input assumptions which were thought to have the potential for upsetting the desired event sequence were changed. These cases demonstrated that, while it is easier to disrupt the desired event sequence at the higher burnups, the event sequence found in the reference transient is likely to hold for the entire range of burnups above about 1 atom $\%$. 
While the response of the 3500-MWt reactor, the PRISM, and the actinide burner to a rapid loss of flow differ somewhat in the accident sequence details, the overall results are very similar. The transient overpower analysis reported here was performed only for the actinide burner, but the character of the results indicate that similar behavior can be expected in other reactors such as the PRISM and the 3500-MWt reactor. A limited amount of recent TOP analysis $[1,16]$ supports this conclusion. In general, the rapid insertion of reactivity brought about by coolant voiding or by the inadvertent motion of control rods causes an increase in power and results in fuel heating and melting with the cladding intact. If the fuel heating rates become high enough, a flow path opens between the high-pressure molten fuel cavity and the lower-pressure fission gas plenum above the core, and rapid in-pin relocation of fuel results. The reactivity effect of this fuel motion is strongly negative, and acts to counter the positive reactivity. Subsequent cladding failures occur at reduced power and reactivity levels, and fuel ejection and relocation aftẹr cladding failures render the core subcritical. This general behavior comes about because the metallic fuel melting temperature is lower than the cladding melting temperature. The lower melting temperature allows in-pin fuel relocation to precede cladding failure. Metallic fuel thus acts as a backup safety mechanism that counters the impact of rapid positive reactivity insertions, whether from coolant voiding or from some other source, and renders the accident sequence nonenergetic, with no potential for breaking the reactor vessel, and a very low risk to the public safety.

\section{ACKNOWLEDGMENTS}

We are grateful to R. H. Sevy for establishing the basic outline for the loss-of-flow analysis and for constructive discussions as the work progressed. We also thank F. E. Dunn for assistance in the use of the boiling model and J. E. Cahalan for general assistance in the use of the SAS4A computer code. 


\section{REFERENCES}

1. J. E. Cahalan, A. M. Tentner, and E. E. Morris, "Advanced LMR Safety Analysis Capabilities in the SASSYS-1 and SAS4A Computer Codes," Proc. of Intl. Topical Meeting on Advanced Reactors Safety, 2:1038-45, Pittsburgh, Pennsylvania (April 1721, 1994).

2. Y. I. Chang et al., "Passive Safety Features of Low Void Worth Metal Fueled Cores in a Bottom Supported Reactor Vessel," Proc. Intl. Conf. on Fast Reactors and Related Fuel Cycles, II:16.2-1, Kyoto, Japan (October 28-November 1, 1991).

3. R. Wigeland and P. Pizzica, "SASSYS Analyses of ATWS Performance for PRISM MOD B/92," Argonne National Laboratory Report, ANL-IFR-198 (May 1993).

4. R. A. Wigeland, R. B. Turski, and R. K. Lo, "Relative Performance of Metallic Fuel and Oxide Fuel During Unprotected Accident Conditions in a 3500 MWth Pool-type LMR," Argonne National Laboratory Report, ANL-IFR-136 (September 1990).

5. R. H. Sevy, "Sudden Loss of Flow in an Integral Fast Reactor," Argonne National Laboratory Report, ANL-IFR-184 (January 1993).

6. W. R. Bohl et al., "An Analysis of Transient Undercooling and Transient Overpower Accidents without Scram in the Clinch River Breeder Reactor," Argonne National Laboratory Report, ANL/RAS 75-29 (July 1975).

7. W. R. Bohl et al., "An Analysis of the Unprotected Loss-of-Flow Accident in the Clinch River Breeder Reactor with an End-of-Equilibrium-Cycle Core," Argonne National Laboratory Report, ANL/RAS 77-15 (May 1977).

8. J. E. Cahalan et al., "An Assessment of the Unprotected LOF Accident at EOC-4 in the CRBRP Heterogeneous Core Design," Argonne National Laboratory Report, ANL/RAS 83-11 (April 1983).

9. J. E. Cahalan, "Homogeneous/Heterogeneous LMFBR Core Design Safety and Licensing Trade-Offs," Argonne National Laboratory Report, ANL/RAS 80-2 (February 1980).

10. E. E. Morris and T. Y. C. Wei, "An Assessment of the Unprotected LOF Accident in the CDS Phase II Heterogeneous Core Design," Argonne National Laboratory Report, ANL/RAS 81-1 (December 1980).

11. Y. I. Chang, "Core Concepts for 'Zero-Sodium-Void-Worth Core' in Metal Fueled Fast Reactor," Proc. Intl. Conf. on Fast Reactors and Related Fuel Cycles, II: 14.5-1, Kyoto, Japan (October 28-November 1, 1991). 
12. R. N. Hill, Argonne National Laboratory, personal communication (March 1991).

13. R. N. Hill, "Neutronics Optimization Studies for PRISM MOD B/92," Argonne National Laboratory Report, ANL-IFR-200 (June 1993).

14. "Reactor Module Size Enhancement Trade Study (Interim Report)," Compiled by D. E. Lutz, General Electric Company Report, GEFR-00912 (December 1992).

15. E. K. Fujita and D. C. Wade, "The Neutronic and Fuel Cycle Performance of Interchangeable 3500 MWth Metal and Oxide Fueled LMRs," Argonne National Laboratory Report, ANL-FRA-163 (March 1989).

16. R. A. Wigeland, Argonne National Laboratory, personal communication (December 1993).

17. R. A. Wigeland, Argonne National Laboratory, personal communication (September 1991).

18. R. B. Vilim and R. N. Hill, "The Steady-State Thermal-Hydraulic Performance of Interchangeable 3500 MWth Metal and Oxide Fueled LMRs," Argonne National Laboratory Report, ANL-FRA-164 (March 1989).

19. J. E. Cahalan, Argonne National Laboratory, personal communication (March 1992).

20. M. L. Hamilton and N. S. Cannon, "HT9 Data-base and Failure Correlation," Westinghouse Hanford Company Report, HEDL-TC-2681 (March 1985).

21. M. L. Hamilton, Westinghouse Hanford Company, personal communication (February 1986).

22. F. H. Huang, Westinghouse Hanford Company, personal communication (August 1986).

23. T. H. Bauer, G. R. Fenske, and J. M. Kramer, "Cladding Failure Margins for Metallic Fuel in the Integral Fast Reactor," Trans. of the 9th Intl. Conf. on Struct. Mech. in Reactor Technol., C:1, Lausanne, Switzerland (August 17-21, 1987).

24. C. Gesh and J. M. Kramer, Argonne National Laboratory, personal communication (July 1987).

25. J. M. Kramer, Argonne National Laboratory, personal communication (April 1993).

26. A. M. Tentner and Kalimullah, "SAS4A Analysis of the M7 Metal Fuel TREAT Experiment," Argonne National Laboratory Report, ANL-IFR-186 (January 1993). 
27. A. M. Tentner, "Status of Metal-Fuel Modeling in the SAS4A Accident Analysis Code," Argonne National Laboratory Report, ANL-IFR-191 (April 1993).

28. T. H. Bauer et al., "Update of Safety Testing in TREAT on U-5Fs Fuel: Data from Test M4 and Combined Analysis of Tests M2, M3, and M4," Argonne National Laboratory Report, ANL-IFR-69 (May 1987).

29. T. H. Bauer et al., "First Overpower Tests of Metallic IFR Fuel in TREAT: Data and Analysis from Tests M5, M6, and M7," Argonne National Laboratory Report, ANL-IFR124 (December 1989).

30. E. E. Gruber and J. M. Kramer, "Analysis of Fission-Gas Behavior with the STARS Code: Steady-State Irradiation of U-Pu-Zr Fuel Pins," Argonne National Laboratory Report, ANL-IFR-90 (July 1988).

31. R. H. Sevy, Argonne National Laboratory, personal communication (June 1993).

32. H. S. Carslaw and J. C. Jaeger, Conduction in Solids, Second Edition, Oxford University Press, Oxford, Great Britian (1959).

33. O. Derollepot, Argonne National Laboratory, personal communication (September 1991). 


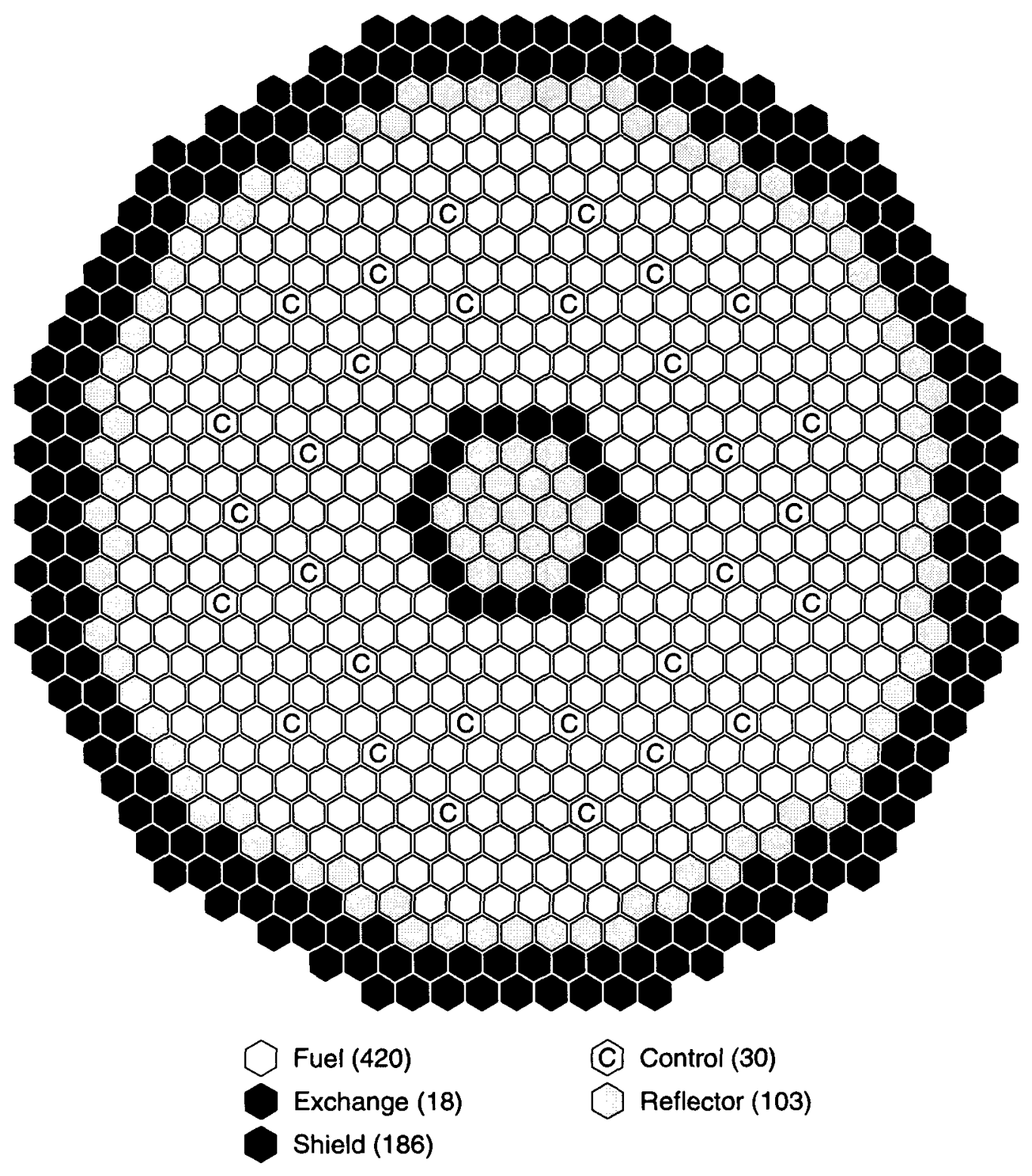

Fig. 1. Plan View of Core for the Actinide Burner 


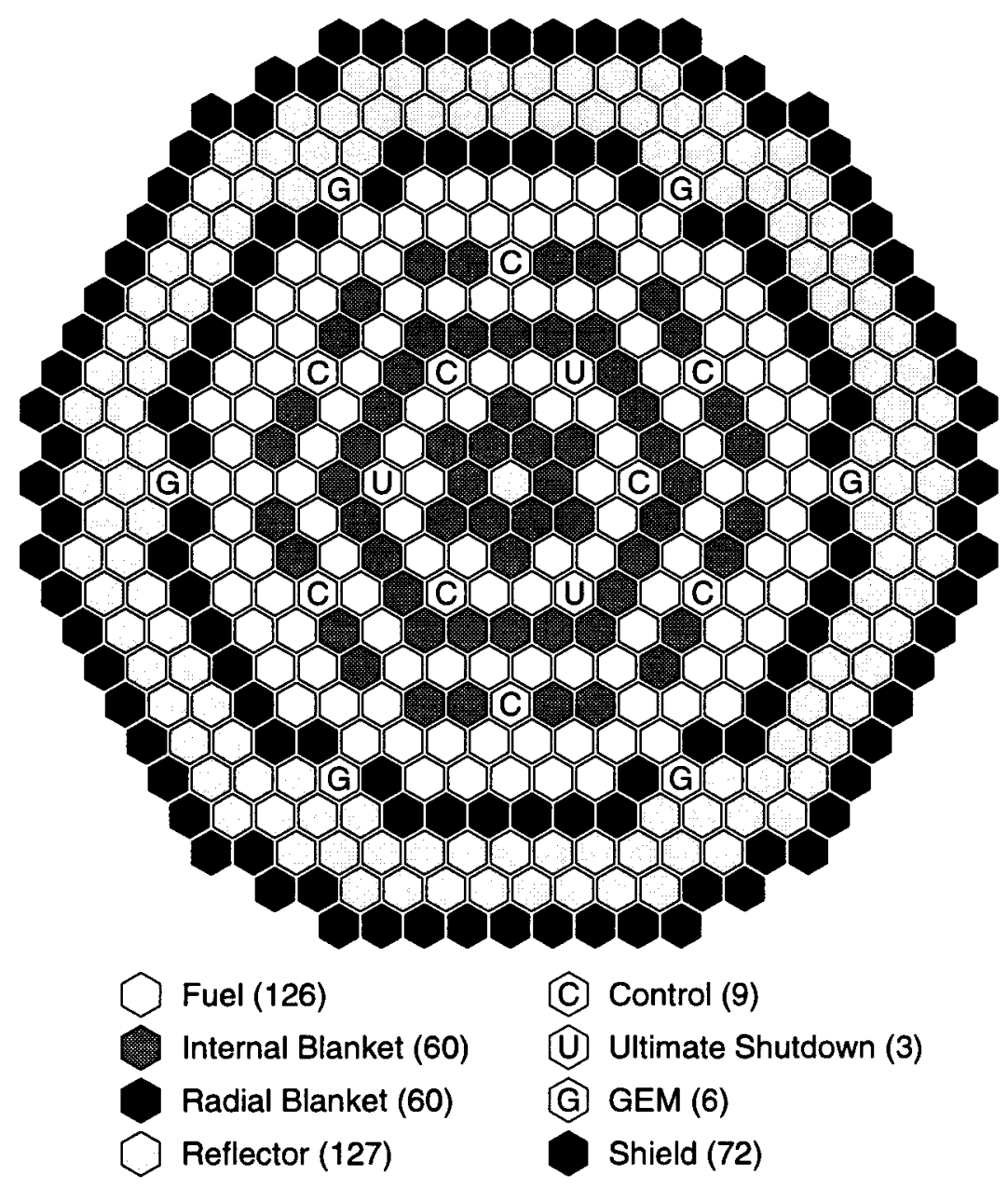

Fig. 2. Plan View of Core for the PRISM Mod B/92 


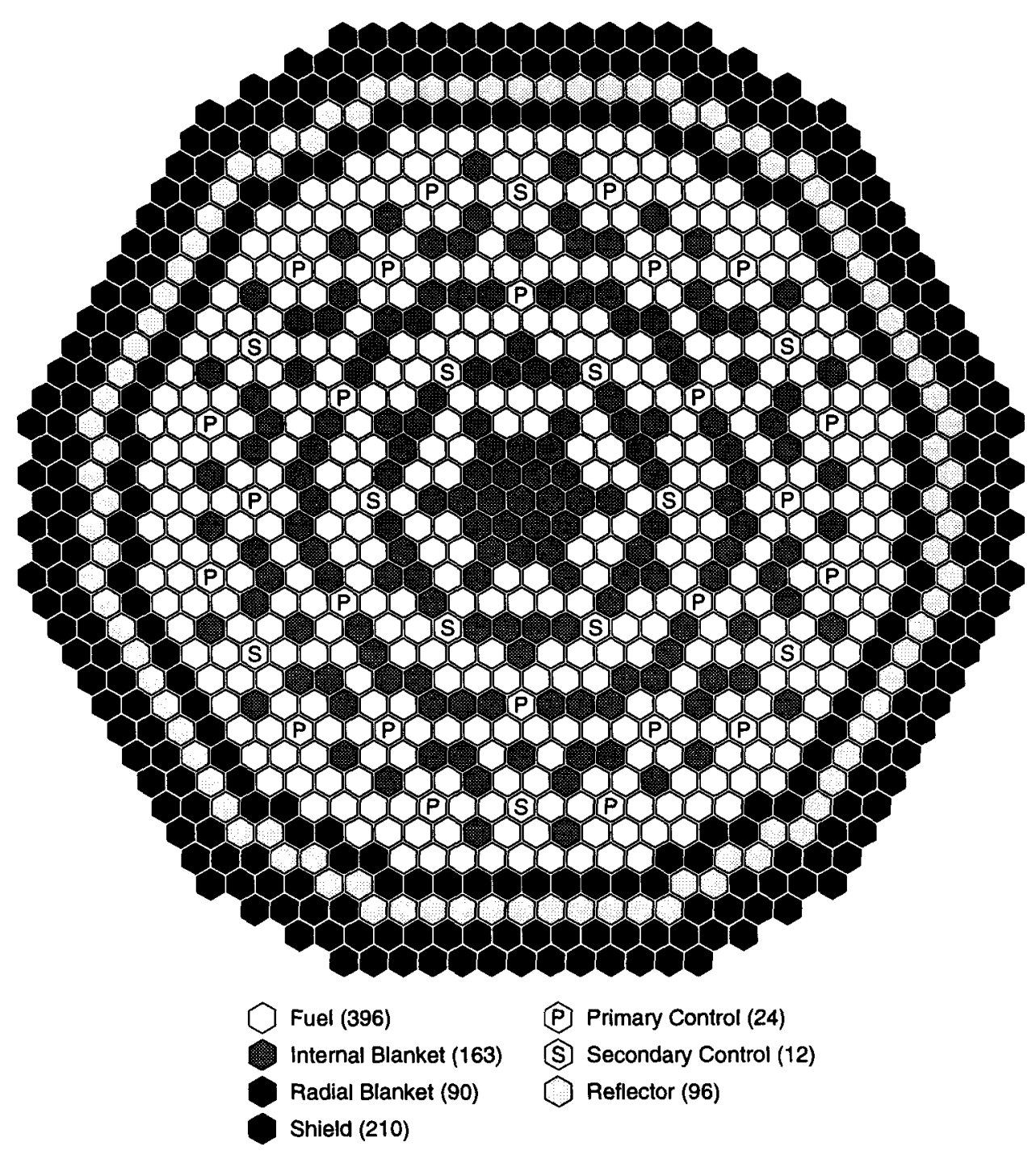

Fig. 3. Plan View of Core for the 3500-MWt Reactor 


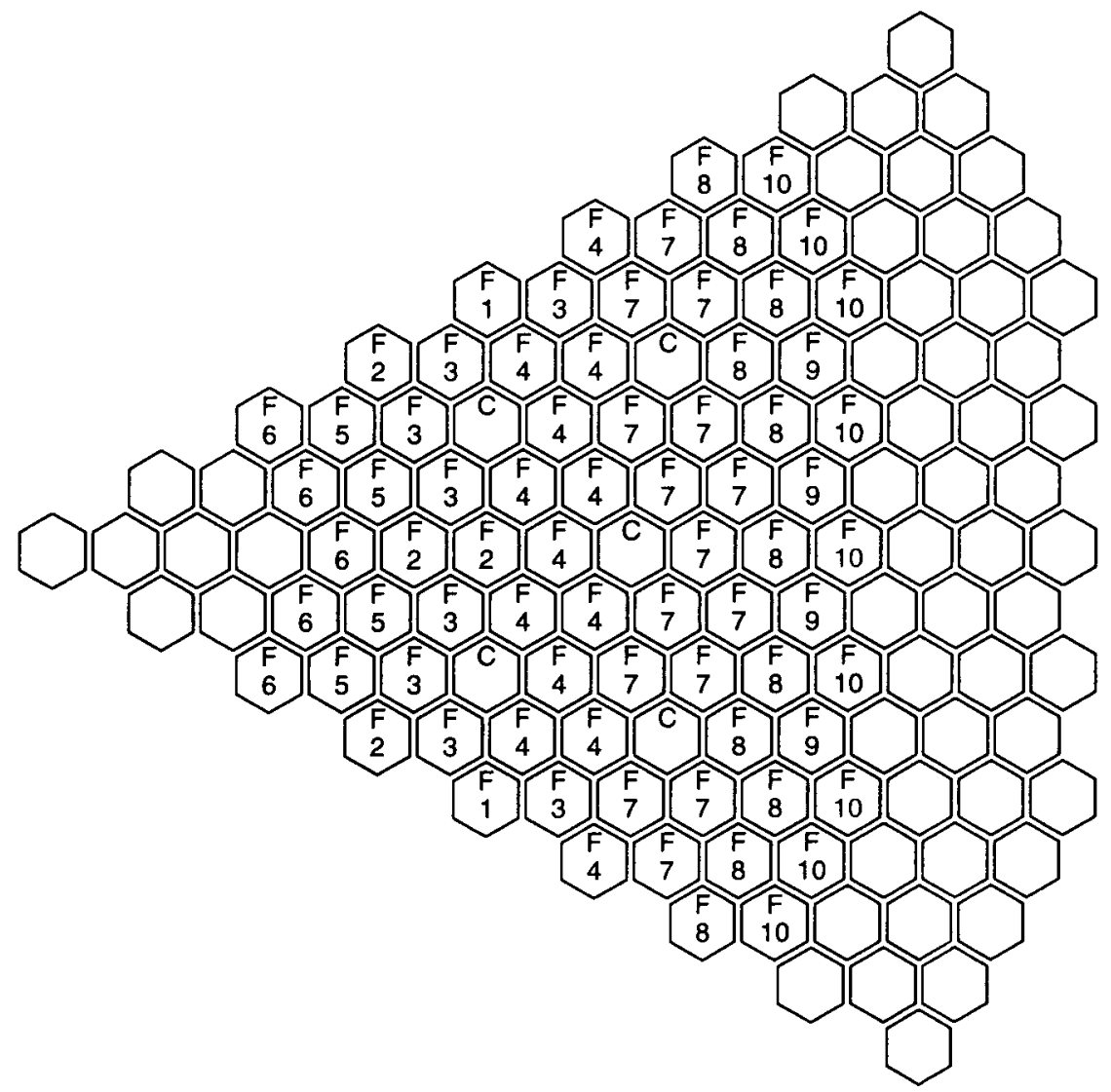

Fig. 4. SAS4A Channel Assignments for the Actinide Burner 


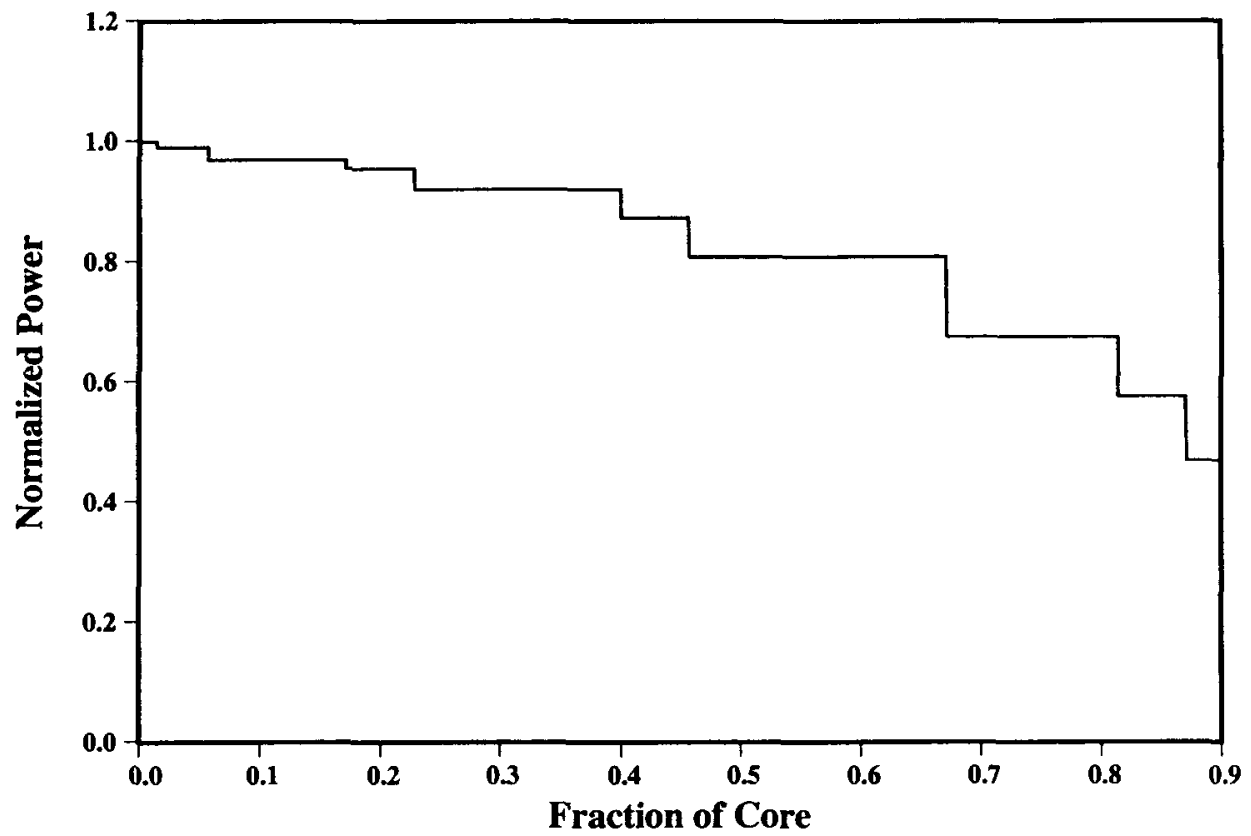

Fig. 5. Fraction of Actinide Burner Core with Power Greater or Equal to Normalized Power 


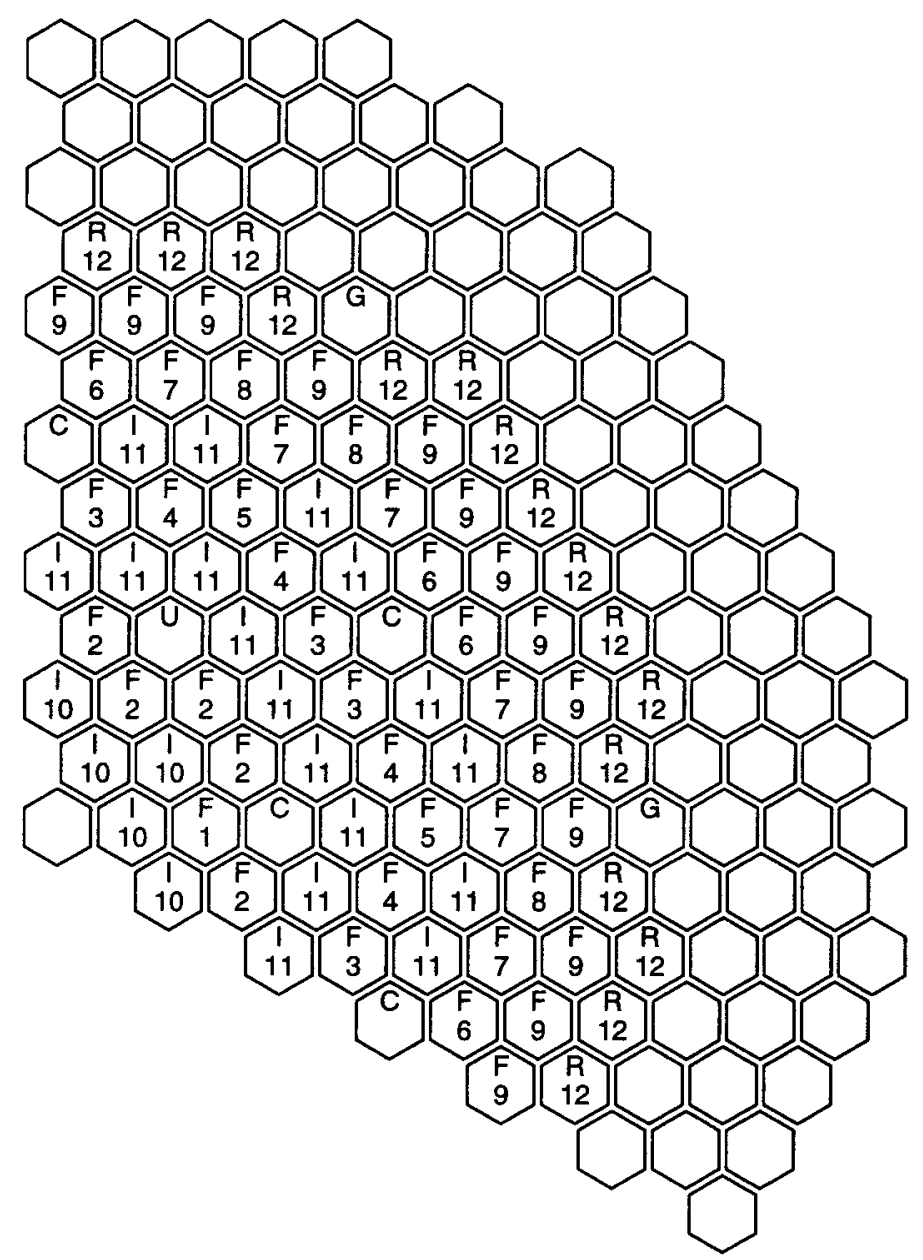

Fig. 6. SAS4A Channel Assignments for the PRISM Mod B/92 


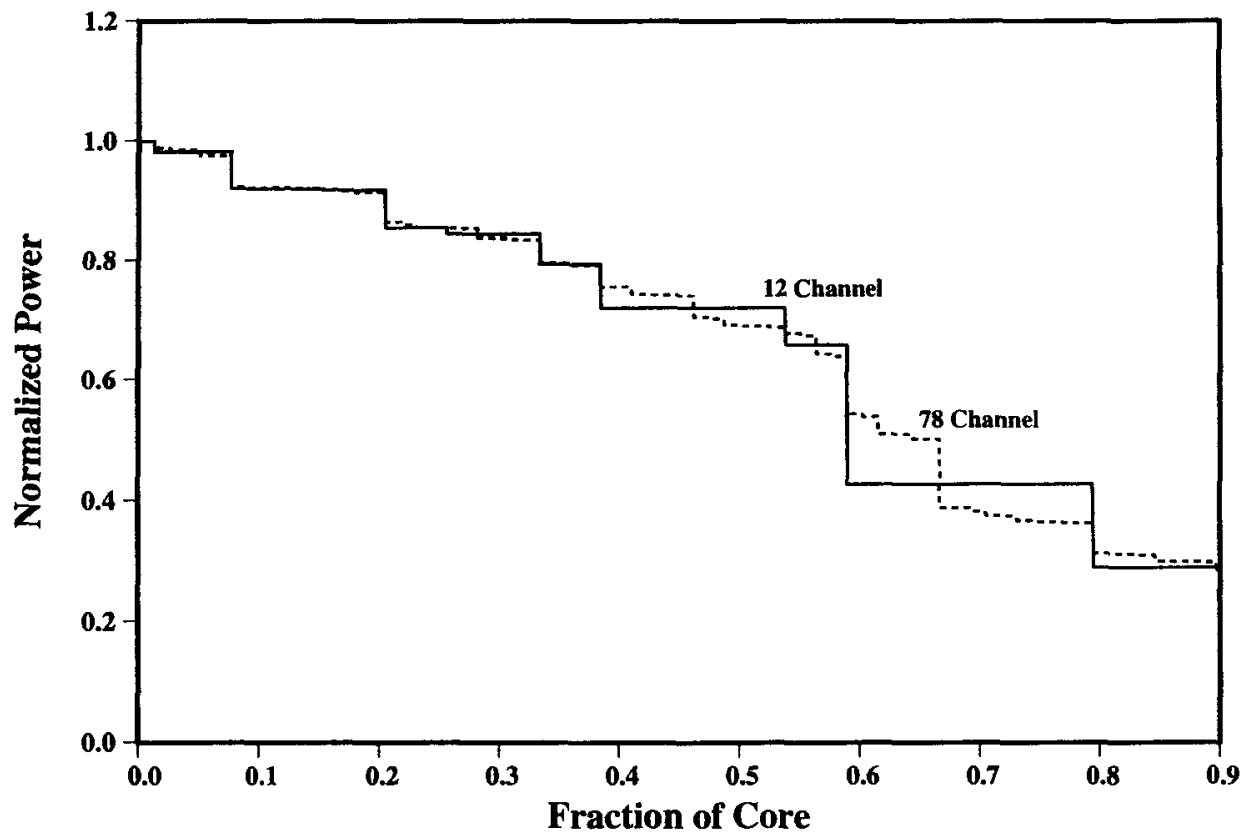

Fig. 7. Seventy-Eight- and 12-channel Representation of the Fraction of the PRISM Mod B/92 Core with Power Greater than the Normalized Power 


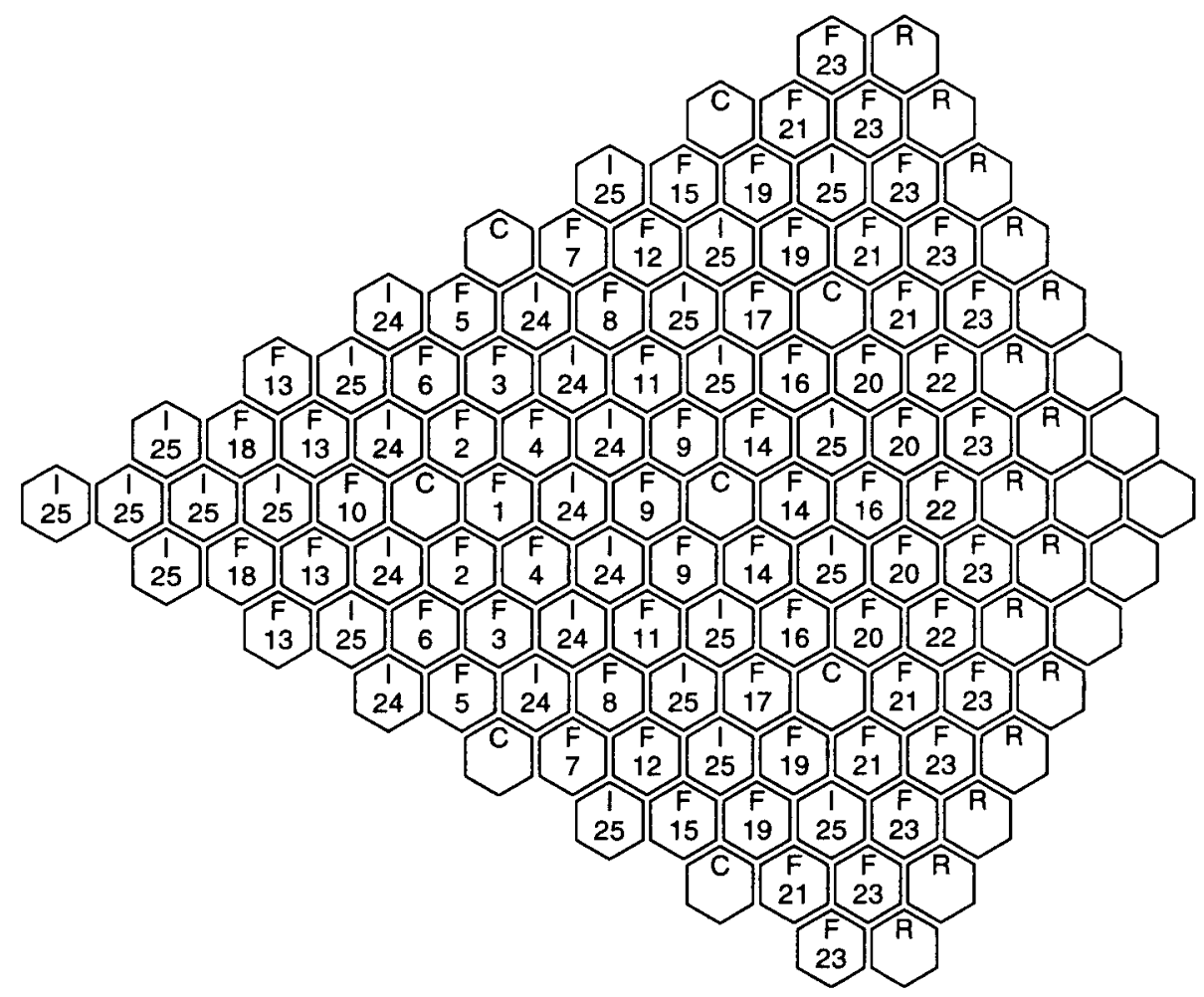

Fig. 8. SAS4A Channel Assignments for the 3500-MWt Reactor 


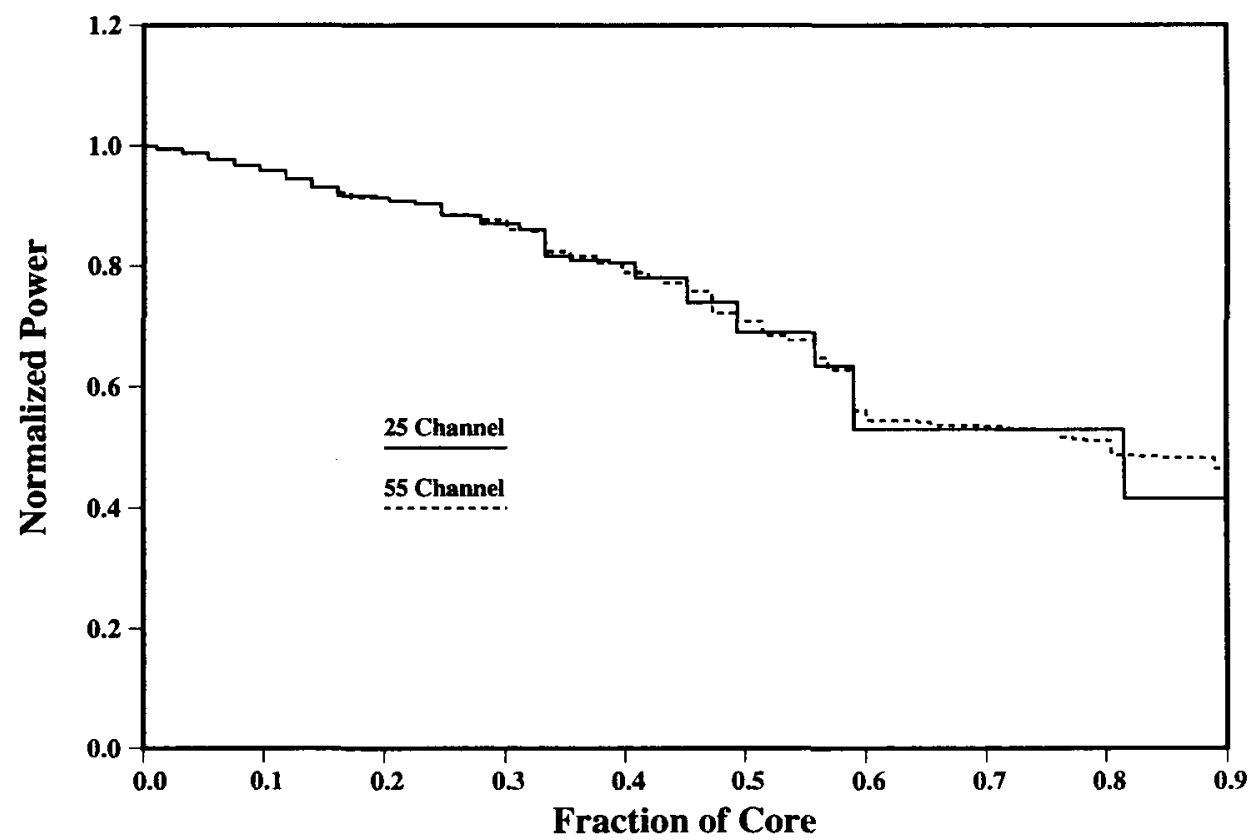

Fig. 9. Fifty-Five- and 25-channel Representation of the Fraction of the 3500-MWt Core with Power Greater than the Normalized Power 


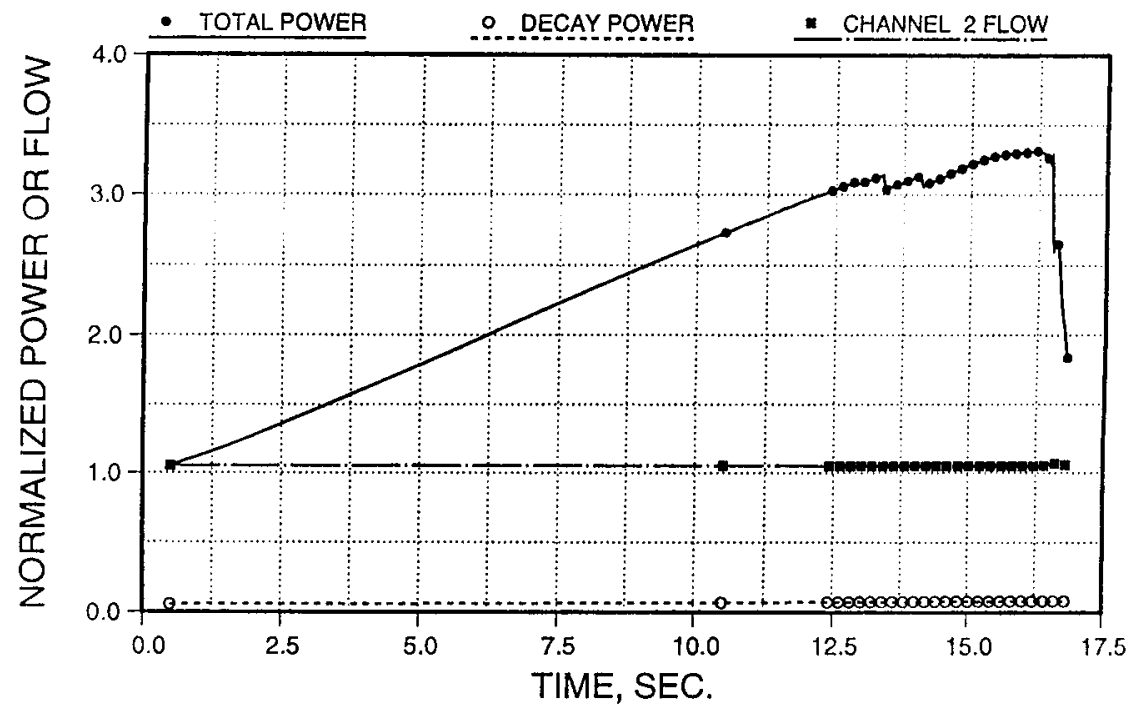

Fig. 10. Reactor Power During a $0.1 \$ / \mathrm{s}$ Reactivity Insertion in the Actinide Burner

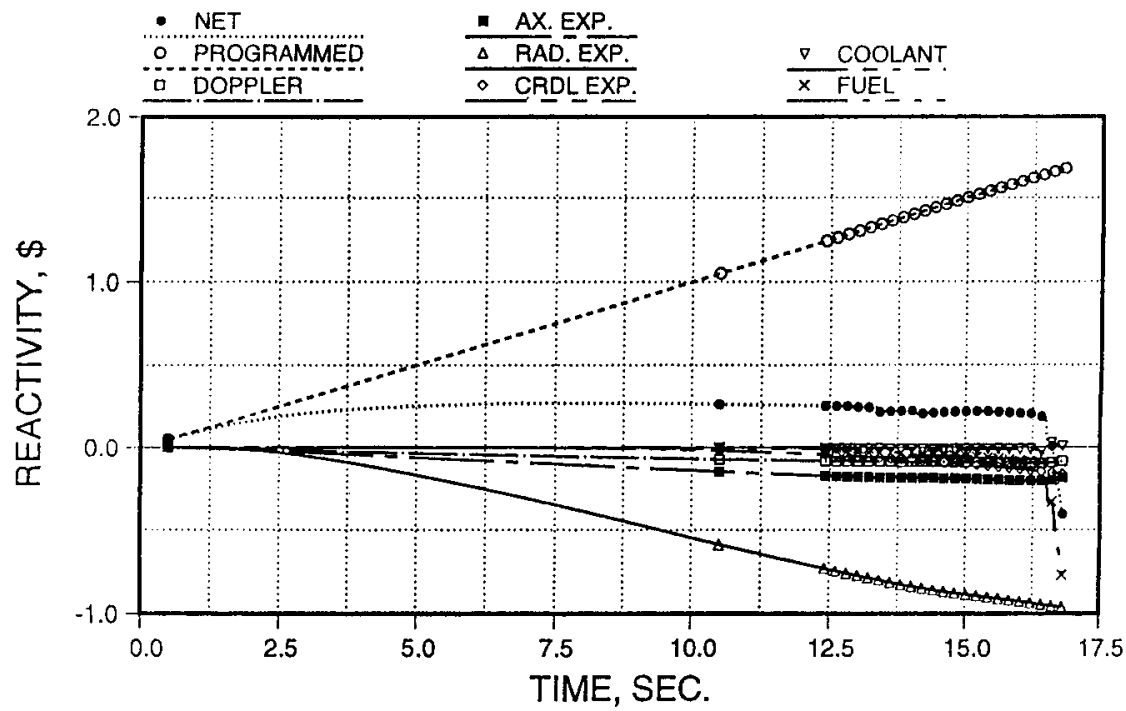

Fig. 11. Reactivities During a $0.1 \$ / \mathrm{s}$ Reactivity Insertion in the Actinide Burner 


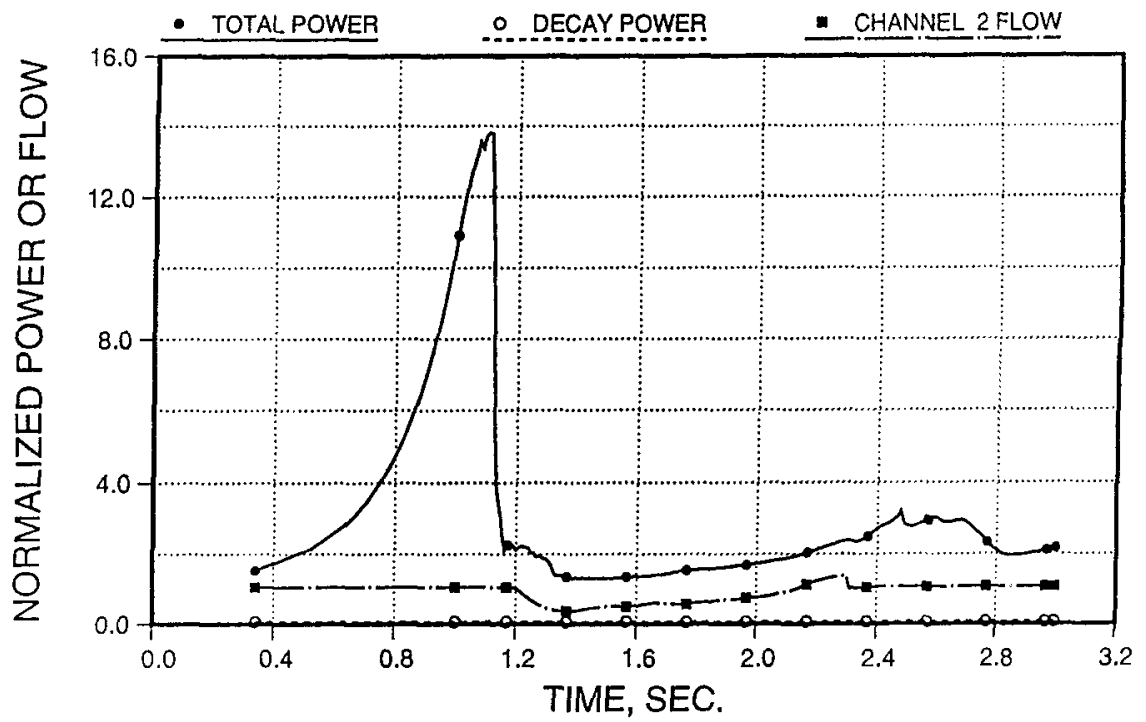

Fig. 12. Reactor Power During a 1 \$/s Reactivity Insertion in the Actinide Burner

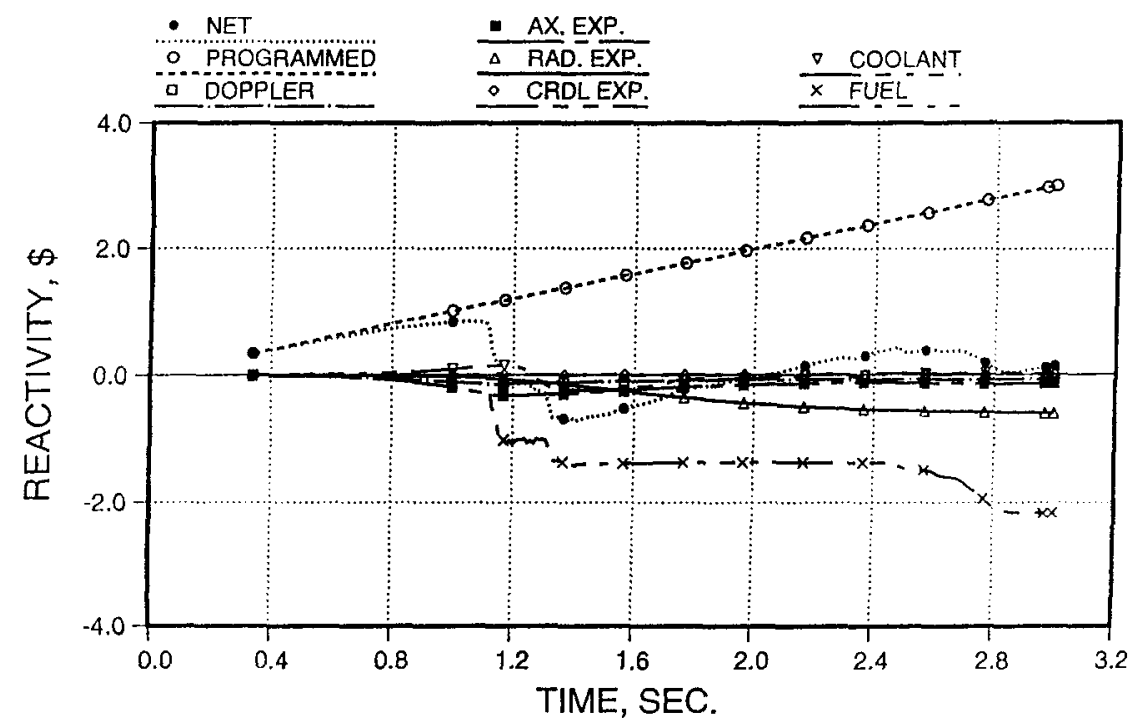

Fig. 13. Reactivities During a $1 \$ / \mathrm{s}$ Reactivity Insertion in the Actinide Burner 


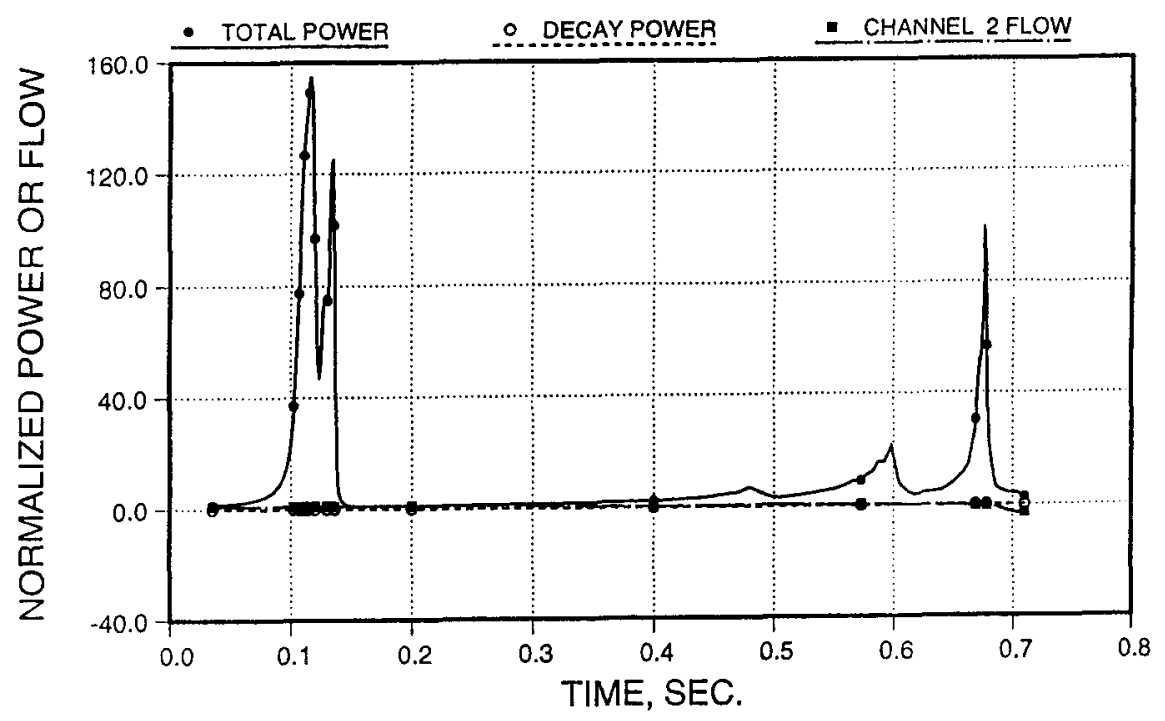

Fig. 14. Reactor Power During a $10 \$ / \mathrm{s}$ Reactivity Insertion in the Actinide Burner

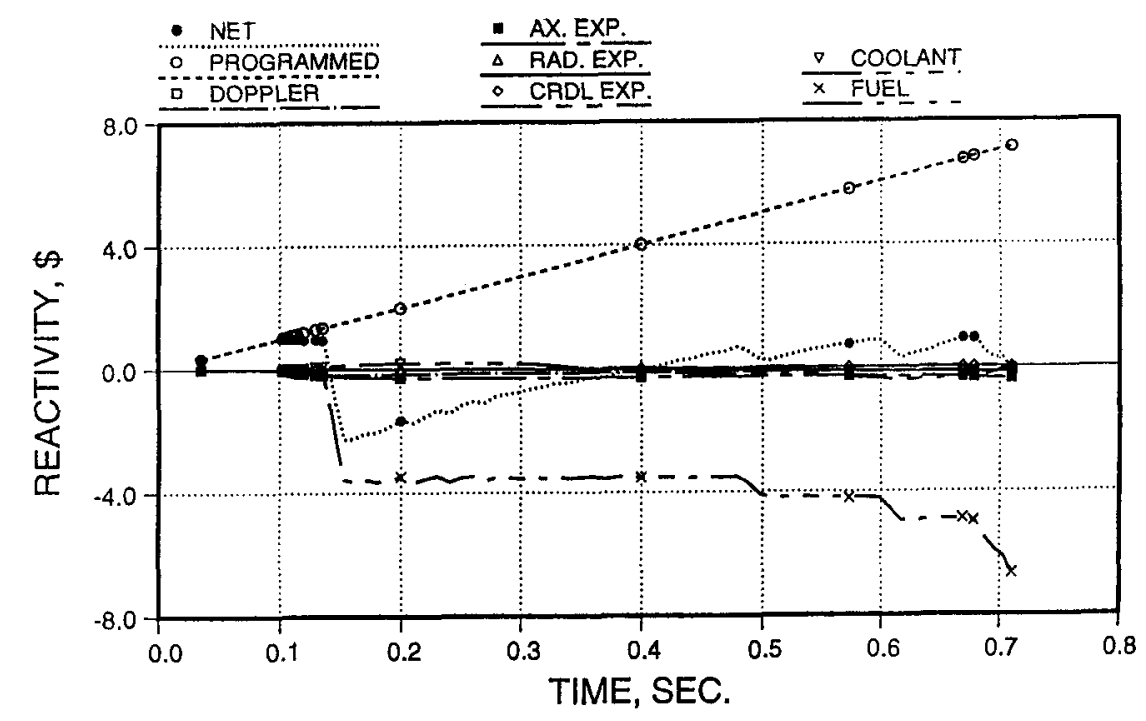

Fig. 15. Reactivities During a $10 \$ / \mathrm{s}$ Reactivity Insertion in the Actinide Burner 


\section{REFERENCE TRANSIENT}

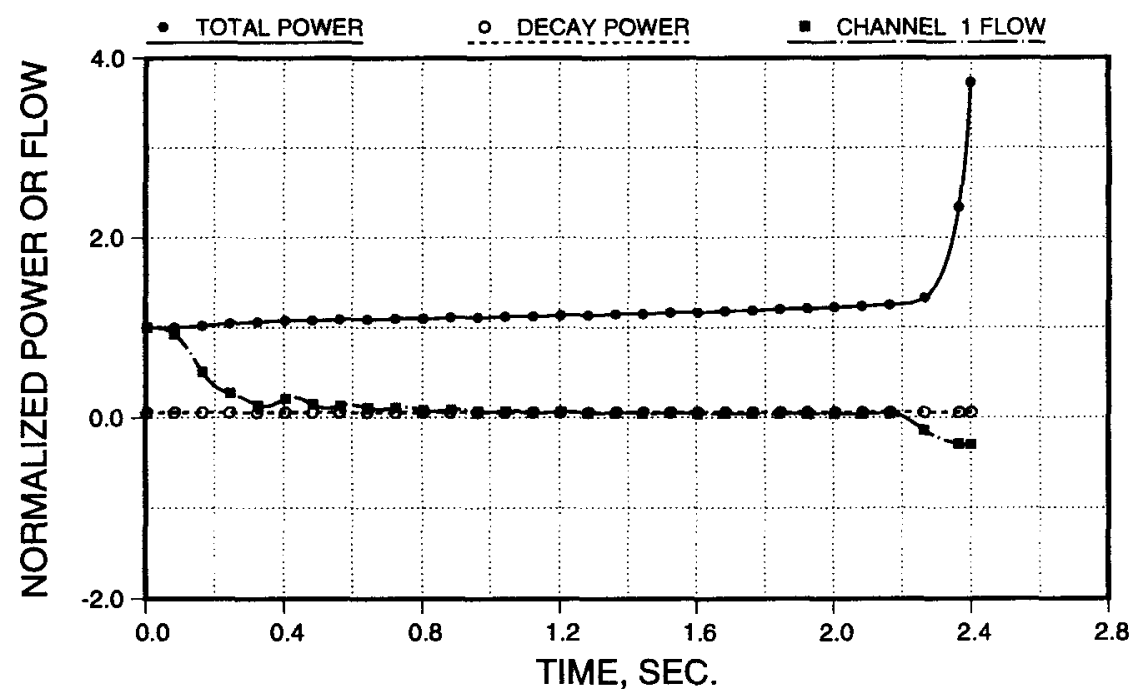

Fig. 16. Power and Flow During the Reference Transient for the 3500-MWt Reactor

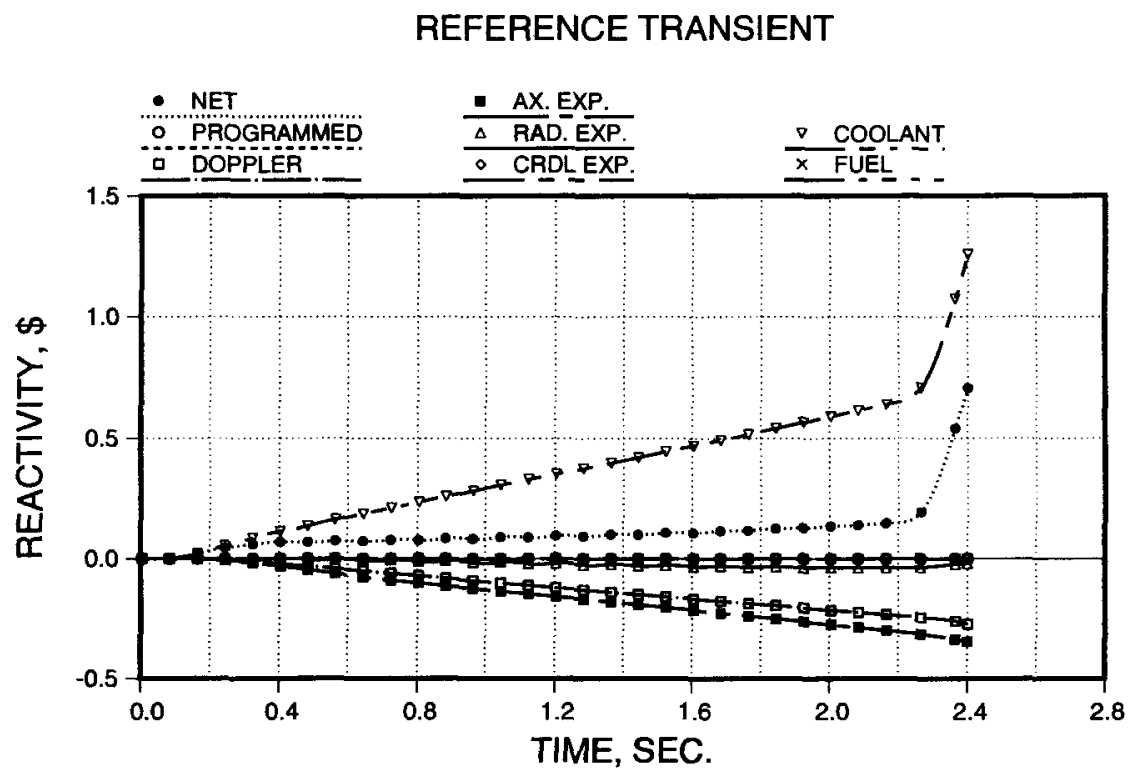

Fig. 17. Net and Component Reactivities During the Reference Transient for the 3500-MWt Reactor 
REFERENCE TRANSIENT

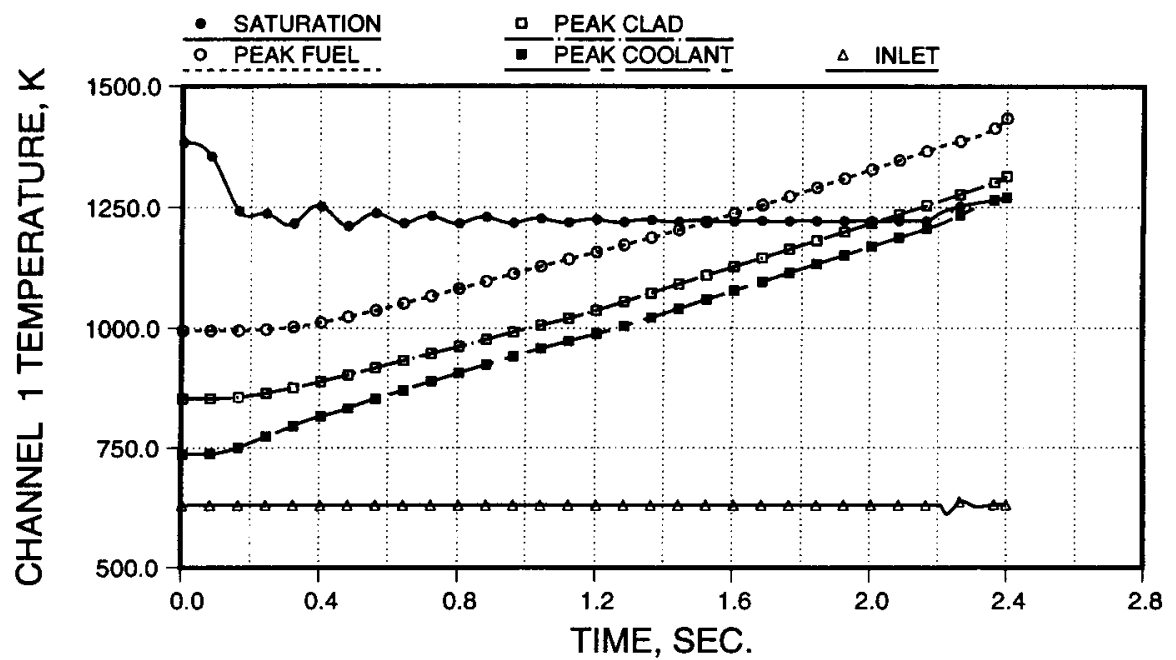

Fig. 18. Representative Temperatures During the Reference Transient for the 3500-MWt Reactor

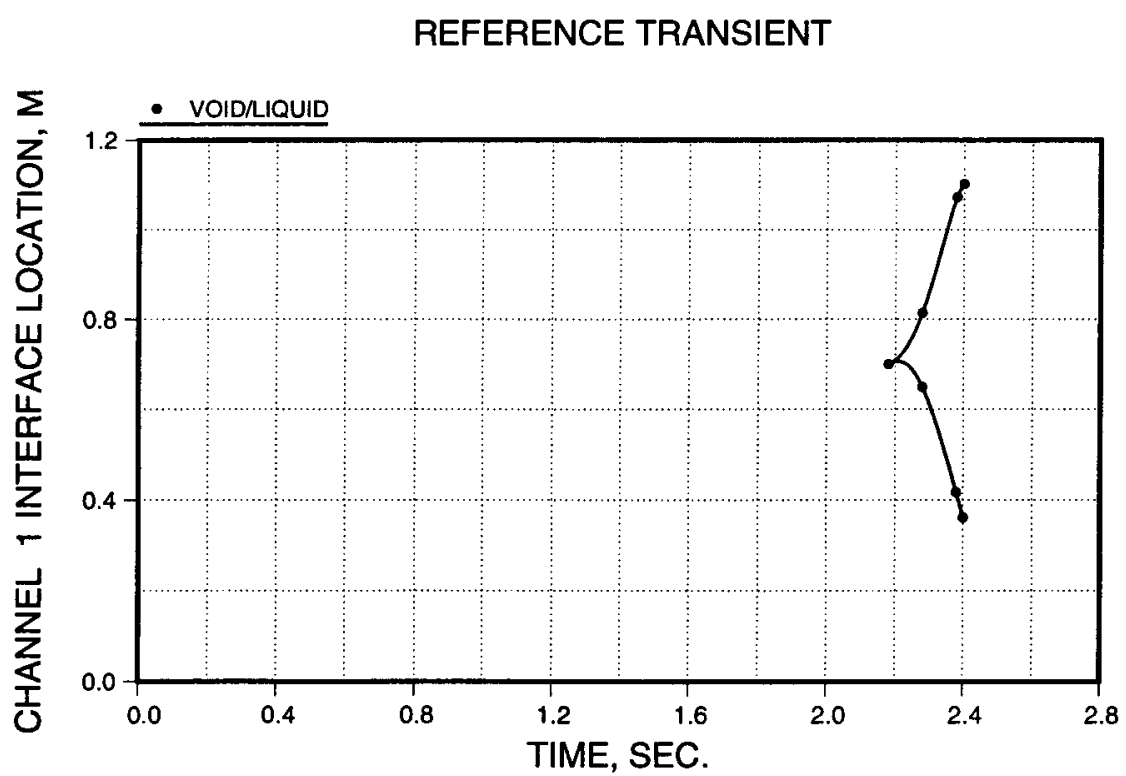

Fig. 19. Top and Bottom of the Voided Region During the Reference Transient for the 3500-MWt Reactor 


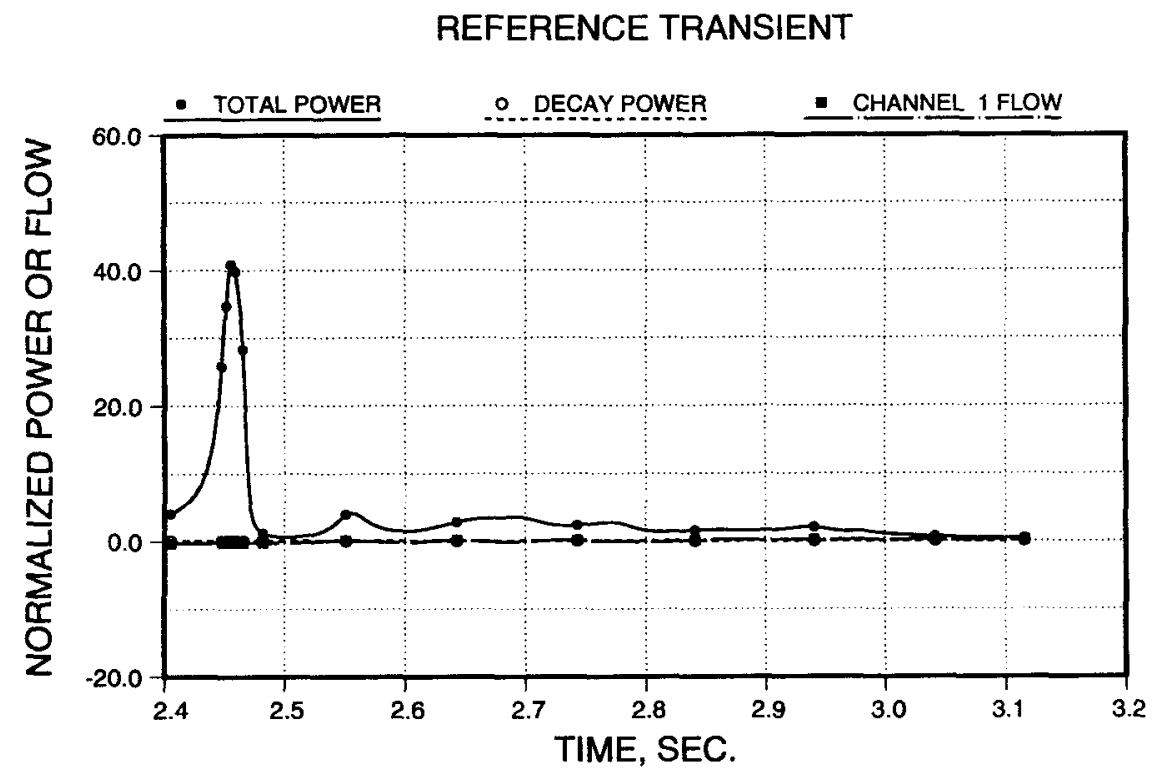

Fig. 20. Power and Flow During the Reference Transient for the 3500-MWt Reactor

\section{REFERENCE TRANSIENT}

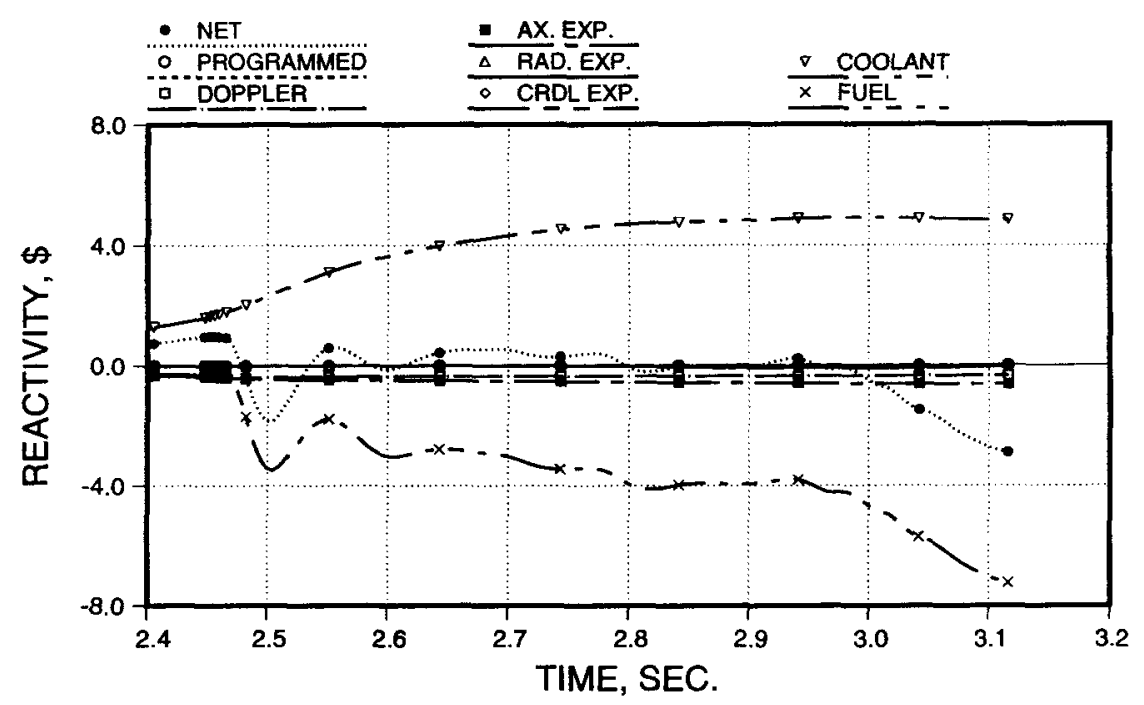

Fig. 21. Net and Component Reactivities During the Reference Transient for the 3500-MWt Reactor 


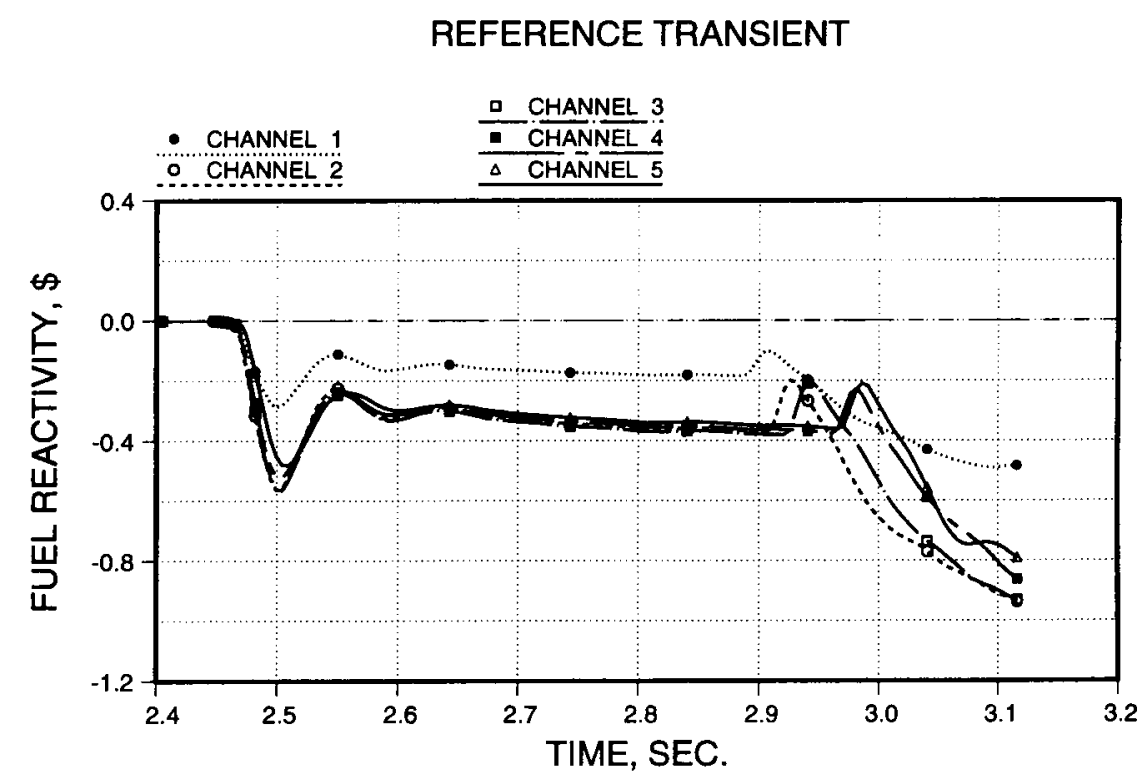

Fig. 22. Channel Dependent Fuel Motion Reactivity Feedback During the Reference Transient for the 3500-MWt Reactor

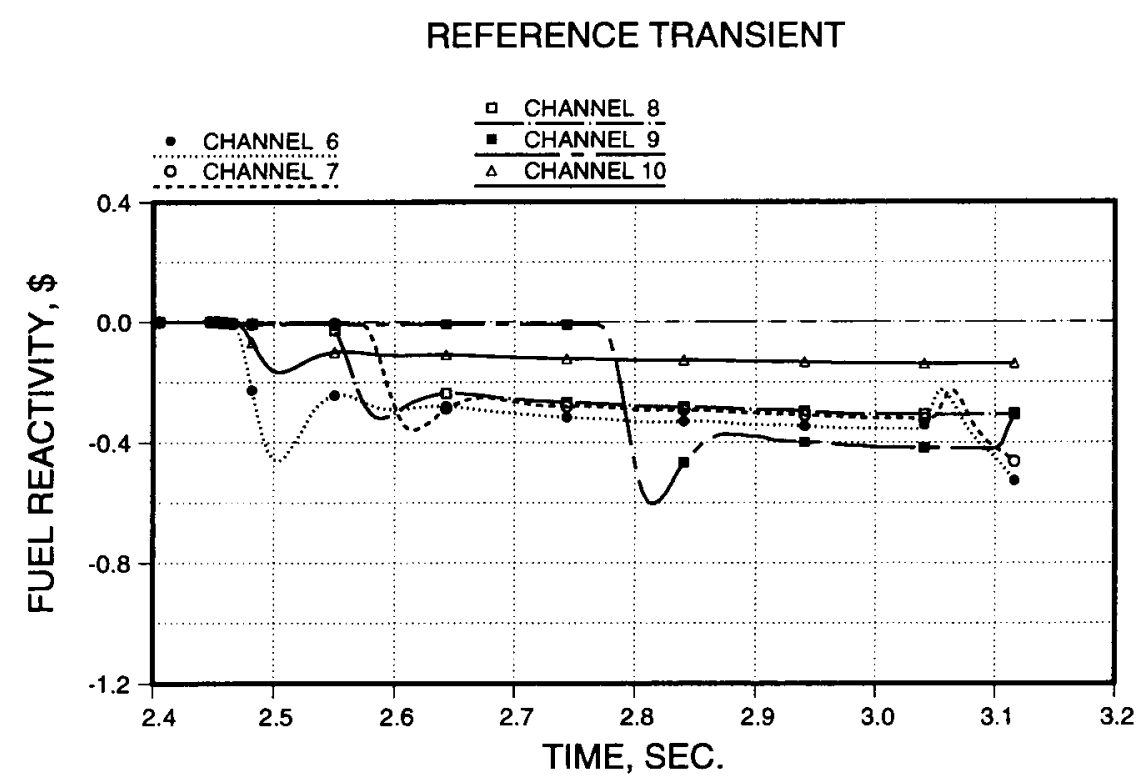

Fig. 23. Channel Dependent Fuel Motion Reactivity Feedback During the Reference Transient for the 3500-MWt Reactor 


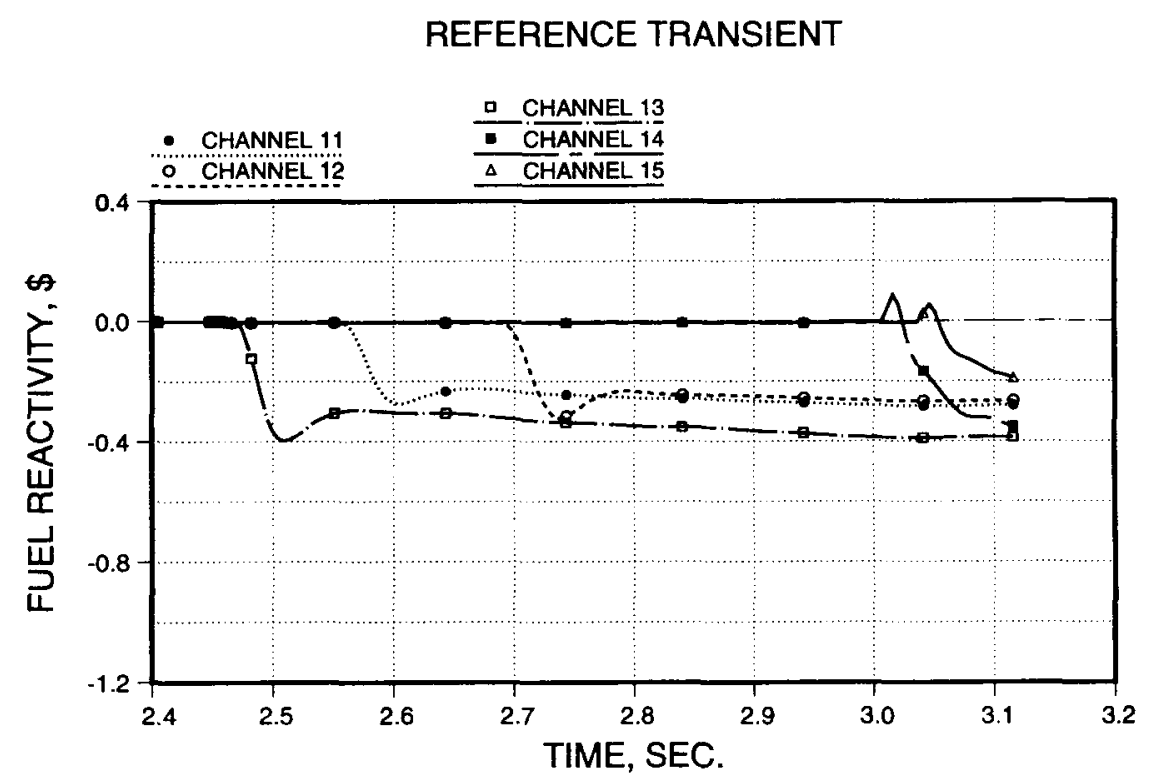

Fig. 24. Channel Dependent Fuel Motion Reactivity Feedback During the Reference Transient for the 3500-MWt Reactor

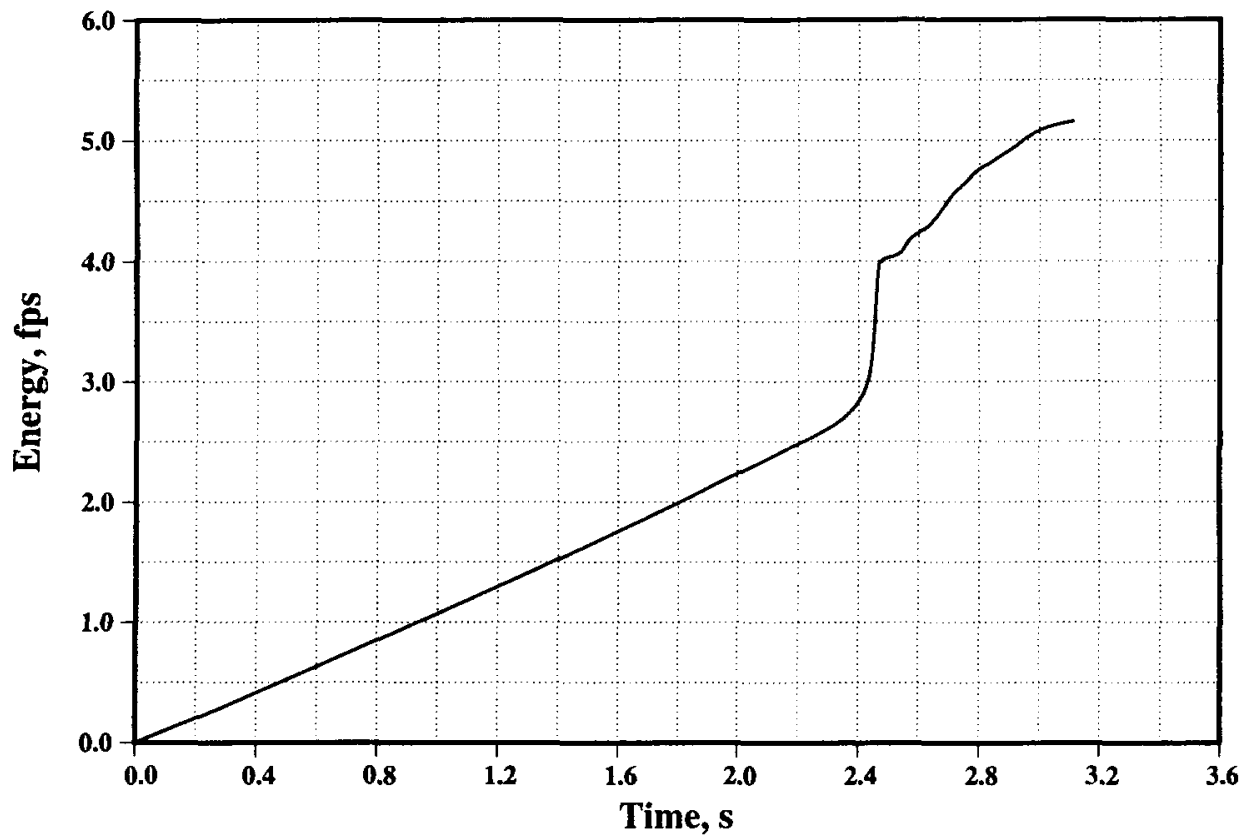

Fig. 25. Energy Release During the Reference Transient in the 3500-MWt Reactor 


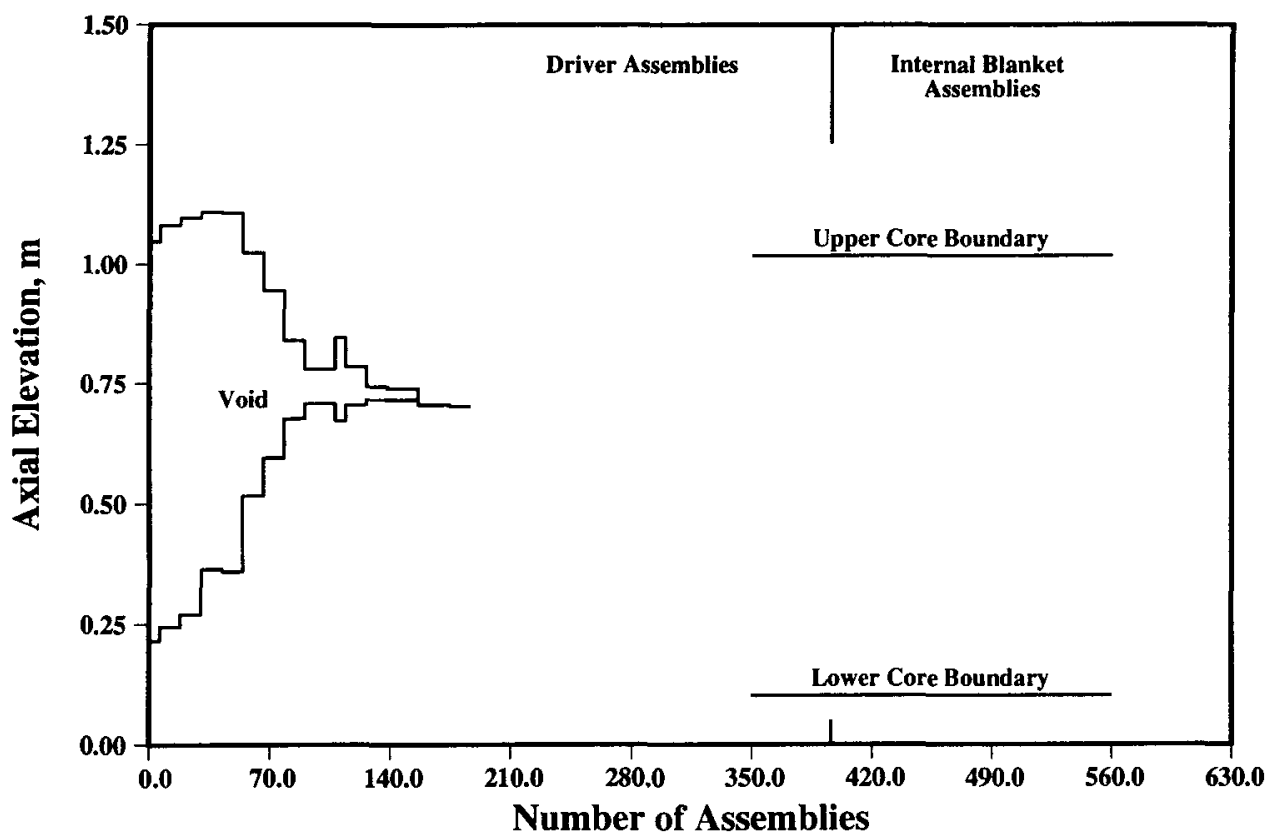

Fig. 26. Void Pattern at $2.46 \mathrm{~s}$ During the Reference Transient in the 3500-MWt Reactor

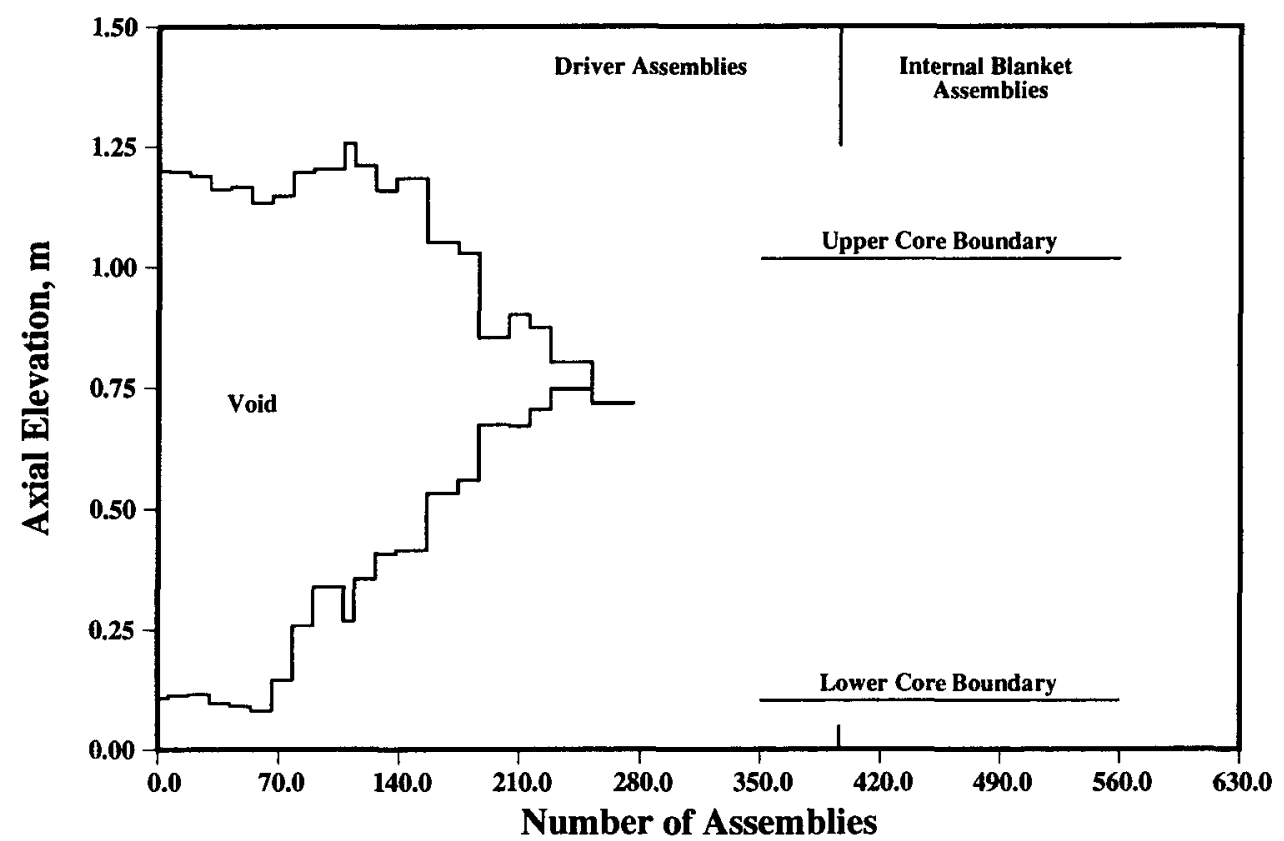

Fig. 27. Void Pattern at $2.55 \mathrm{~s}$ During the Reference Transient in the 3500-MWt Reactor 


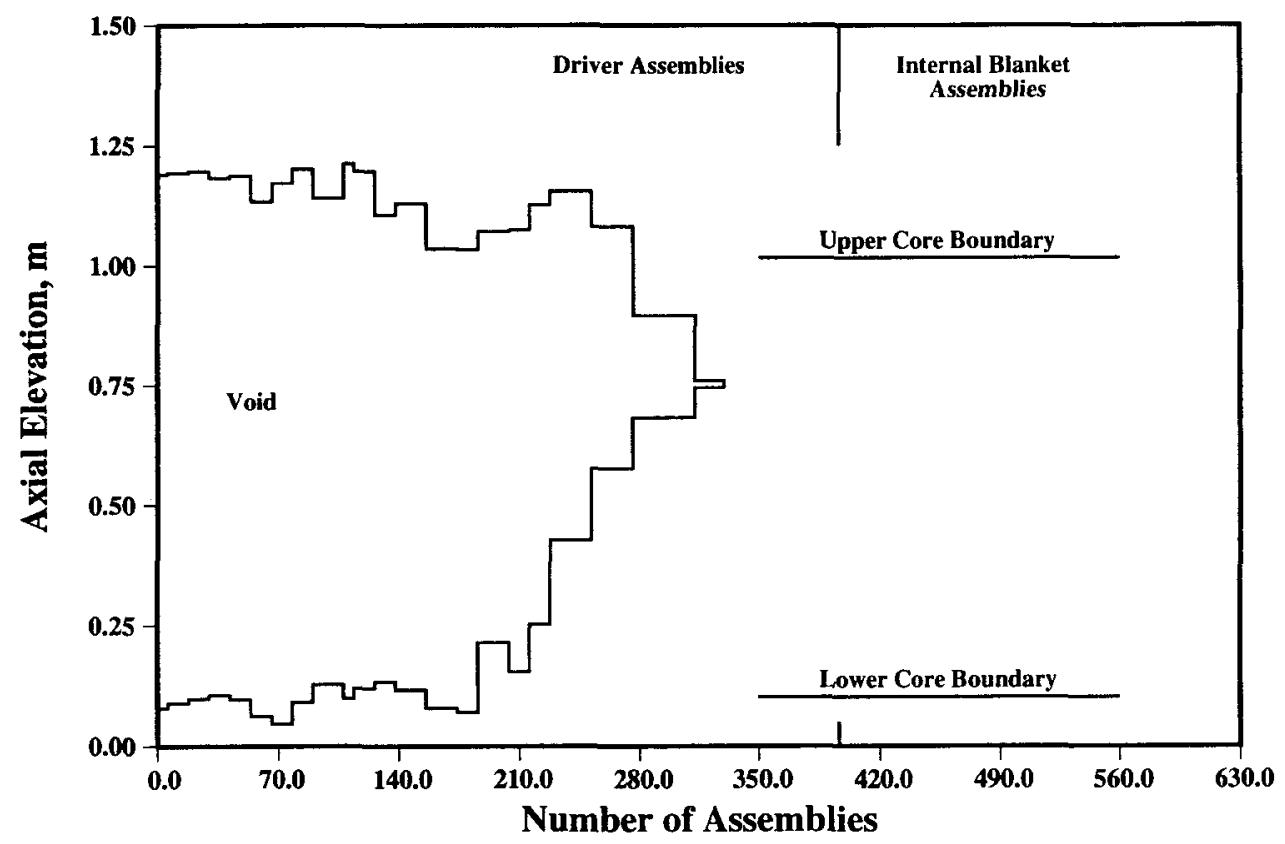

Fig. 28. Void Pattern at $2.68 \mathrm{~s}$ During the Reference Transient in the 3500-MWt Reactor

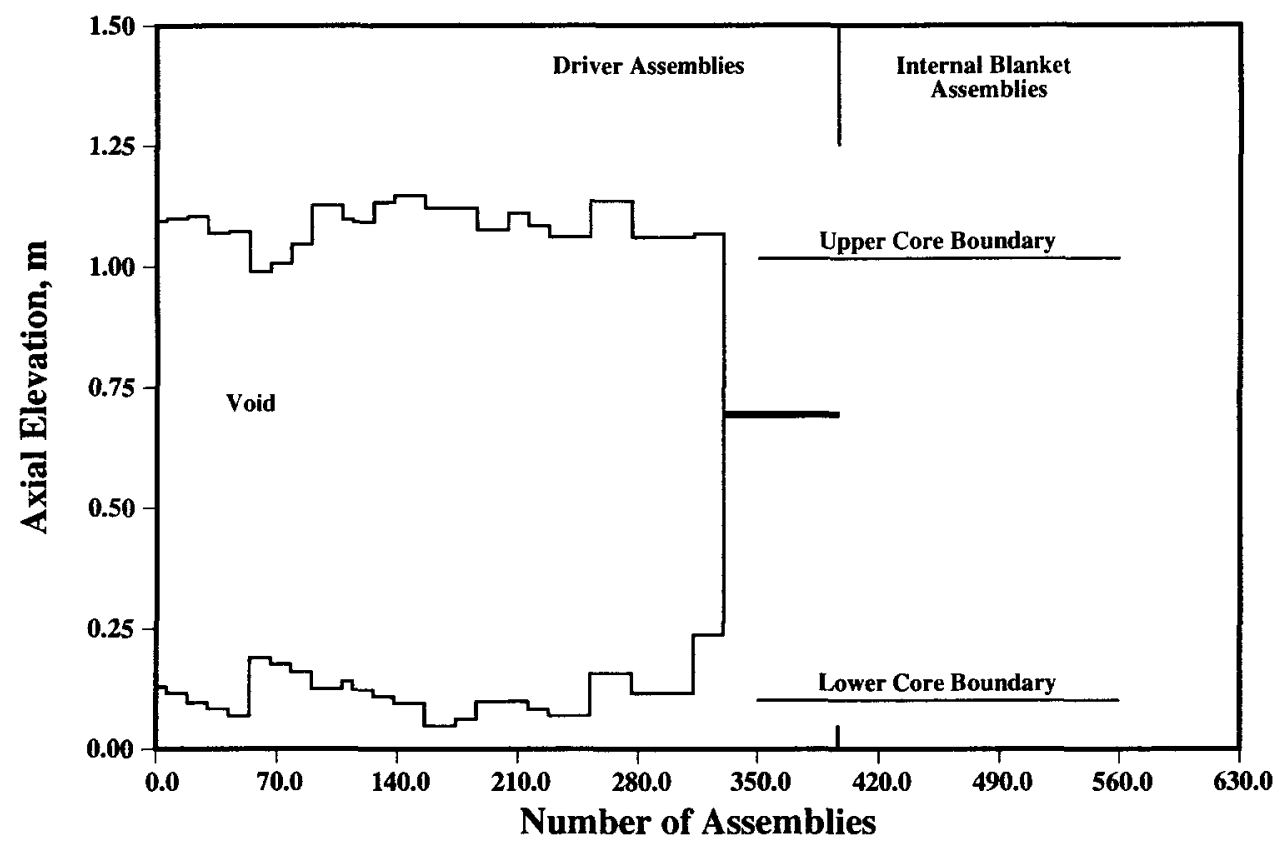

Fig. 29. Void Pattern at 2.88 s During the Reference Transient in the 3500-MWt Reactor 


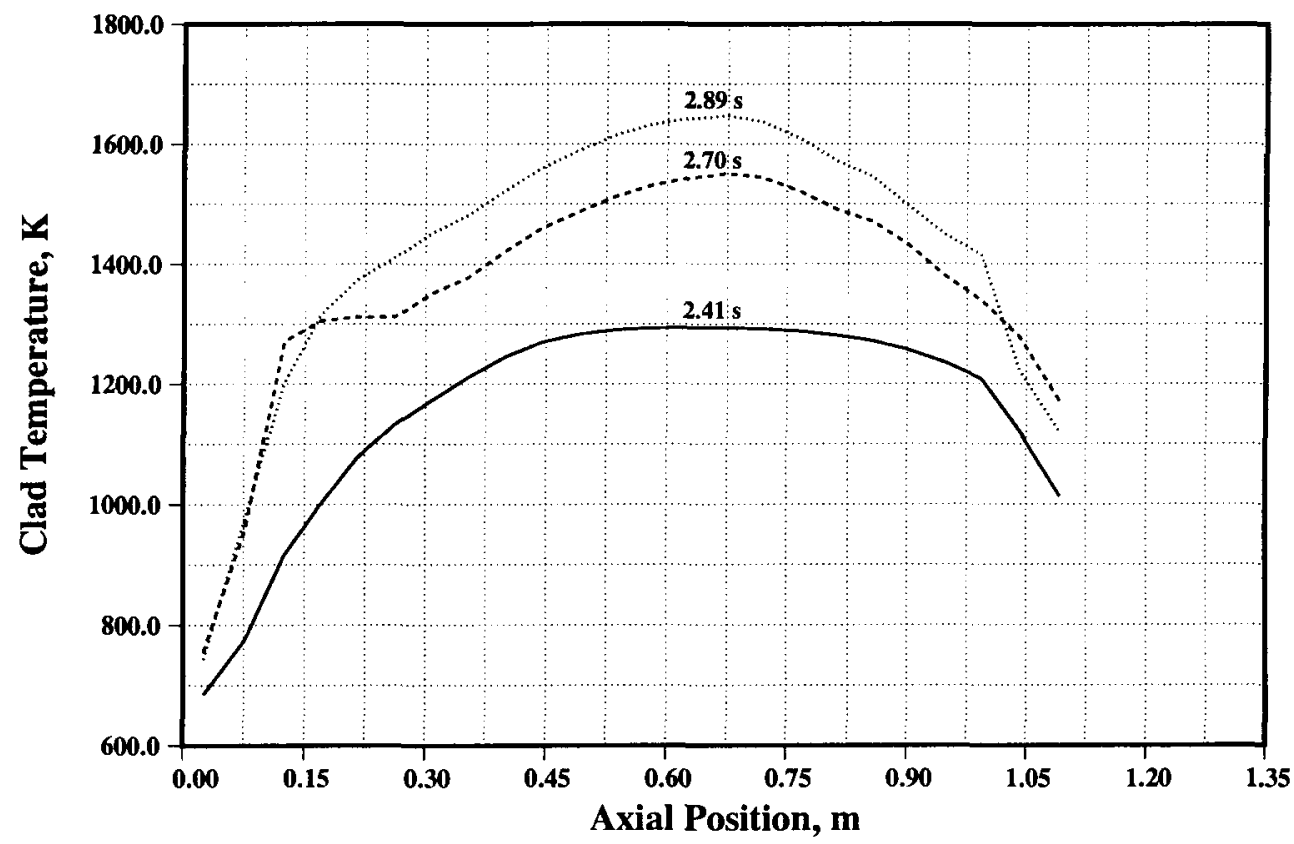

Fig. 30. Selected Cladding Temperatures in Channel 1 During the Reference Transient for the 3500-MWt Reactor

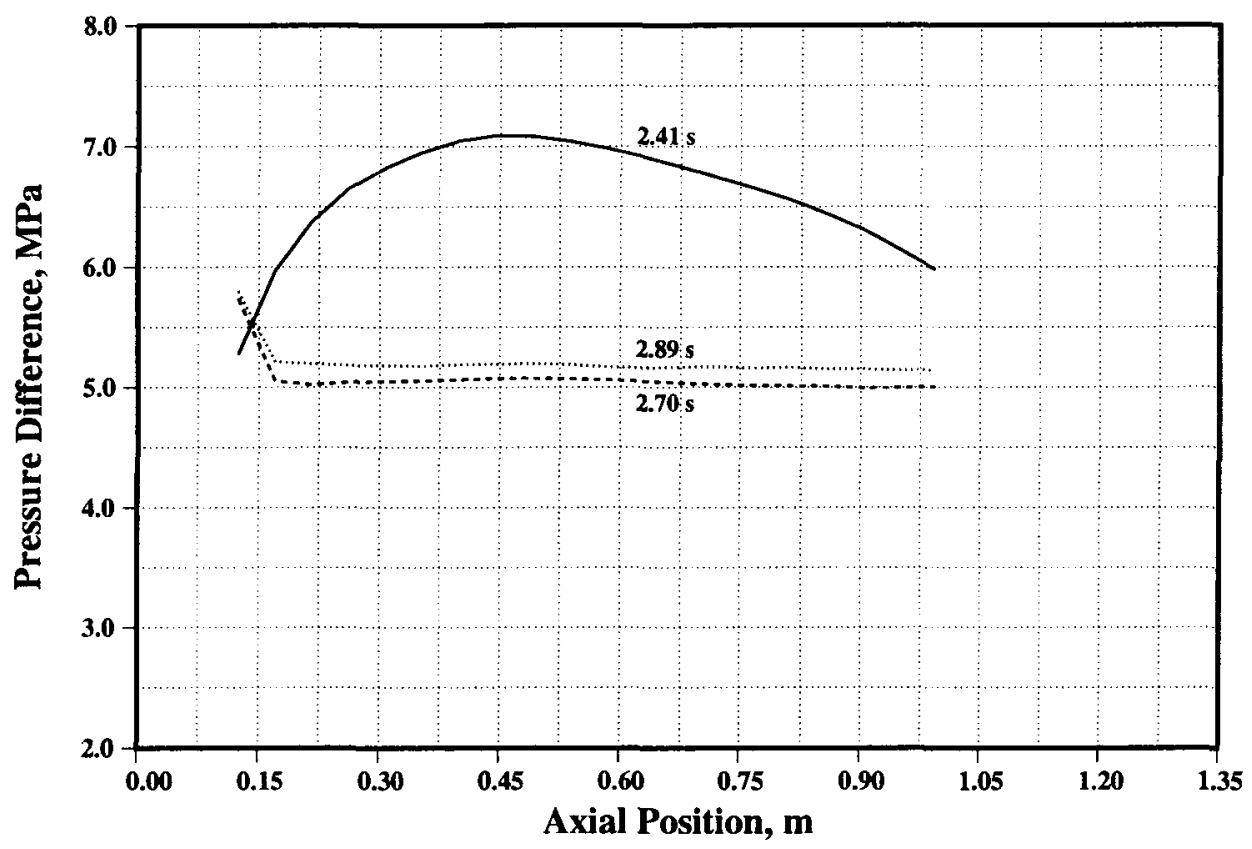

Fig. 31. Selected Pressure Differences in Channel 1 During the Reference Transient for the 3500-MWt Reactor 


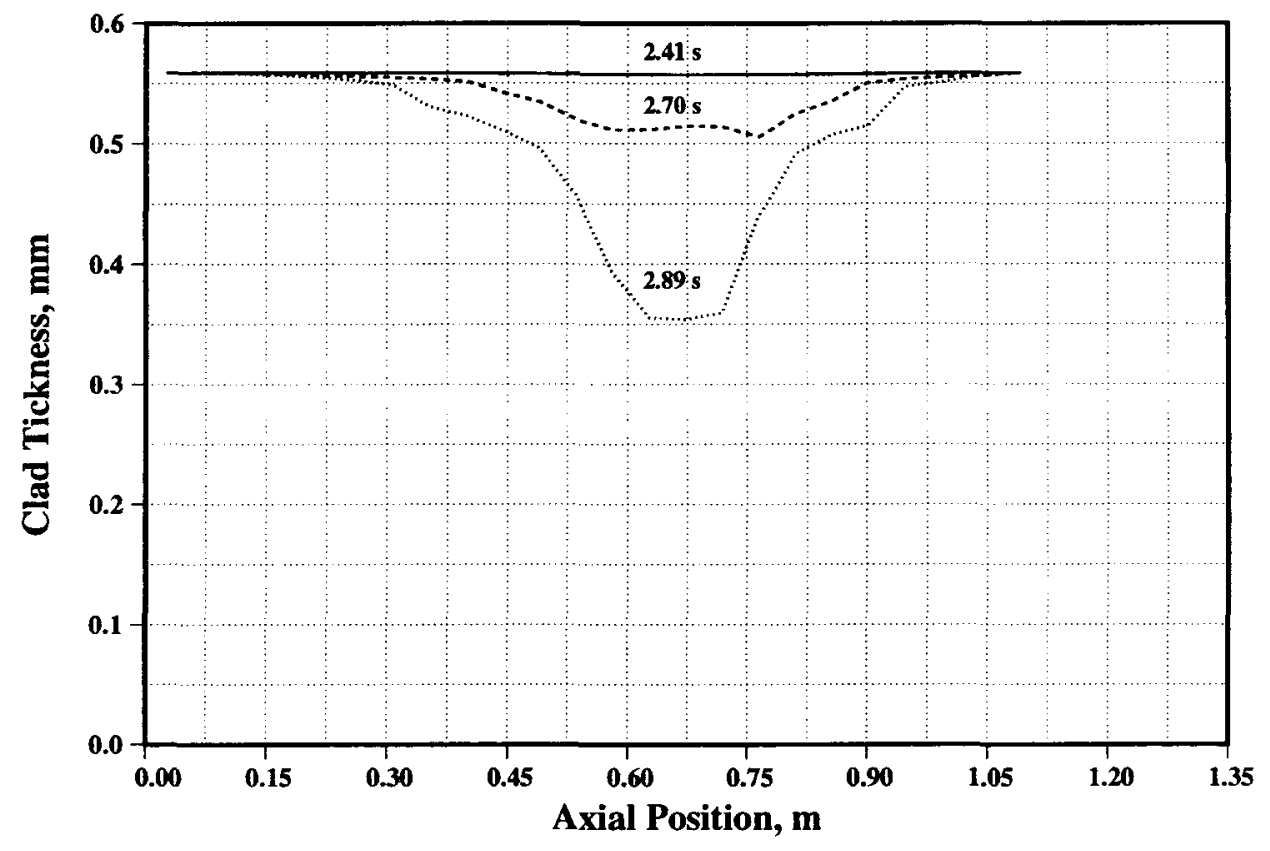

Fig. 32. Cladding Thicknesses in Channel 1 During the Reference Transient for the 3500-MWt Reactor 


\section{Reference Transient: Channel 1}

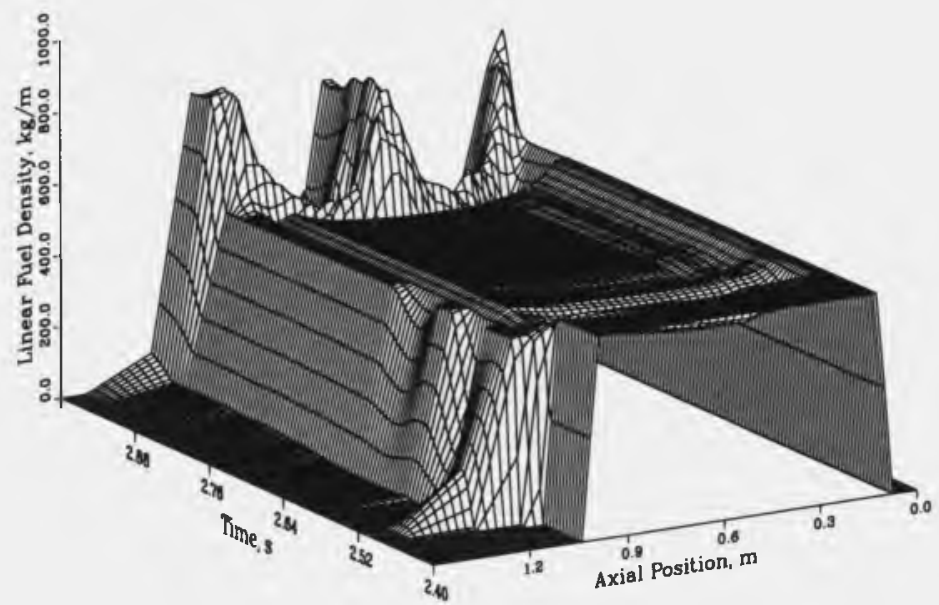

Fig. 33. Linear Fuel Density as a Function of Time and Axial Position During the Reference Transient in the 3500-MWt Reactor

Reference Transient: Channel 1

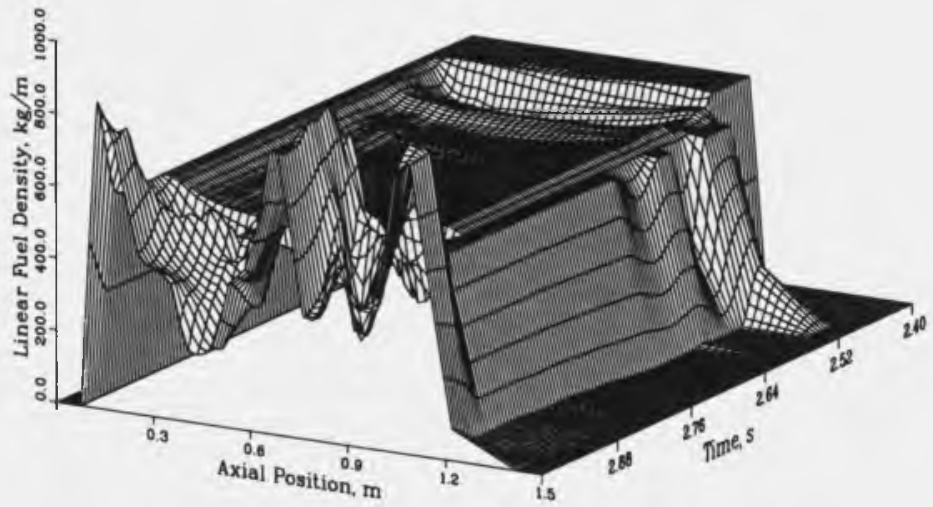

Fig. 34. Linear Fuel Density as a Function of Time and Axial Position During the Reference Transient in the 3500-MWt Reactor 
Reference Transient: Channel 1

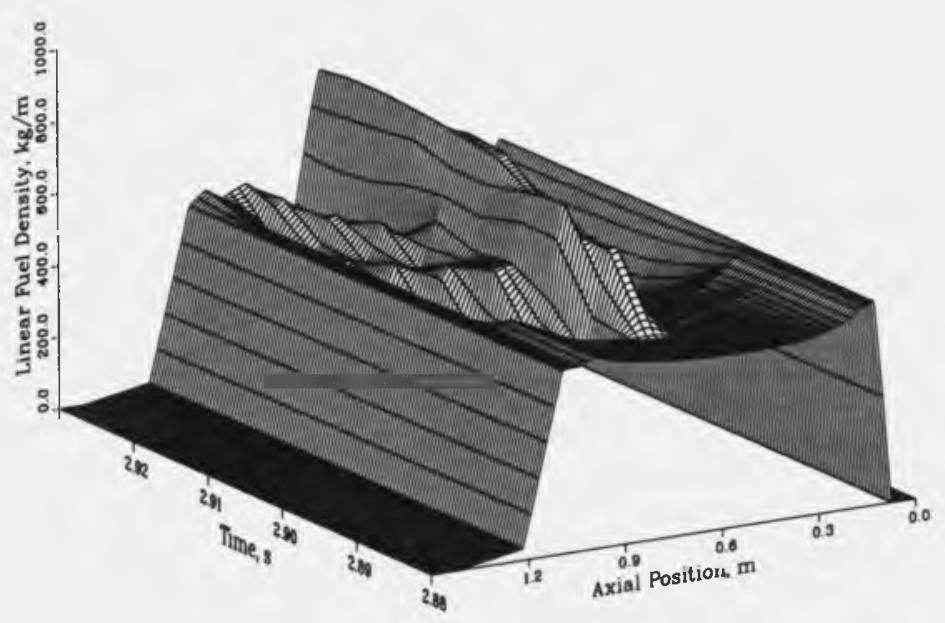

Fig. 35. Linear Fuel Density as a Function of Time and Axial Position During the Reference Transient in the 3500-MWt Reactor

Reference Transient: Channel 1

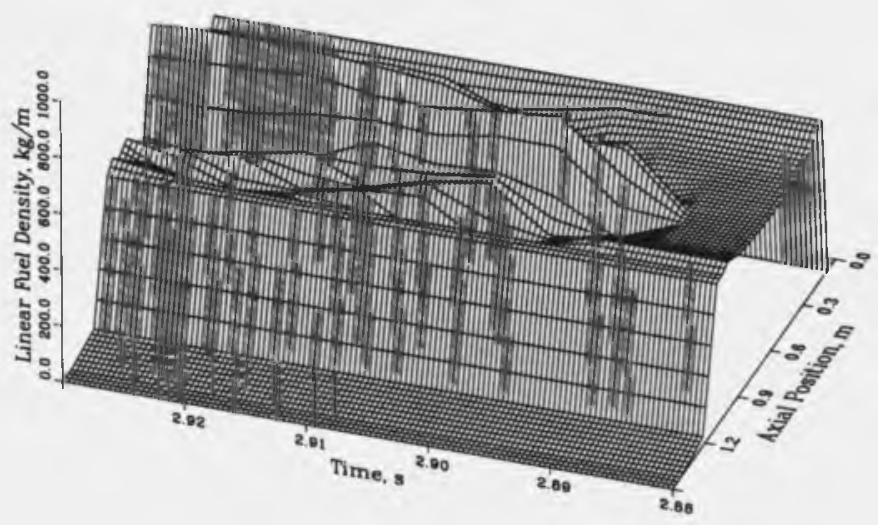

Fig. 36. Linear Fuel Density as a Function of Time and Axial Position During the Reference Transient in the 3500-MWt Reactor 


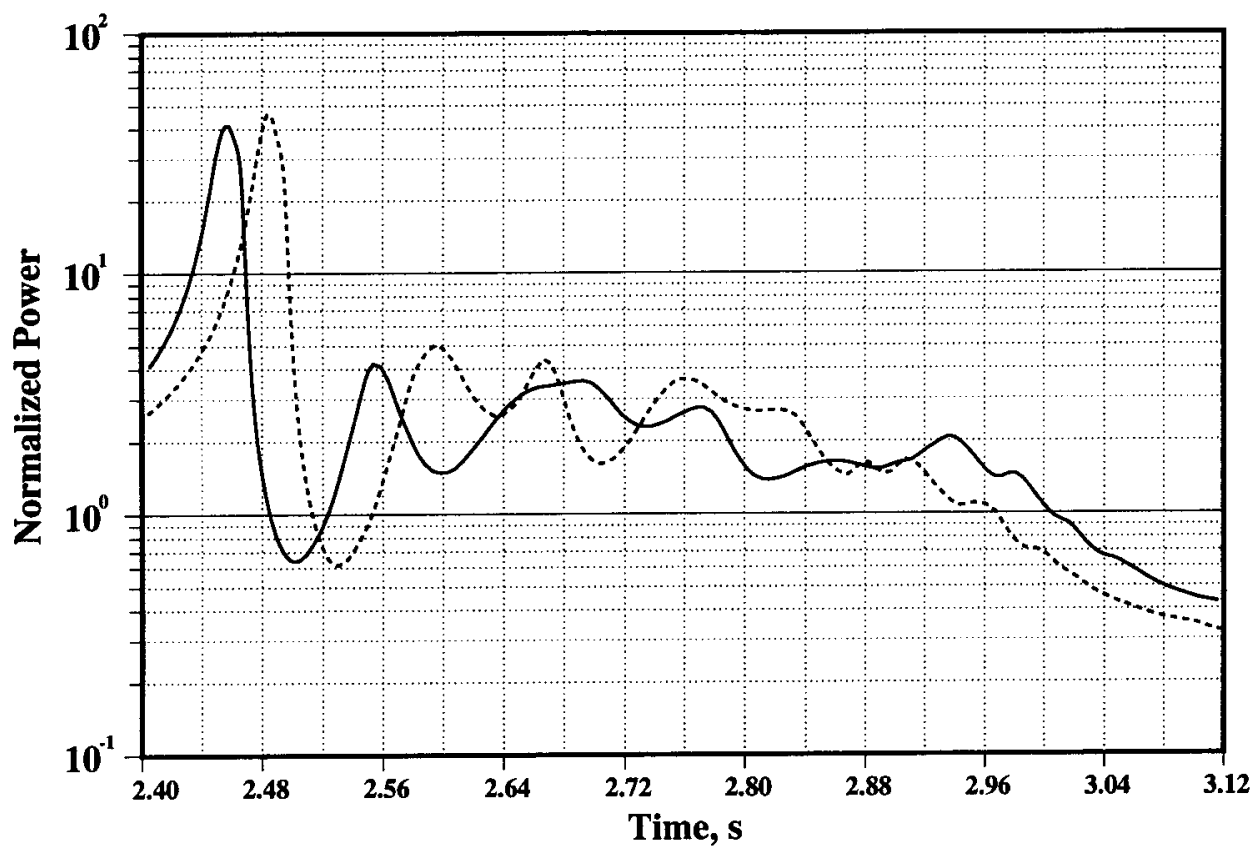

Fig. 37. Comparison of Case 1 (Dashed Curve) with Reference Transient (Solid Curve) for the 3500-MWt Reactor

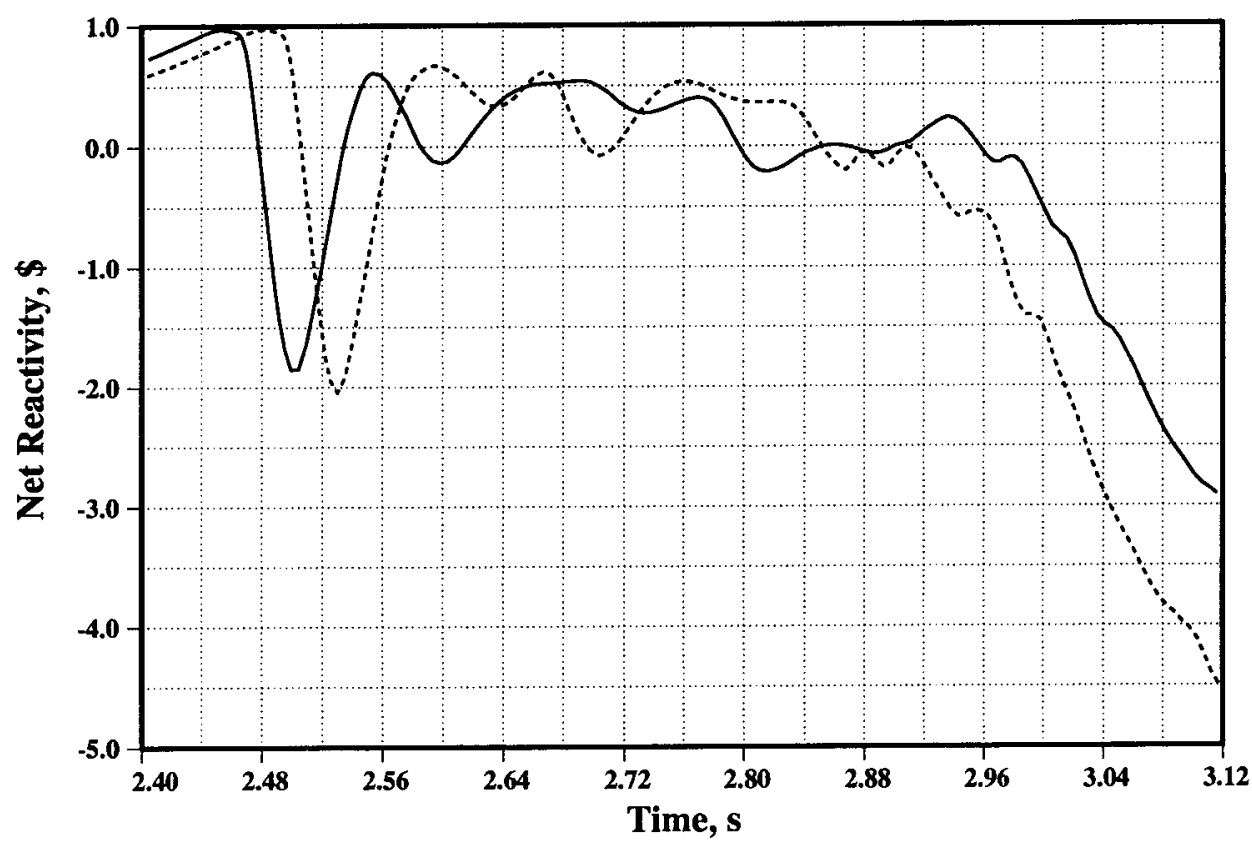

Fig. 38. Comparison of Case 1 (Dashed Curve) with Reference Transient (Solid Curve) for the 3500-MWt Reactor 


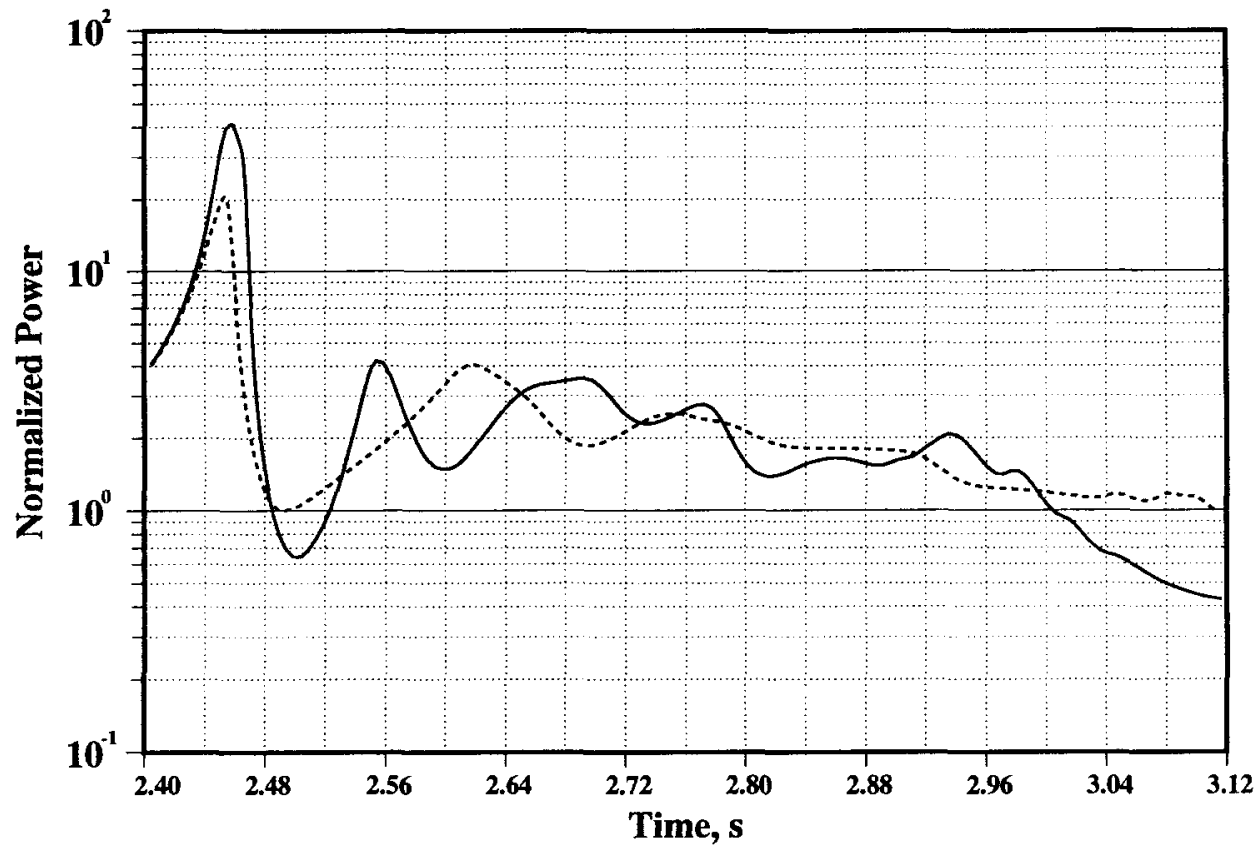

Fig. 39. Comparison of Case 2 (Dashed Curve) with Reference Transient (Solid Curve) for the 3500-MWt Reactor

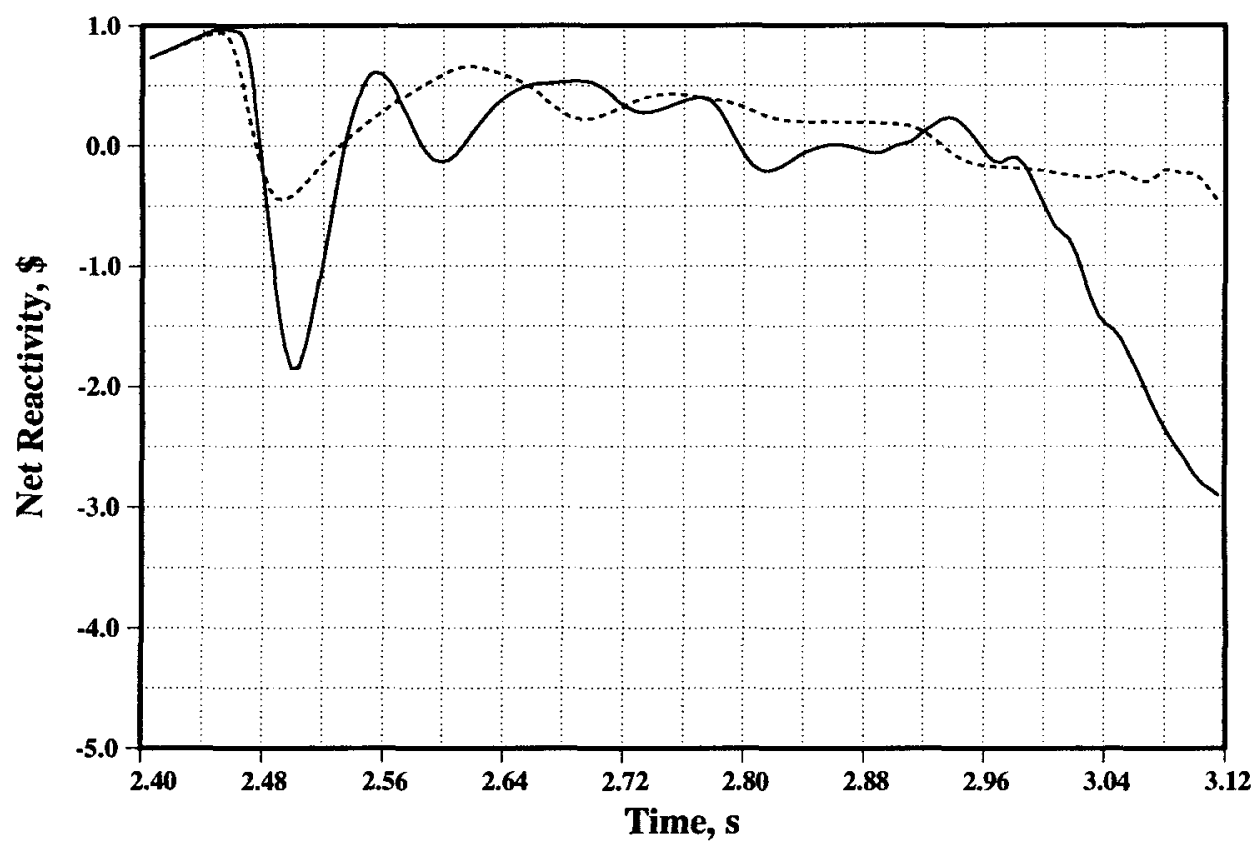

Fig. 40. Comparison of Case 2 (Dashed Curve) with Reference Transient (Solid Curve) for the 3500-MWt Reactor 


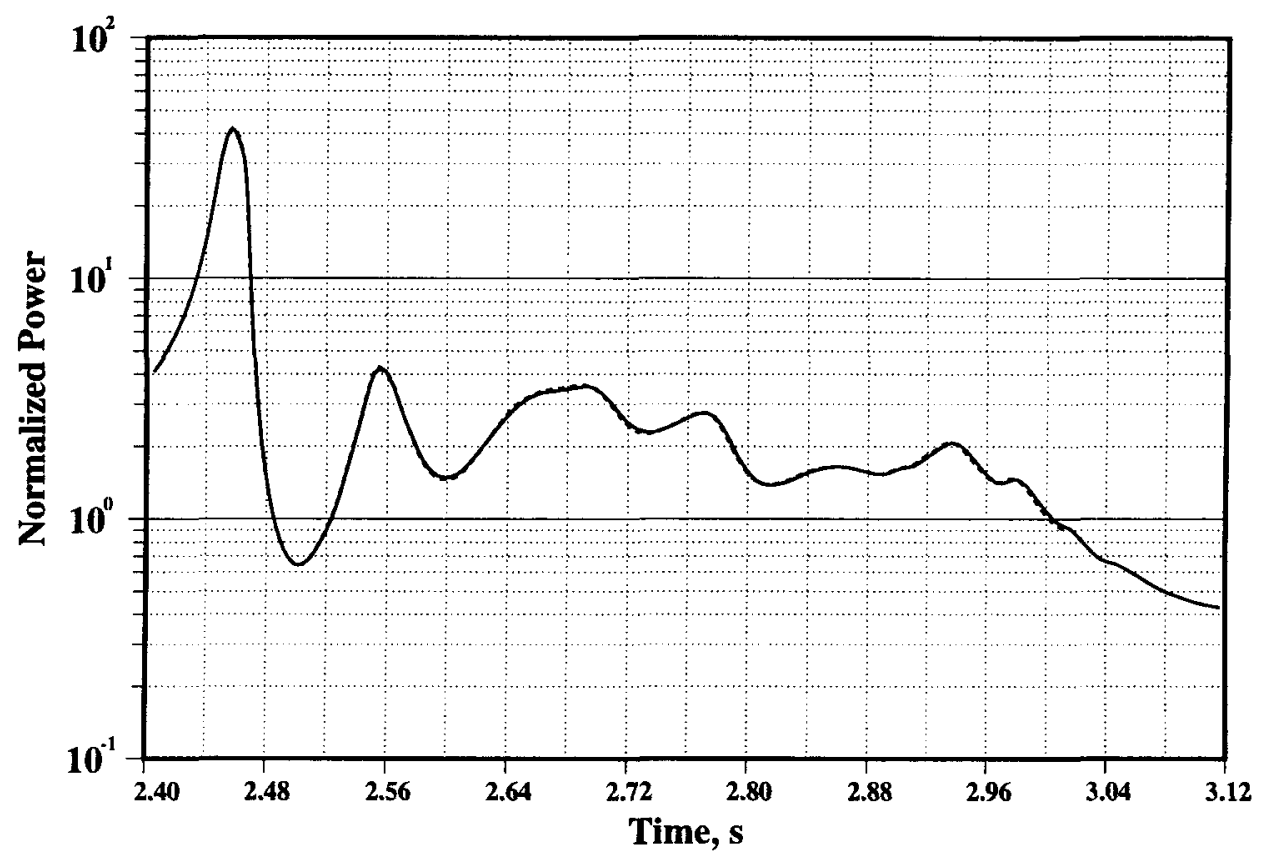

Fig. 41. Comparison of Case 3 (Dashed Curve) with Reference Transient (Solid Curve) for the 3500-MWt Reactor

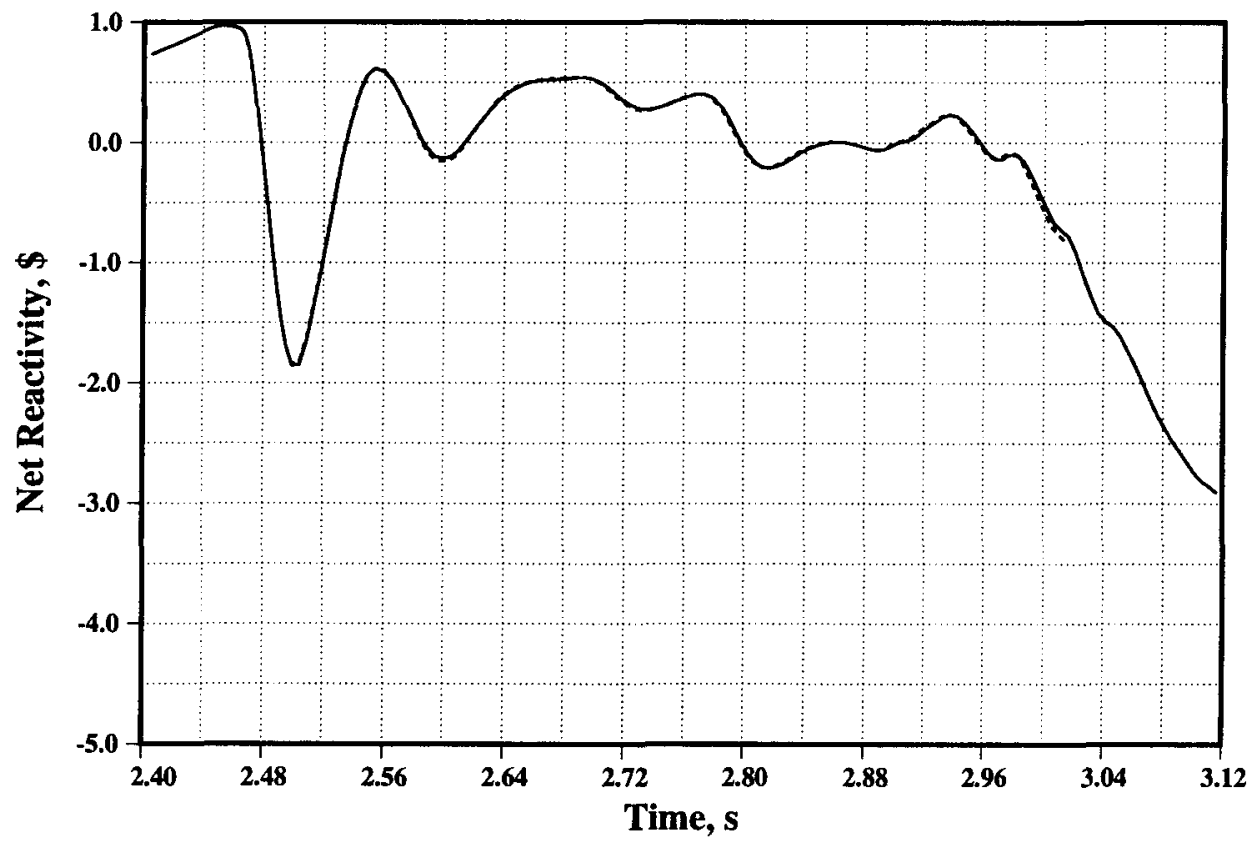

Fig. 42. Comparison of Case 3 (Dashed Curve) with Reference Transient (Solid Curve) for the 3500-MWt Reactor 


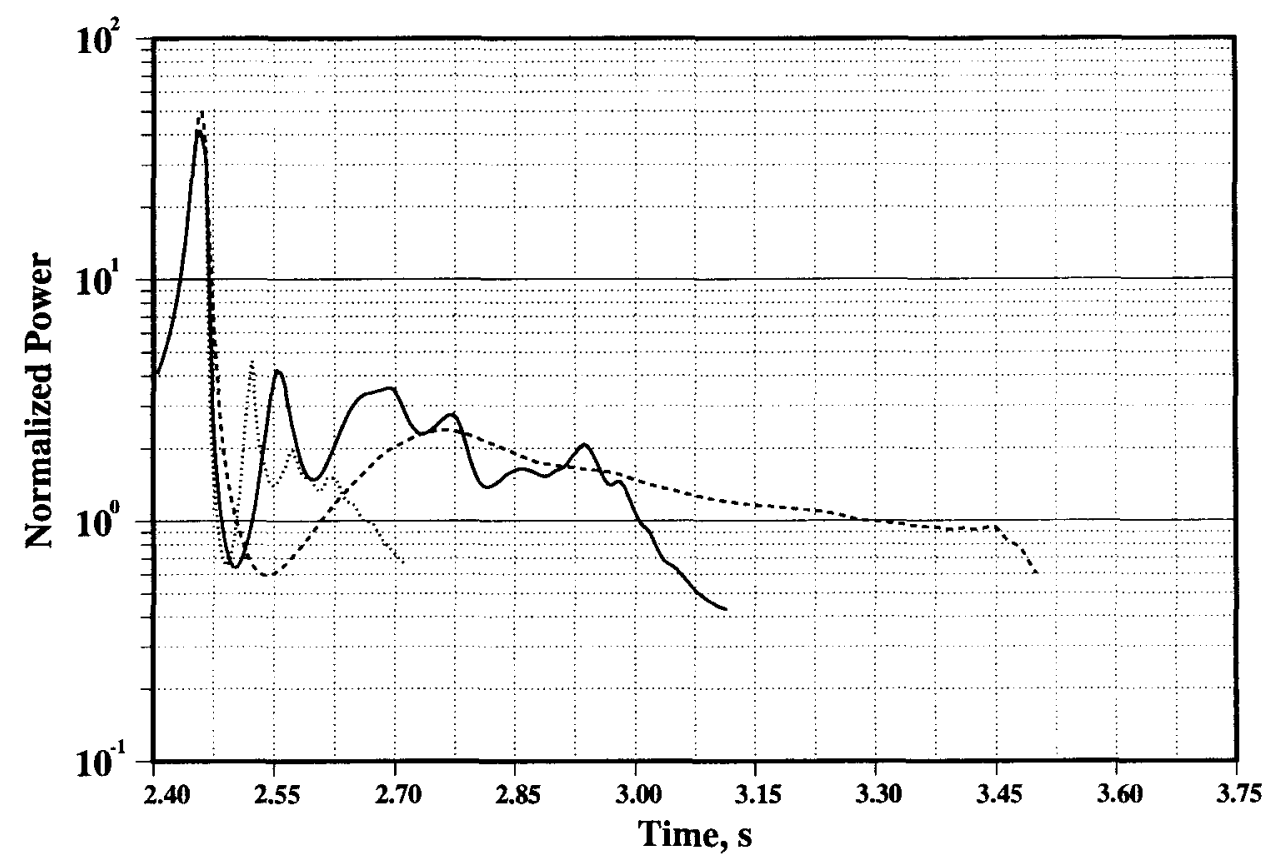

Fig. 43. Comparison of Case 4 (Dashed Curve) and Case 5 (Dotted Curve) with Reference Transient (Solid Curve) for the 3500-MWt Reactor

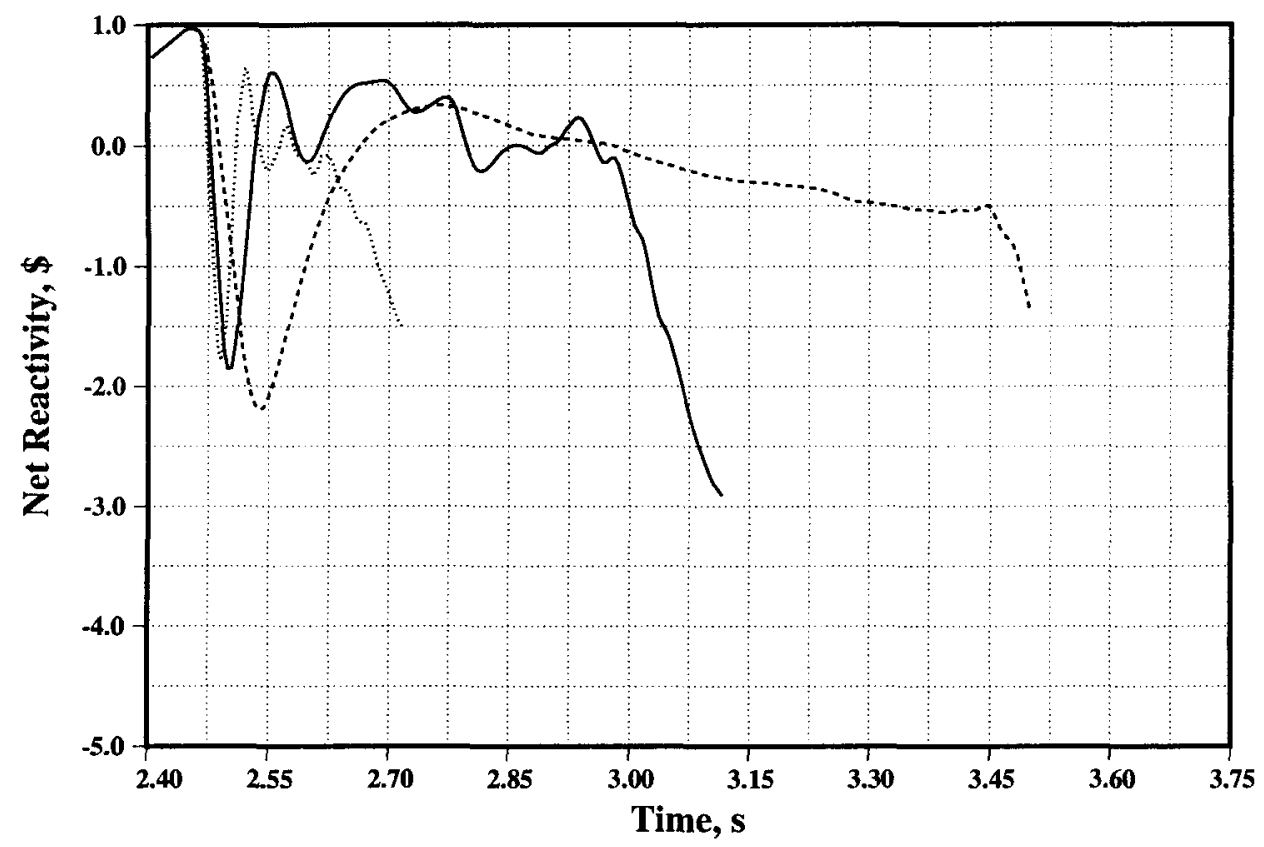

Fig. 44. Comparison of Case 4 (Dashed Curve) and Case 5 (Dotted Curve) with Reference Transient (Solid Curve) for the 3500-MWt Reactor 


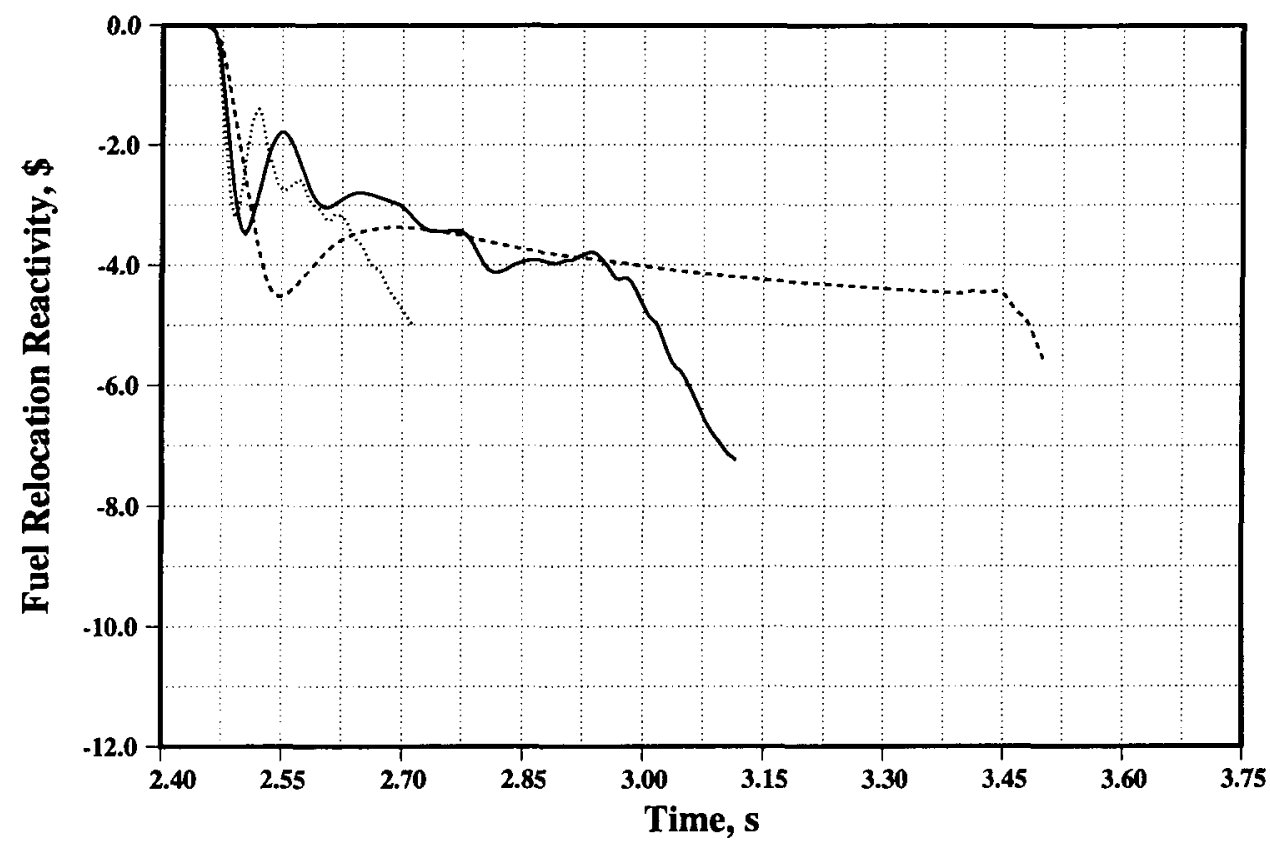

Fig. 45. Comparison of Case 4 (Dashed Curve) and Case 5 (Dotted Curve) with Reference Transient (Solid Curve) for the 3500-MWt Reactor

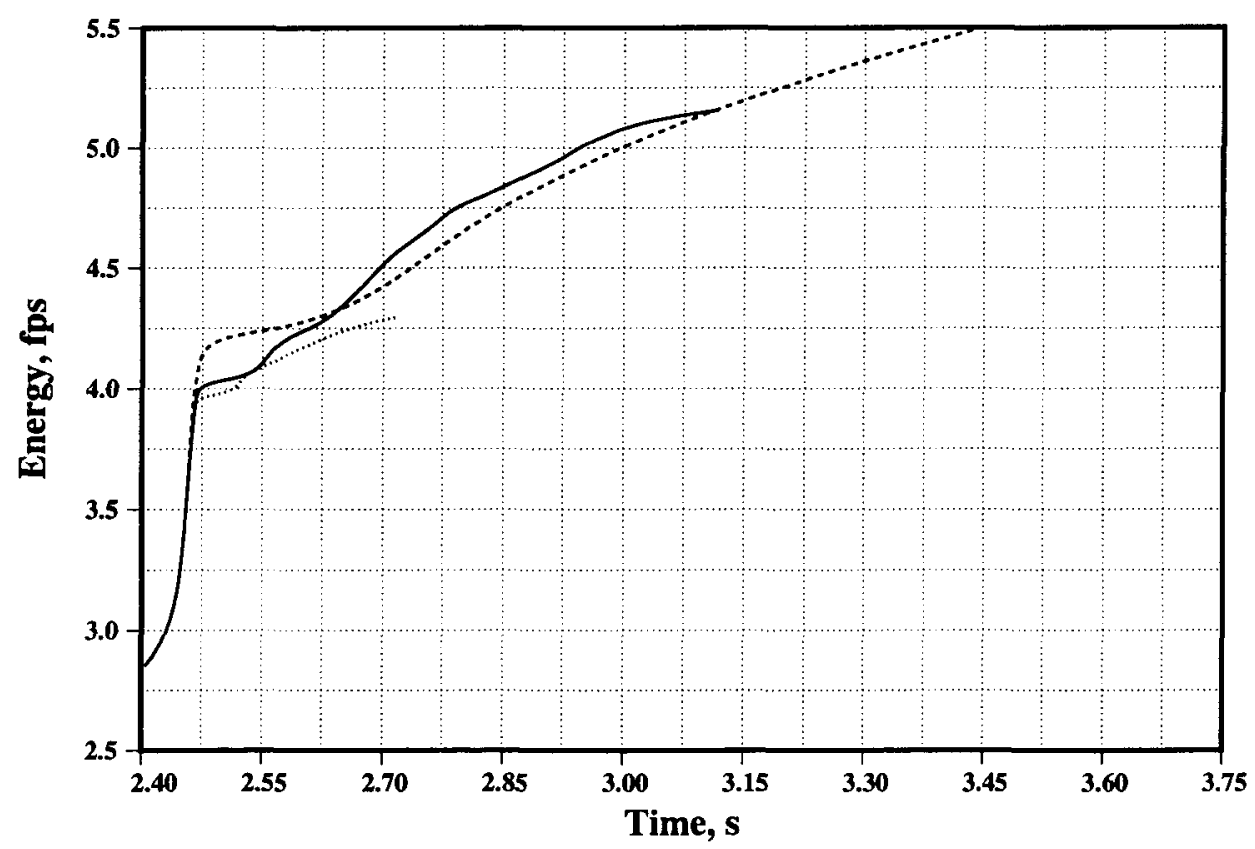

Fig. 46. Comparison of Case 4 (Dashed Curve) and Case 5 (Dotted Curve) with Reference Transient (Solid Curve) for the 3500-MWt Reactor 


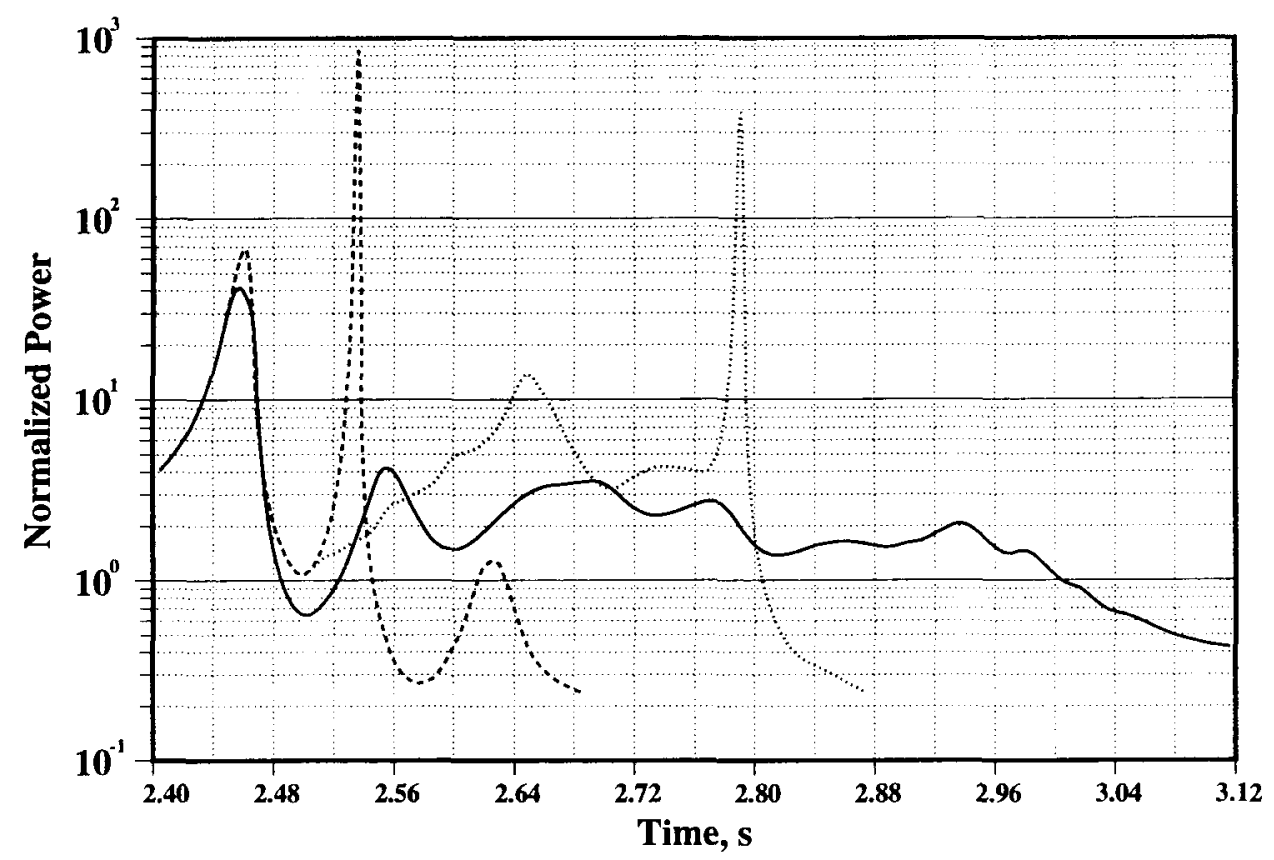

Fig. 47. Comparison of Case 6 (Dashed Curve) and Case 7 (Dotted Curve) with Reference Transient (Solid Curve) for the 3500-MWt Reactor

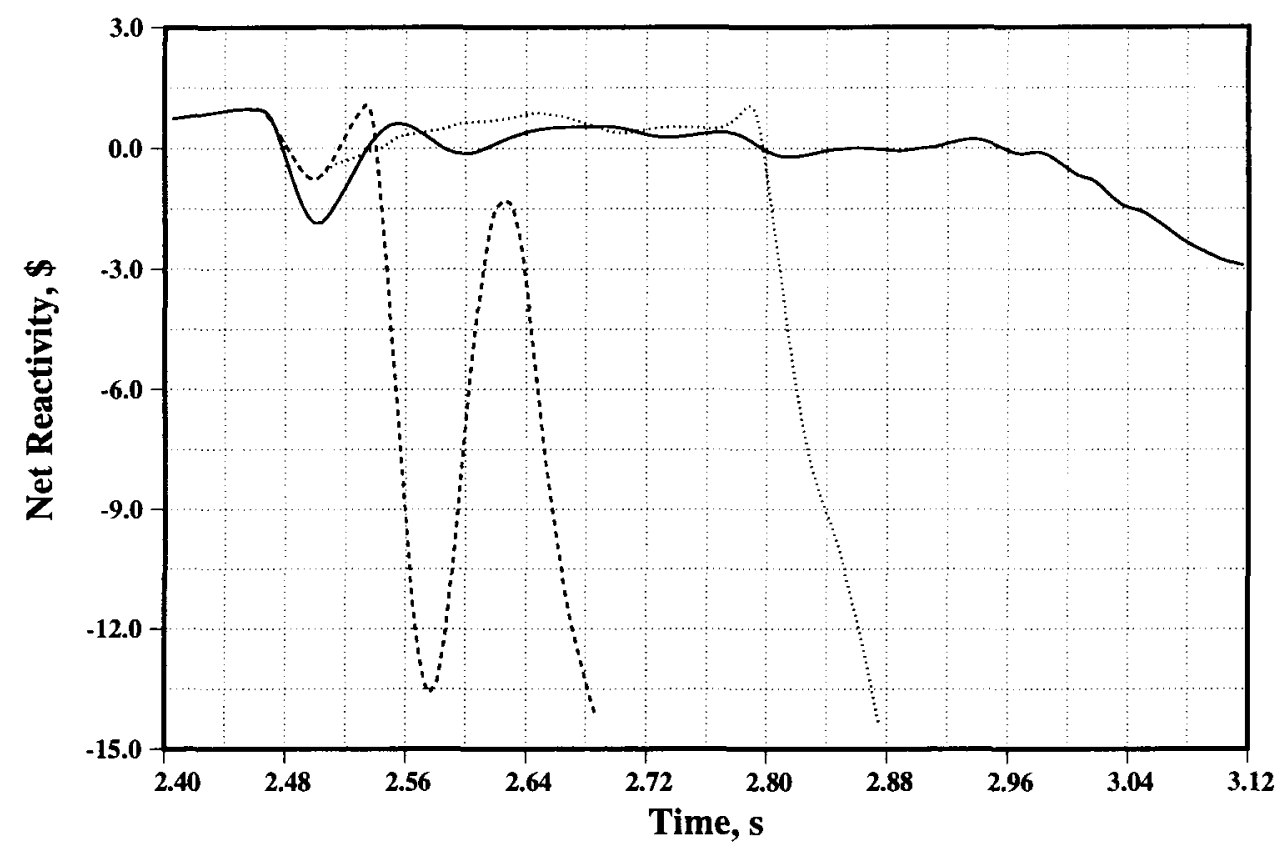

Fig. 48. Comparison of Case 6 (Dashed Curve) and Case 7 (Dotted Curve) with Reference Transient (Solid Curve) for the 3500-MWt Reactor 


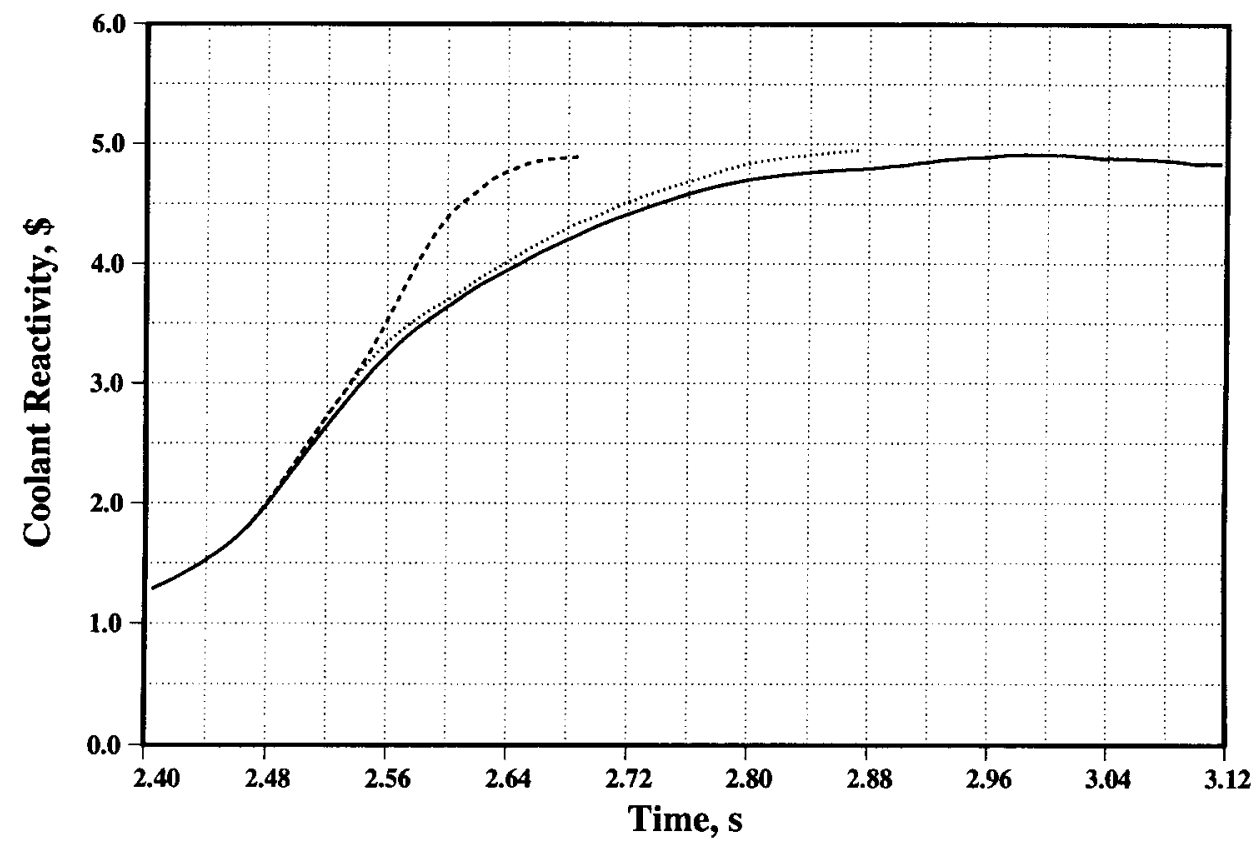

Fig. 49. Comparison of Case 6 (Dashed Curve) and Case 7 (Dotted Curve) with Reference Transient (Solid Curve) for the 3500-MWt Reactor

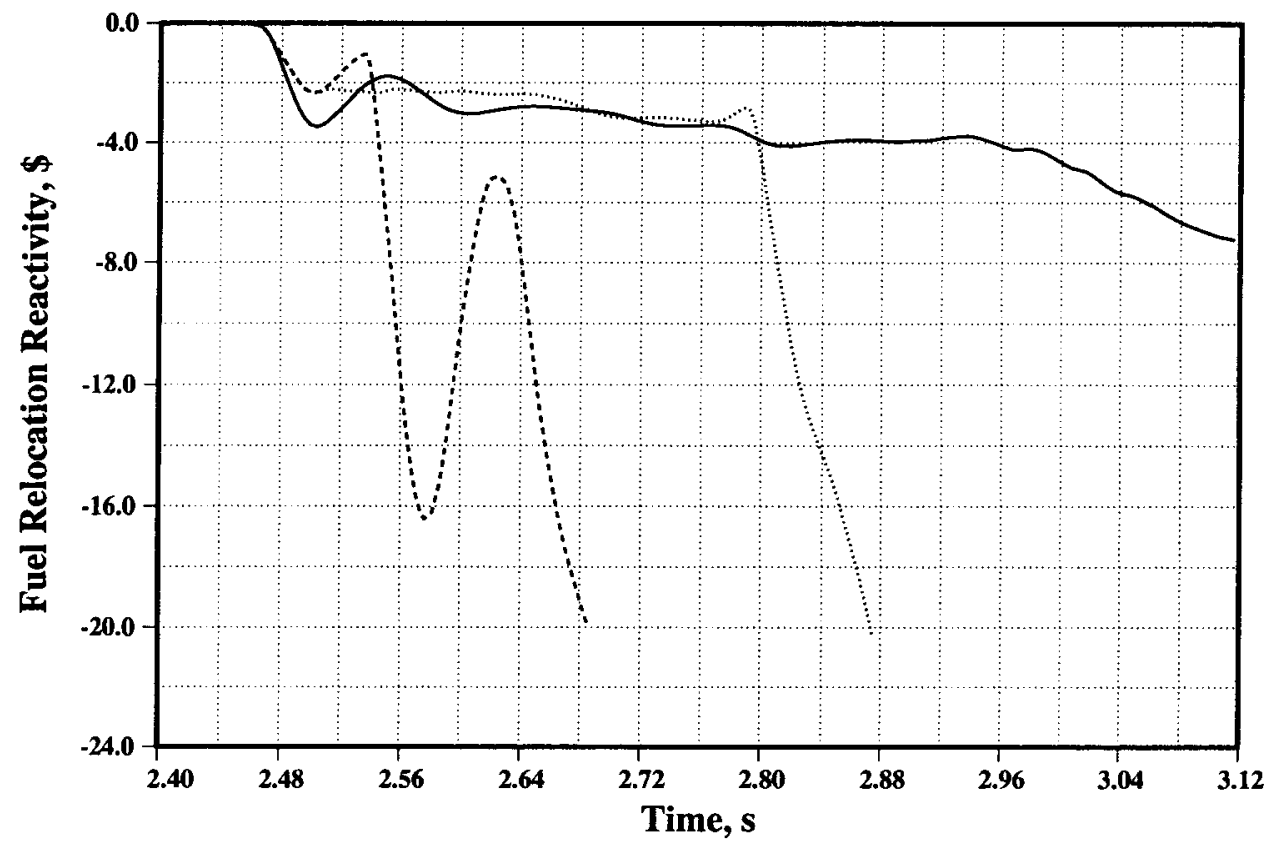

Fig. 50. Comparison of Case 6 (Dashed Curve) and Case 7 (Dotted Curve) with Reference Transient (Solid Curve) for the 3500-MWt Reactor 


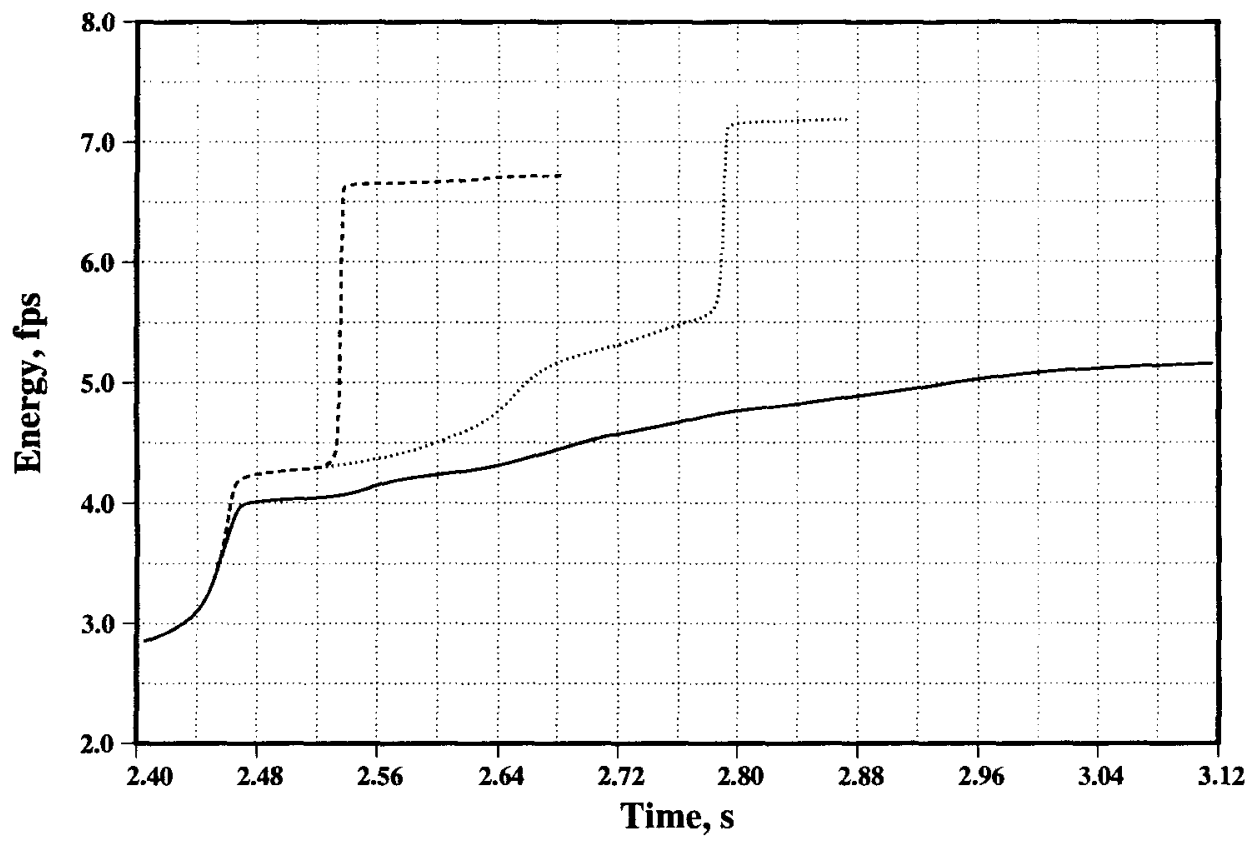

Fig. 51. Comparison of Case 6 (Dashed Curve) and Case 7 (Dotted Curve) with Reference Transient (Solid Curve) for the 3500-MWt Reactor 


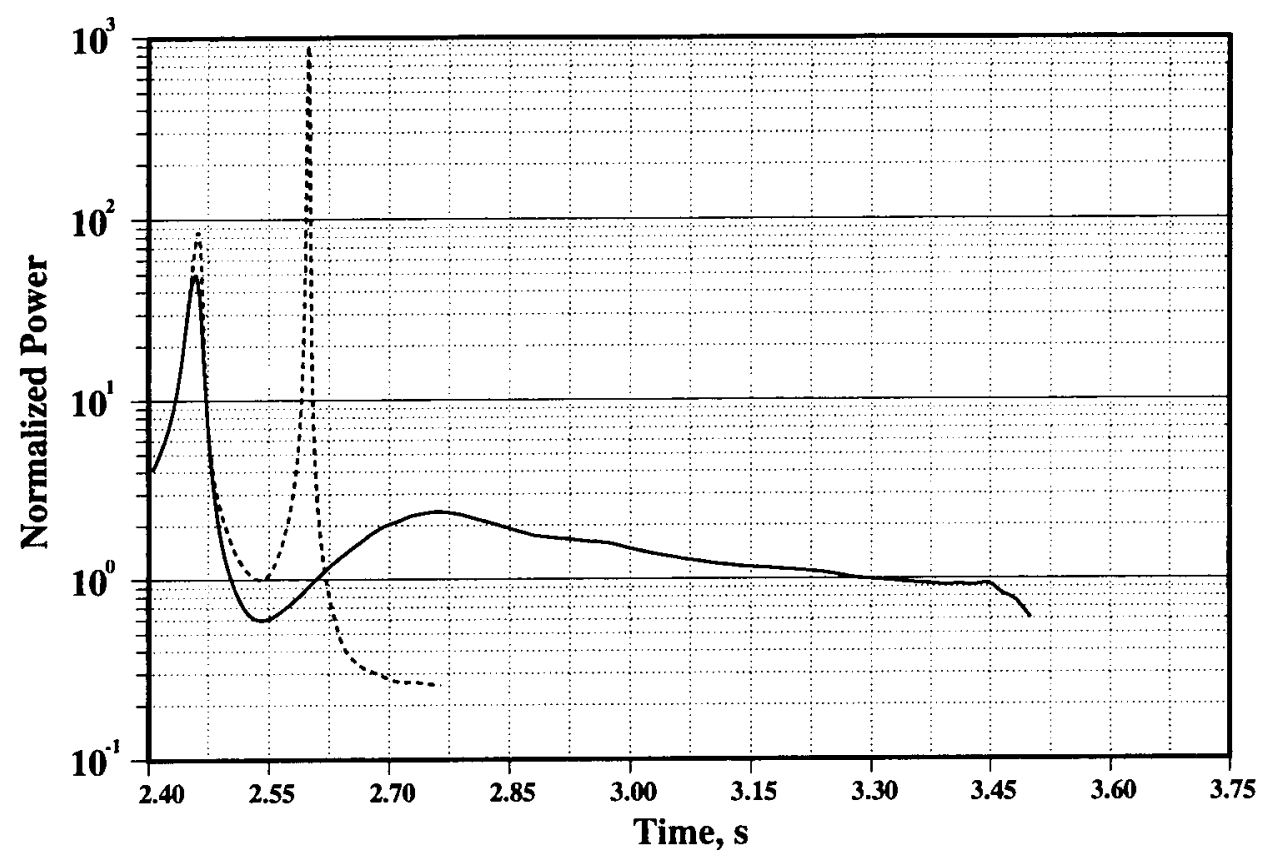

Fig. 52. Comparison of Case 4 (Solid Curve) and Case 8 (Dashed Curve) for the 3500-MWt Reactor

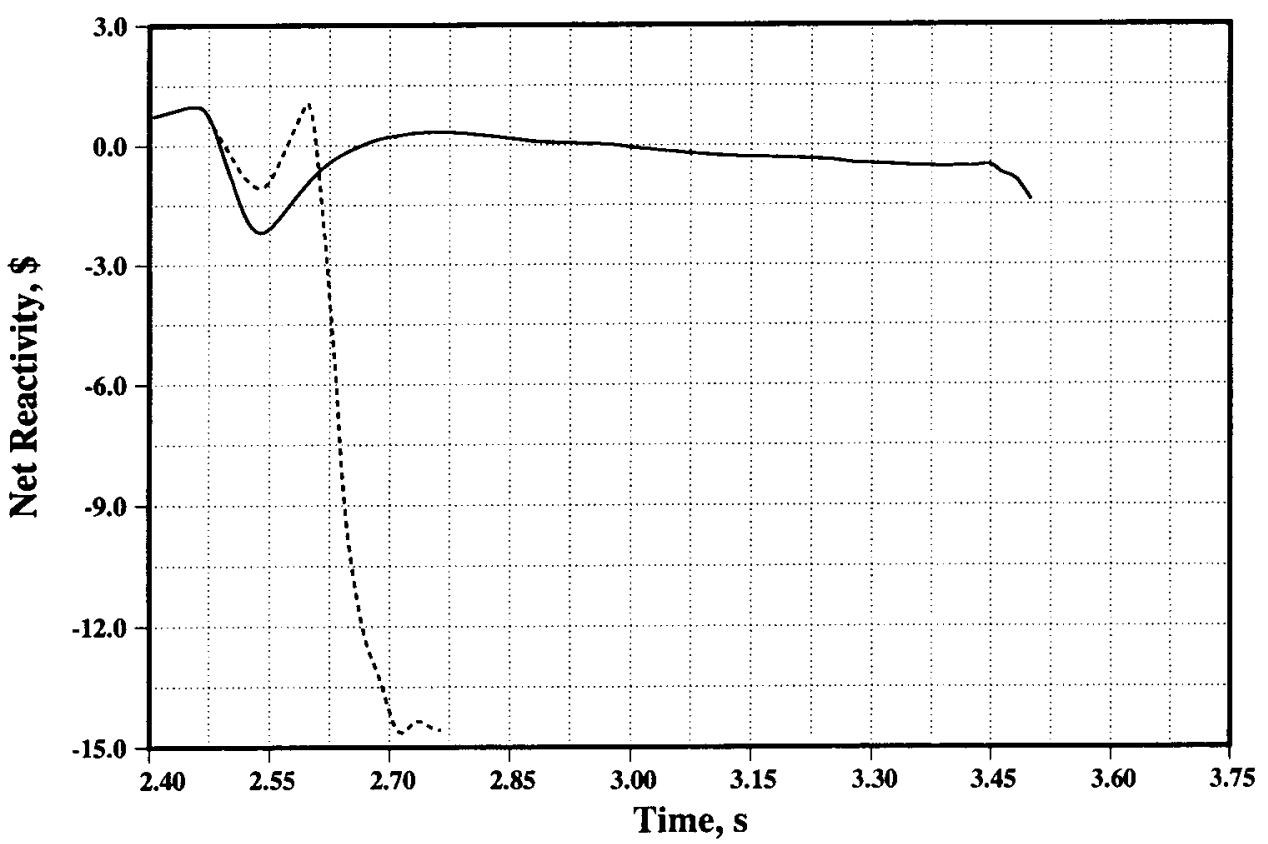

Fig. 53. Comparison of Case 4 (Solid Curve) and Case 8 (Dashed Curve) for the 3500-MWt Reactor 


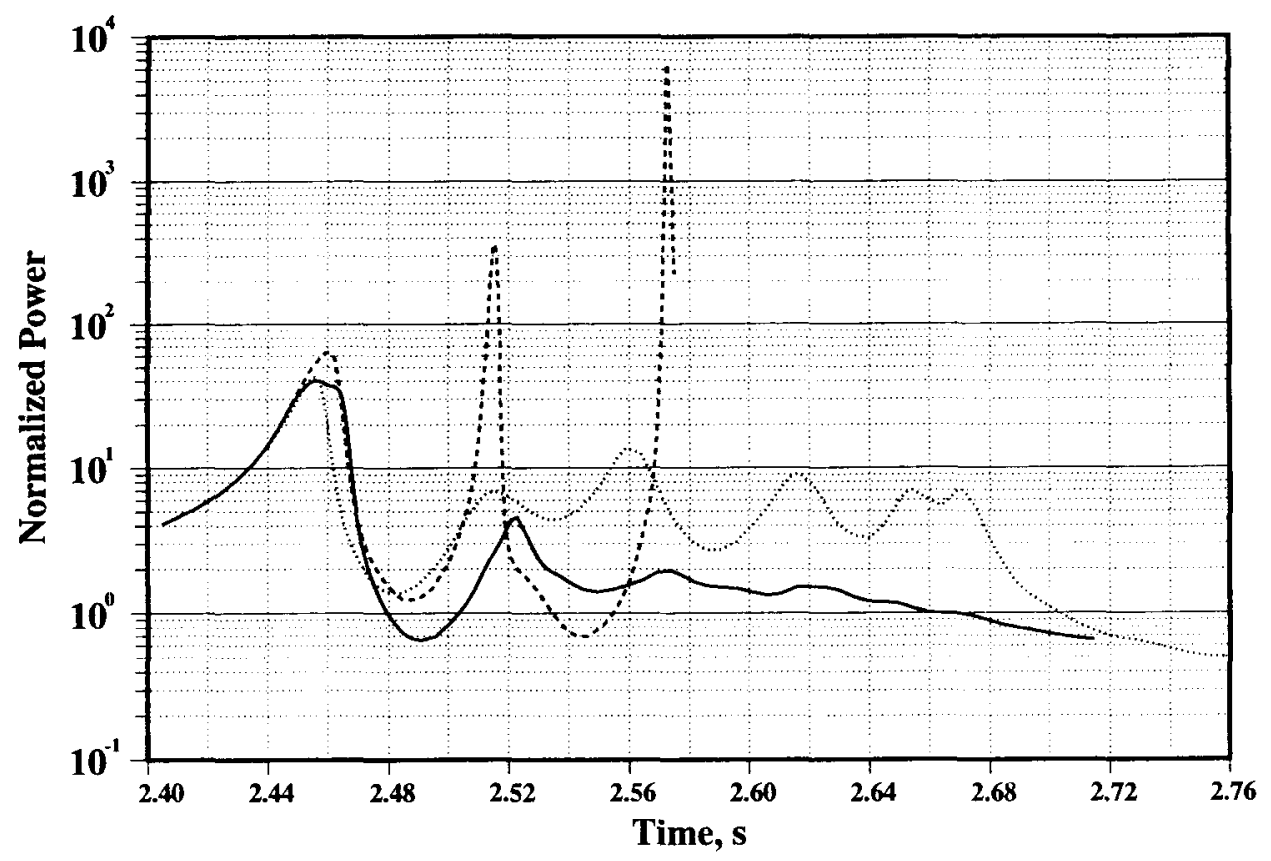

Fig. 54. Comparison of Cases 5 (Solid Curve), 9 (Dashed Curve), and 10 (Dotted Curve) for the 3500-MWt Reactor

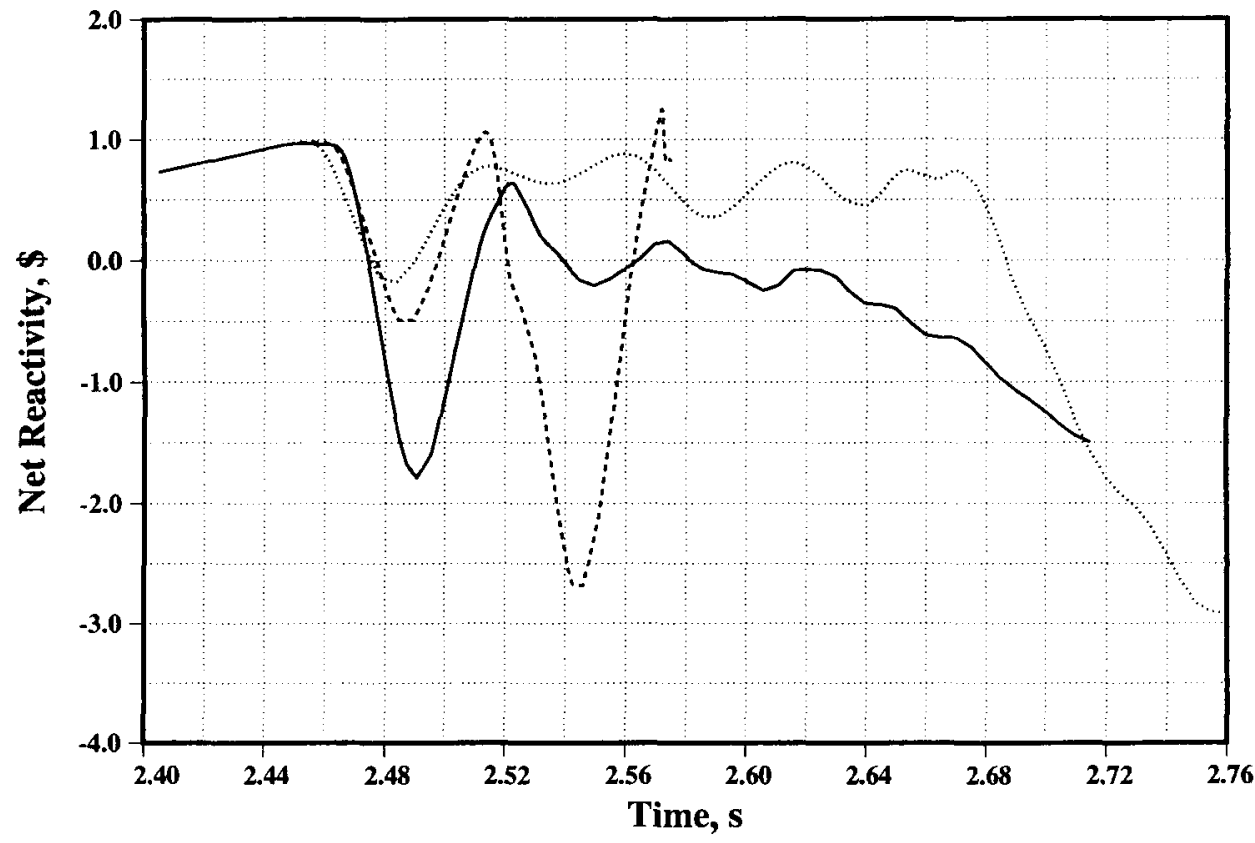

Fig. 55. Comparison of Cases 5 (Solid Curve), 9 (Dashed Curve), and 10 (Dotted Curve) for the 3500-MWt Reactor 


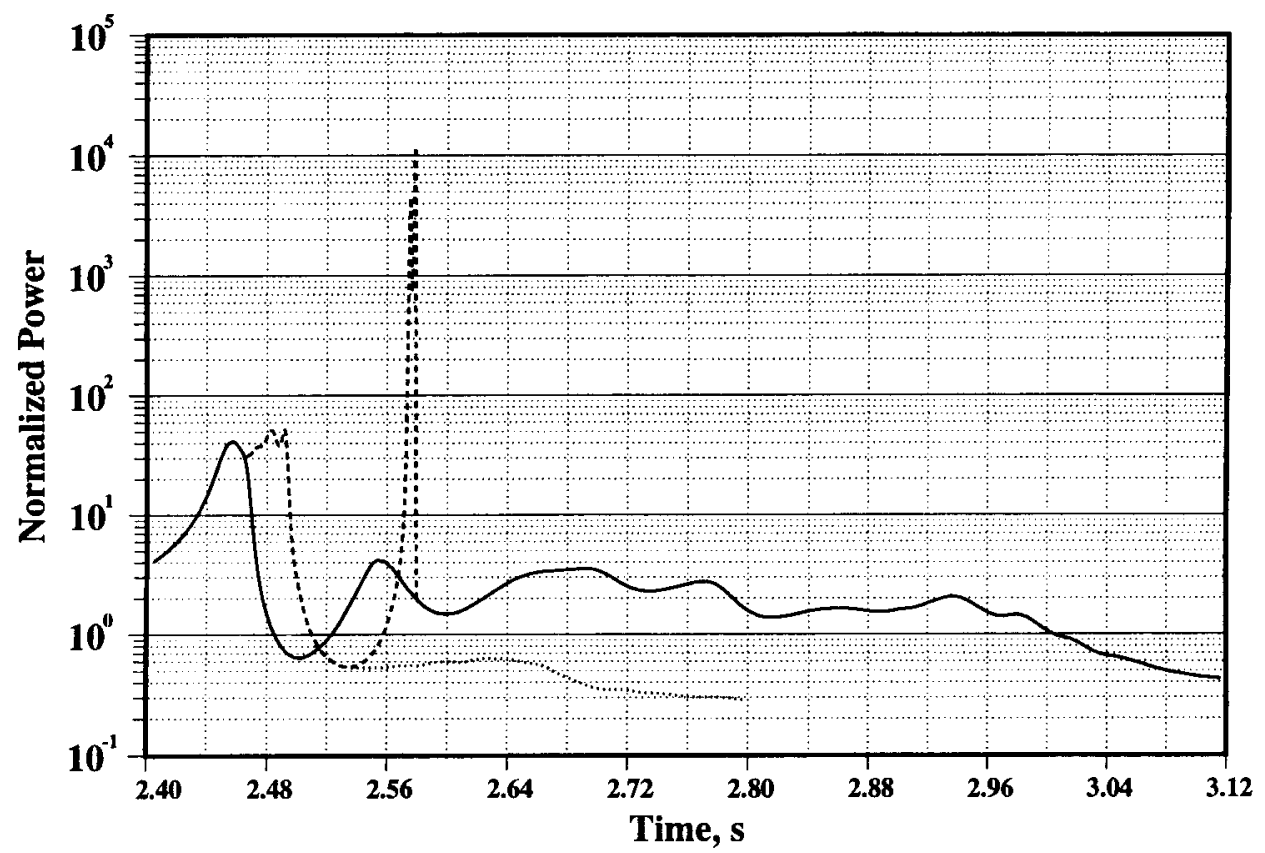

Fig. 56. Comparison of Case 11 (Dashed Curve) and Case 12 (Dotted Curve) with Reference Transient (Solid Curve) for the 3500-MWt Reactor

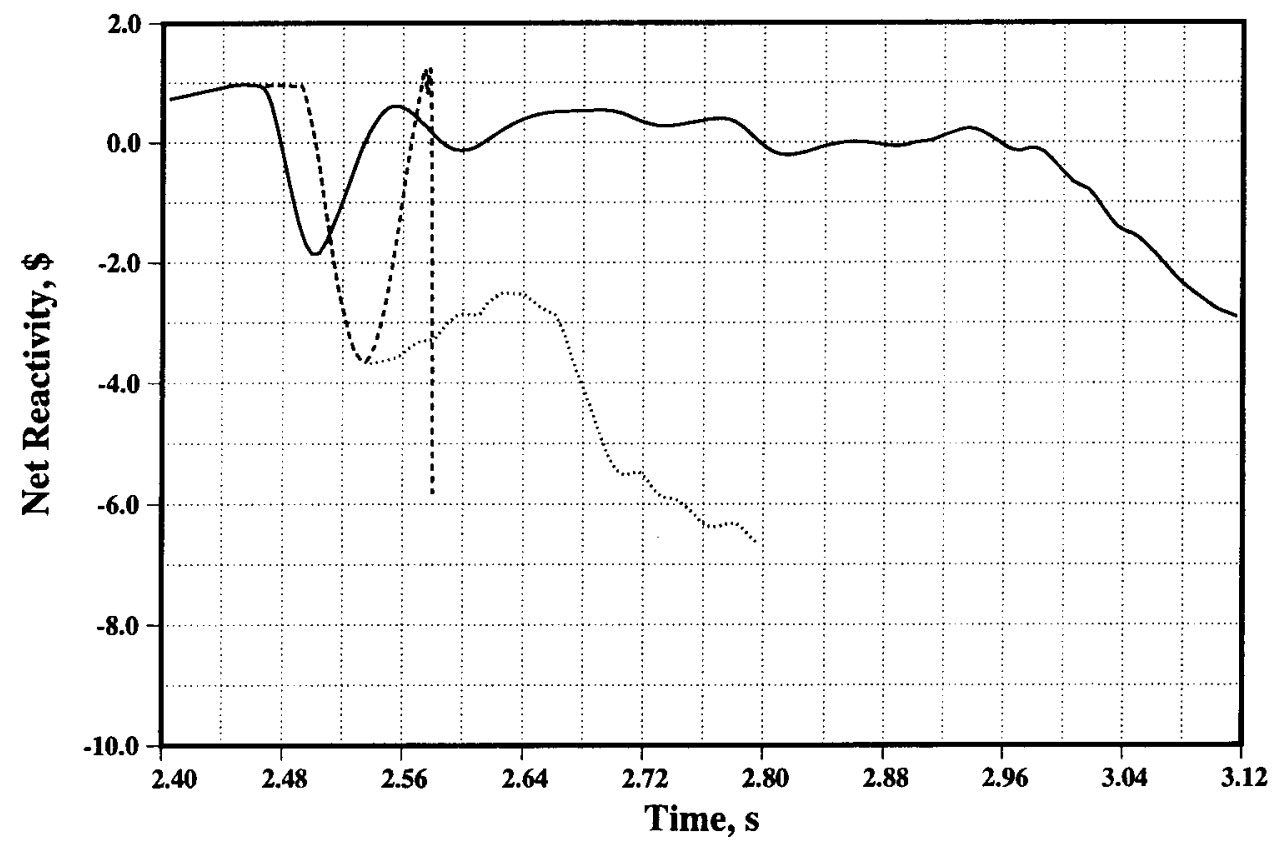

Fig. 57. Comparison of Case 11 (Dashed Curve) and Case 12 (Dotted Curve) with Reference Transient (Solid Curve) for the 3500-MWt Reactor 


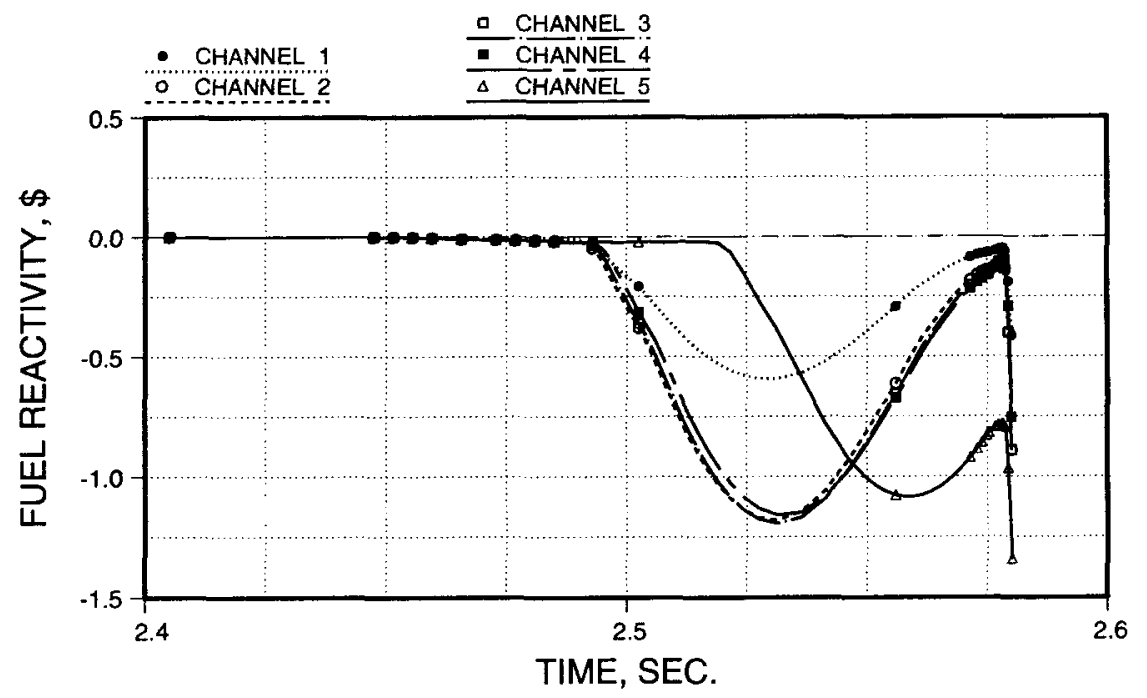

Fig. 58. Channel Dependent Fuel Motion Reactivity Feedback for Case 11

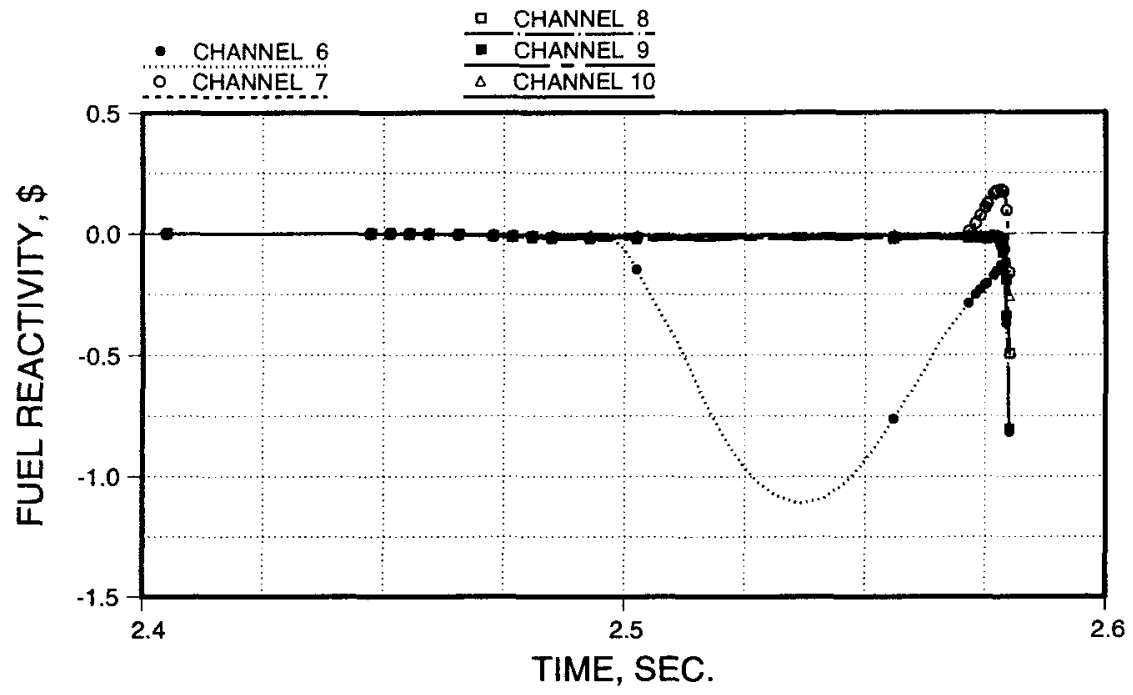

Fig. 59. Channel Dependent Fuel Motion Reactivity Feedback for Case 11 


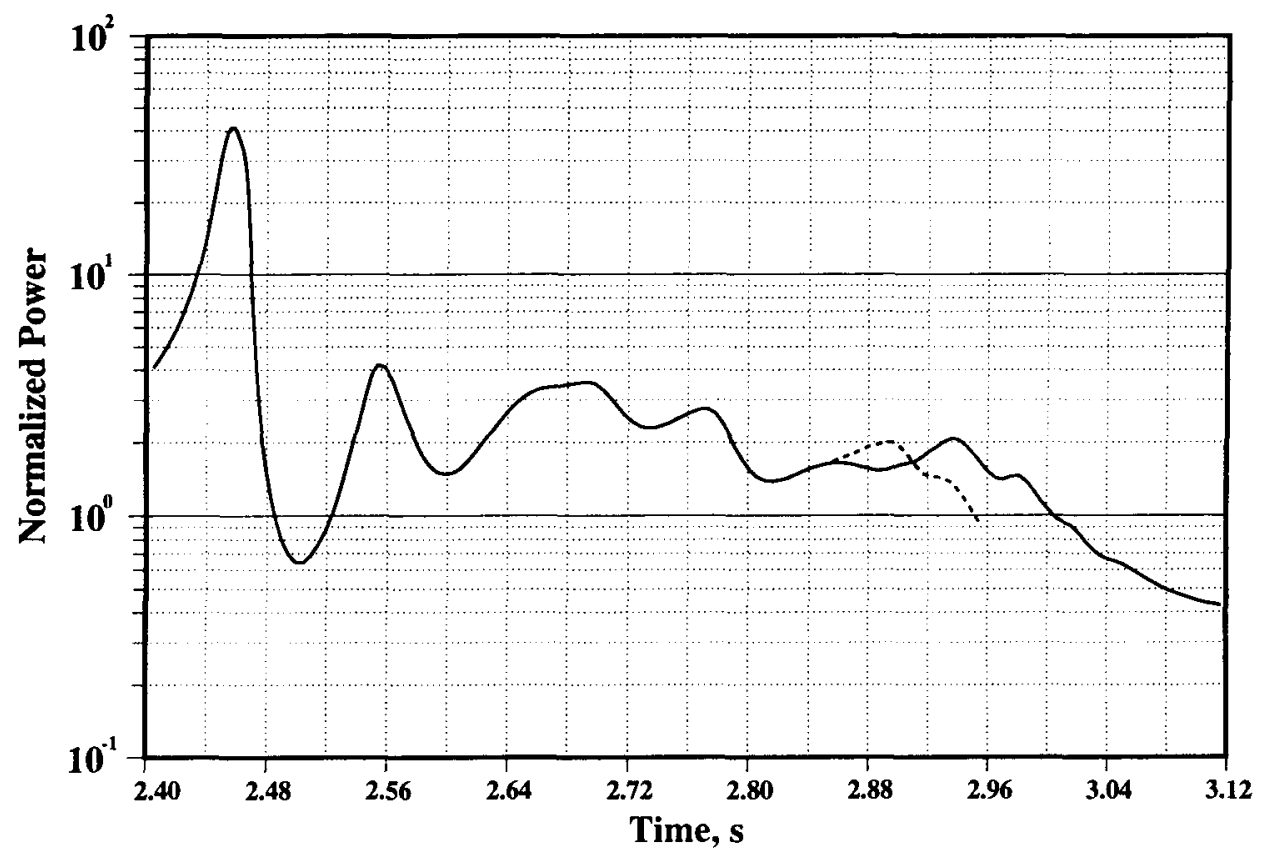

Fig. 60. Comparison of Case 13 (Dashed Curve) with the Reference Transient (Solid Curve) for the 3500-MWt Reactor

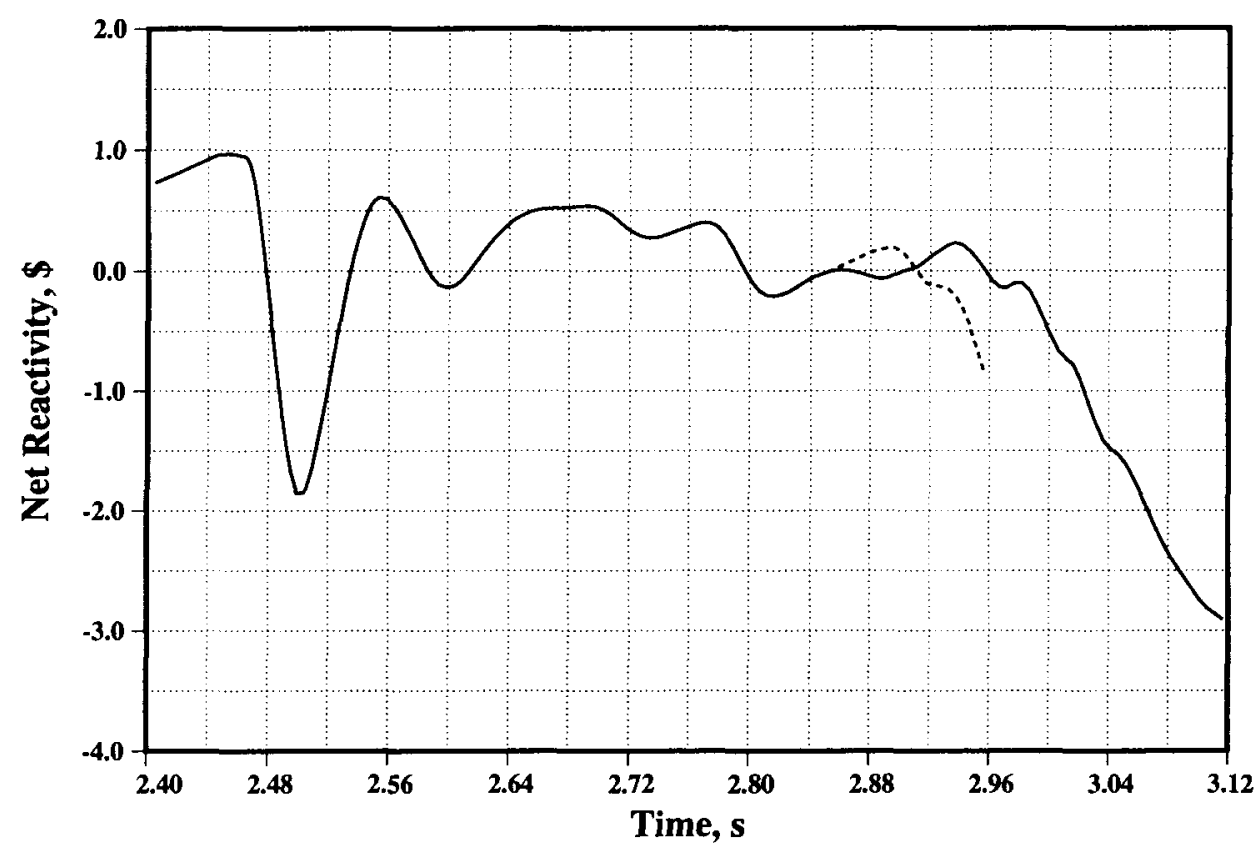

Fig. 61. Comparison of Case 13 (Dashed Curve) with the Reference Transient (Solid Curve) for the 3500-MWt Reactor 


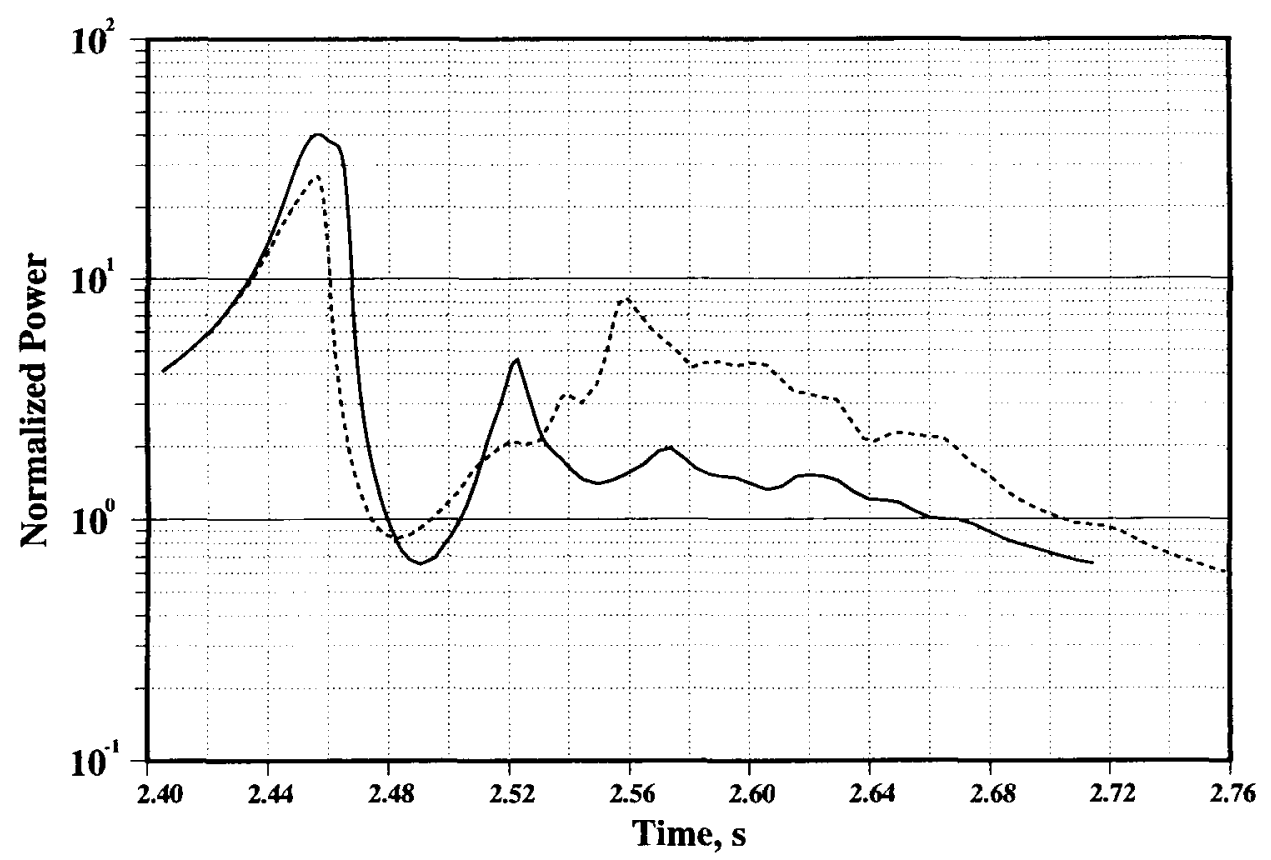

Fig. 62. Comparison of Case 14 (Dashed Curve) with Case 5 (Solid Curve) for the 3500-MWt Reactor

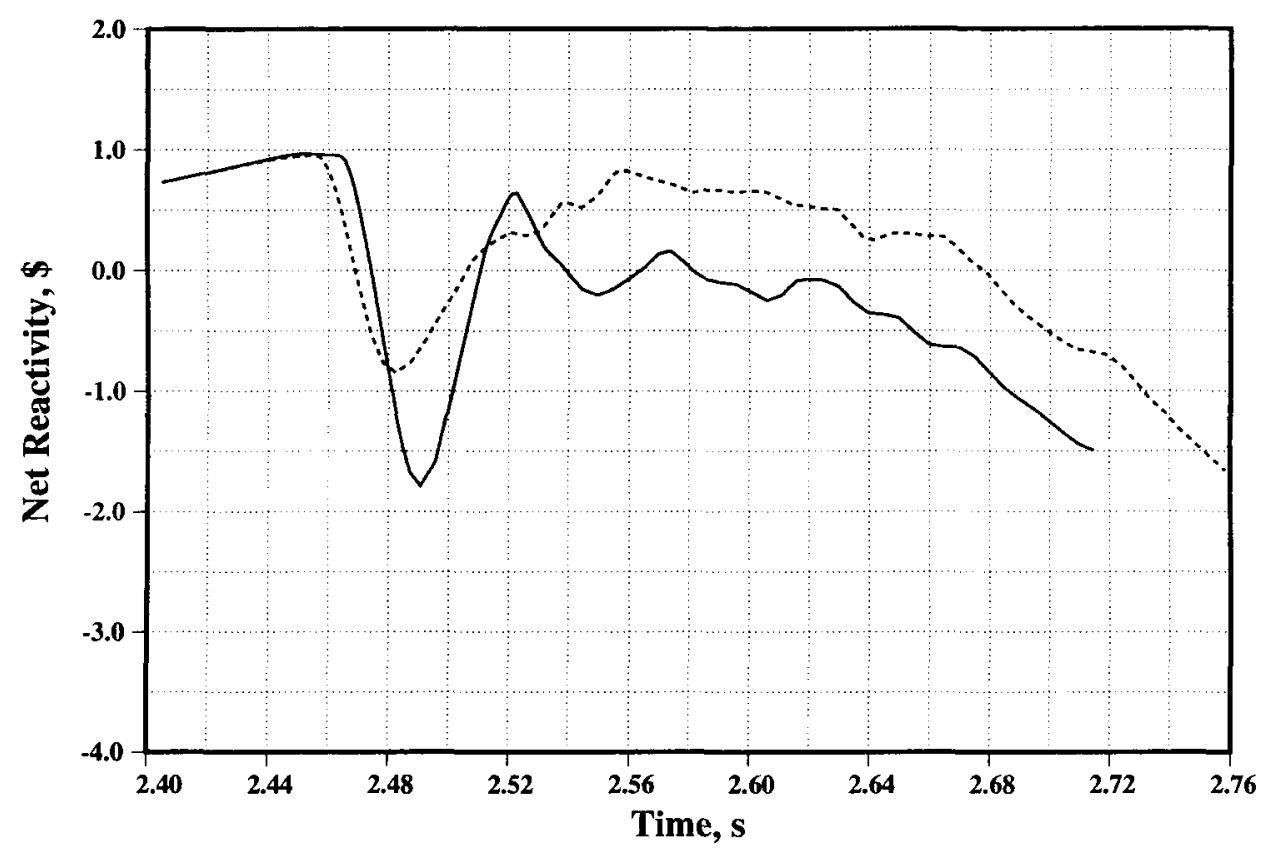

Fig. 63. Comparison of Case 14 (Dashed Curve) with Case 5 (Solid Curve) for the 3500-MWt Reactor 


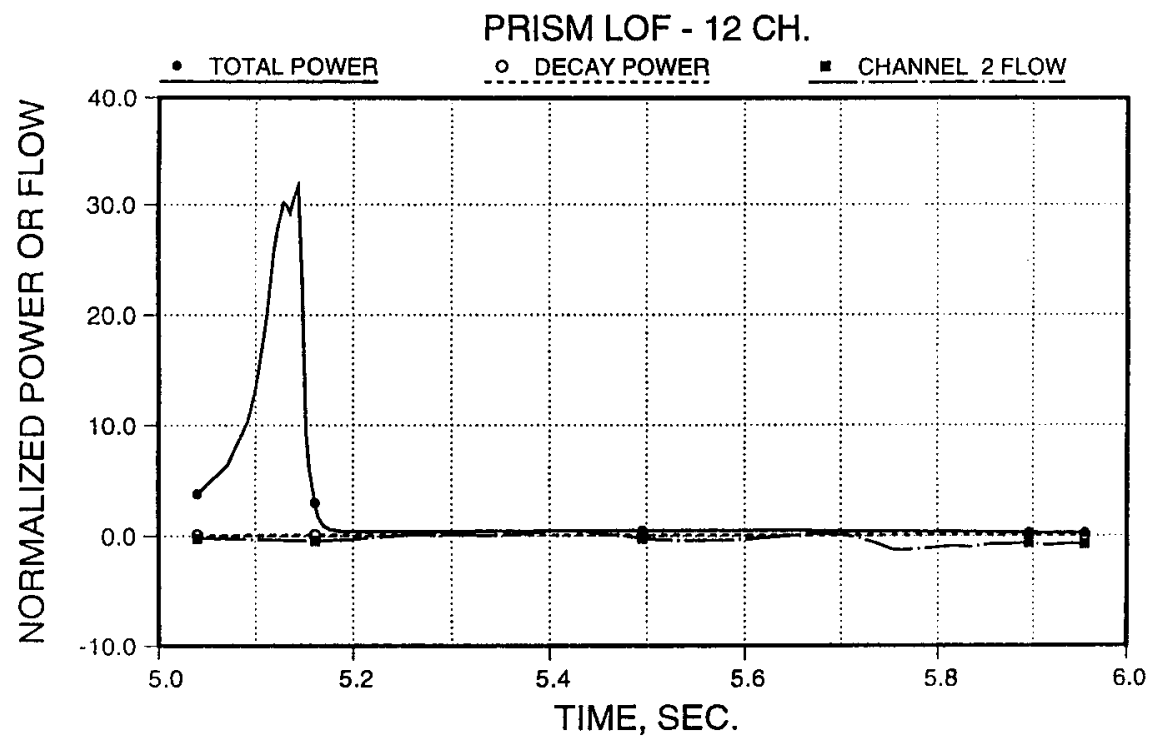

Fig. 64. Power and Flow During the Reference Transient for the PRISM Mod B/92

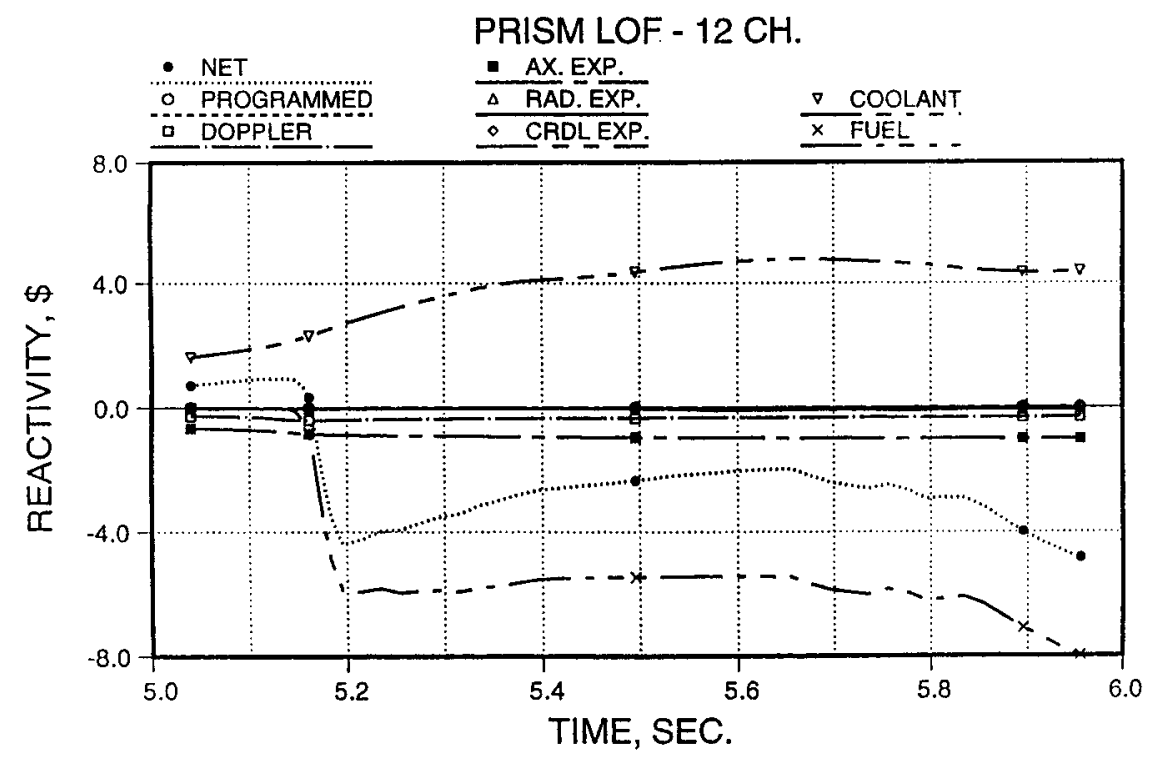

Fig. 65. Net and Component Reactivities During the Reference Transient for the PRISM Mod B/92 


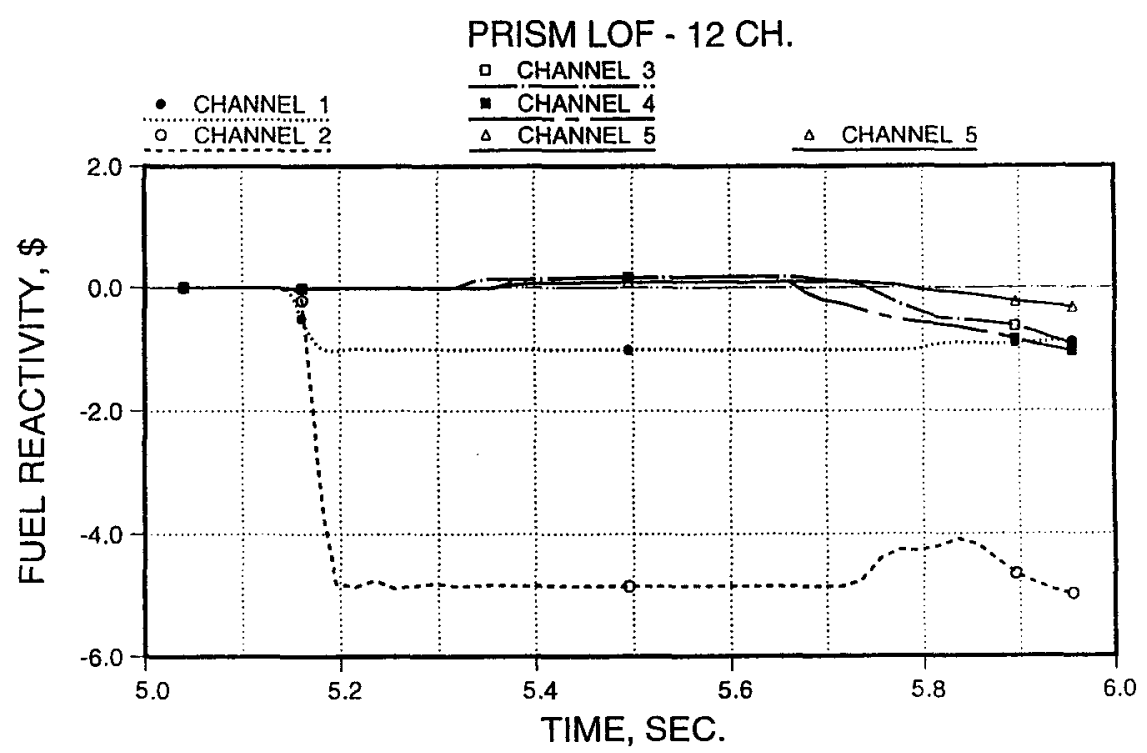

Fig. 66. Channel Dependent Fuel Motion Reactivity Feedback During the Reference Transient for the PRISM Mod B/92

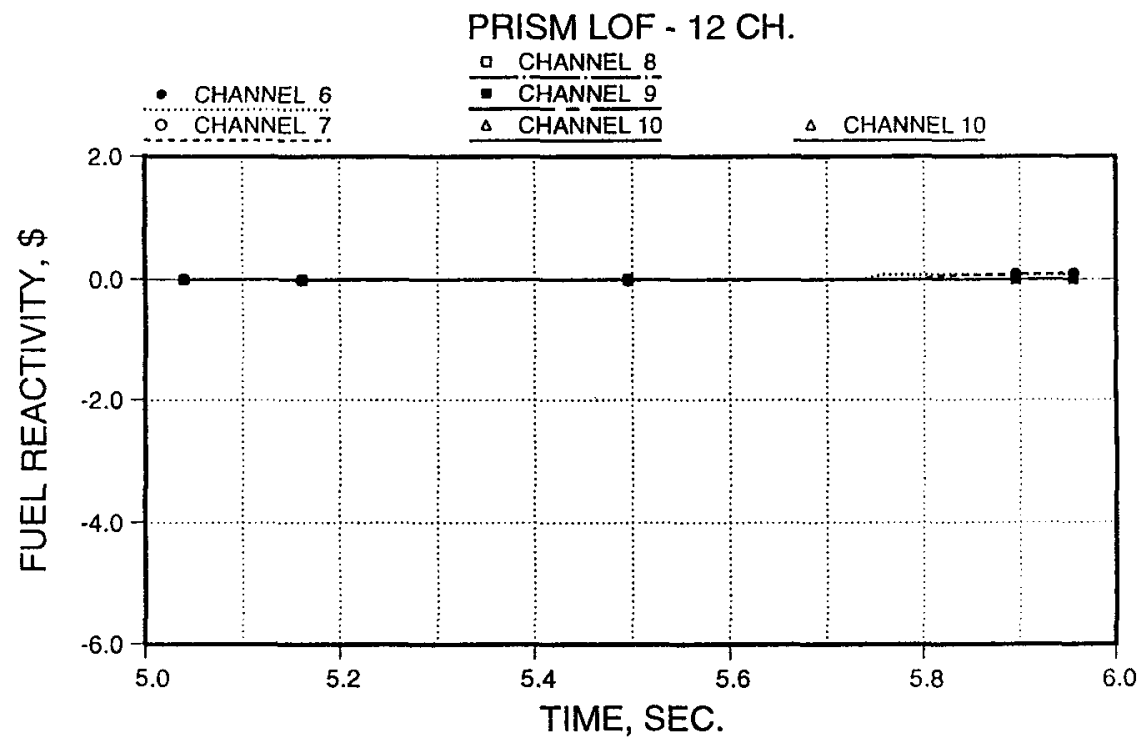

Fig. 67. Channel Dependent Fuel Motion Reactivity Feedback During the Reference Transient for the PRISM Mod B/92 


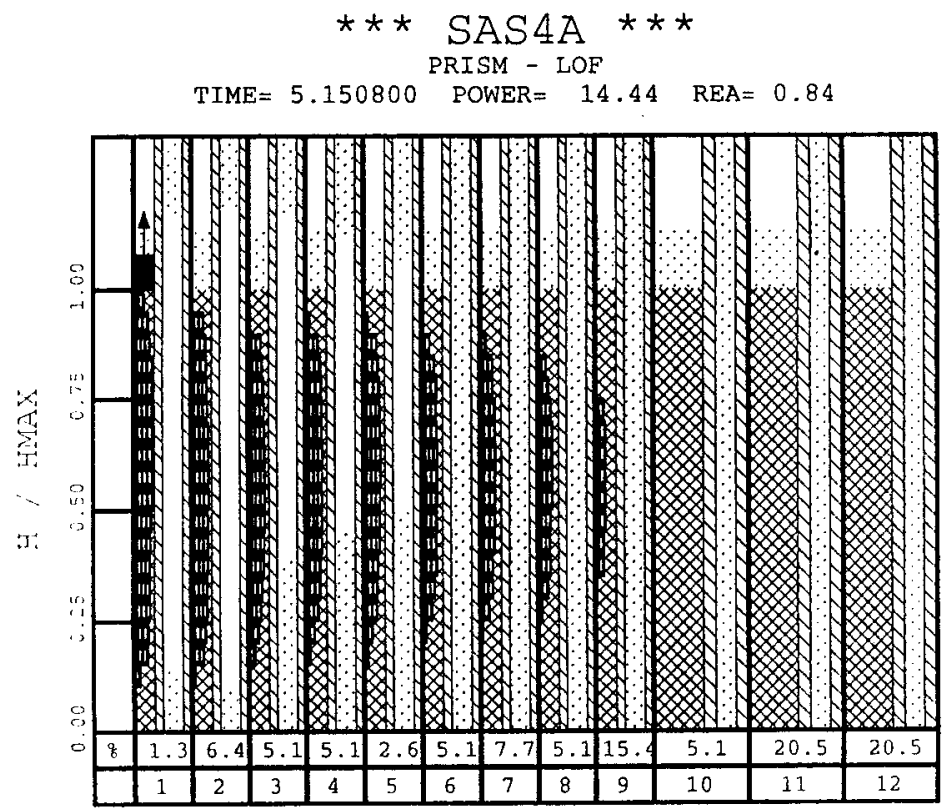

CHANNEL

Fig. 68. Status of the Core at $5.15 \mathrm{~s}$ During the Reference Transient for the PRISM Mod B/92

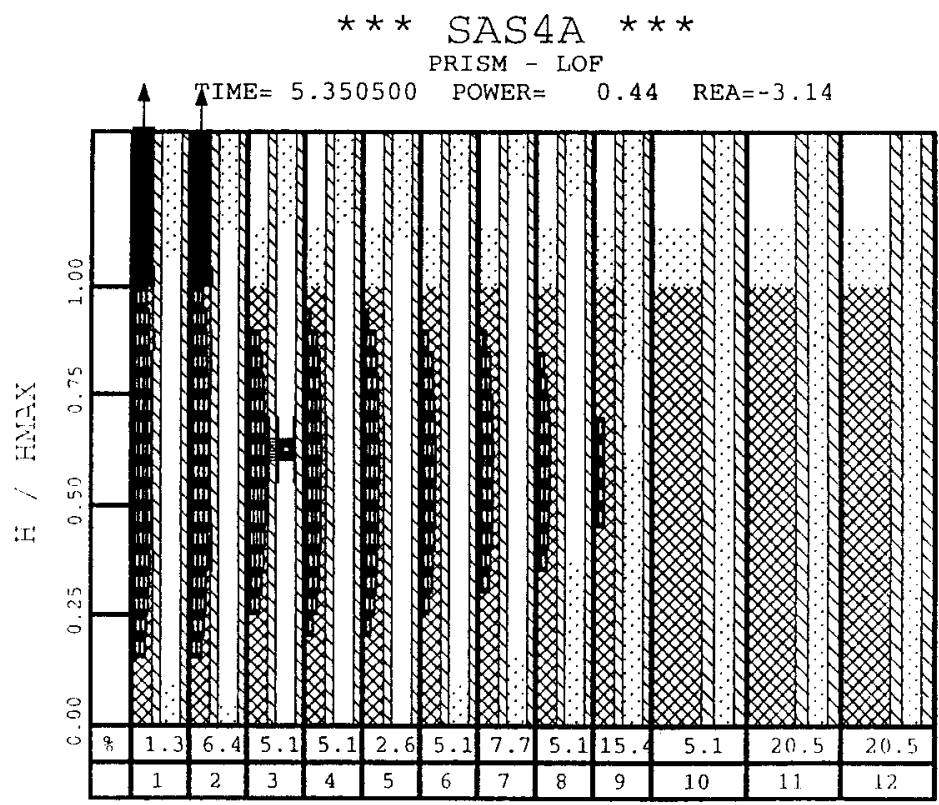

CHANNEL

Fig. 69. Status of the Core at $5.35 \mathrm{~s}$ During the Reference Transient for the PRISM Mod B/92 


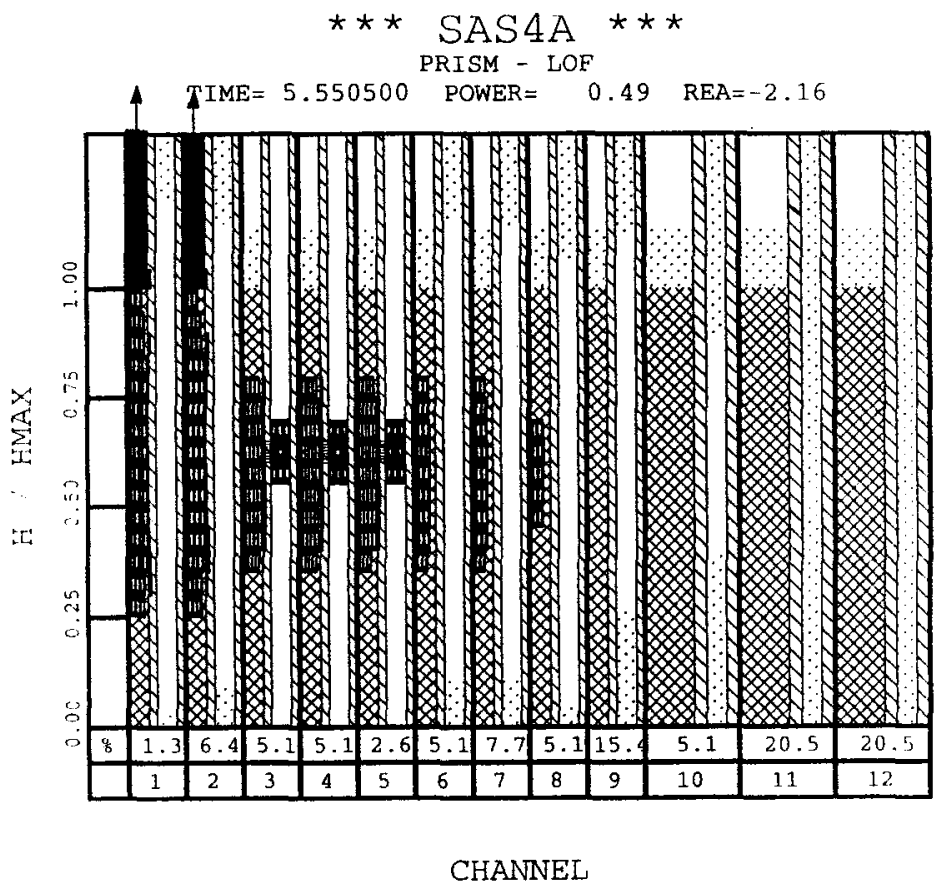

Fig. 70. Status of the Core at $5.55 \mathrm{~s}$ During the Reference Transient for the PRISM Mod B/92 


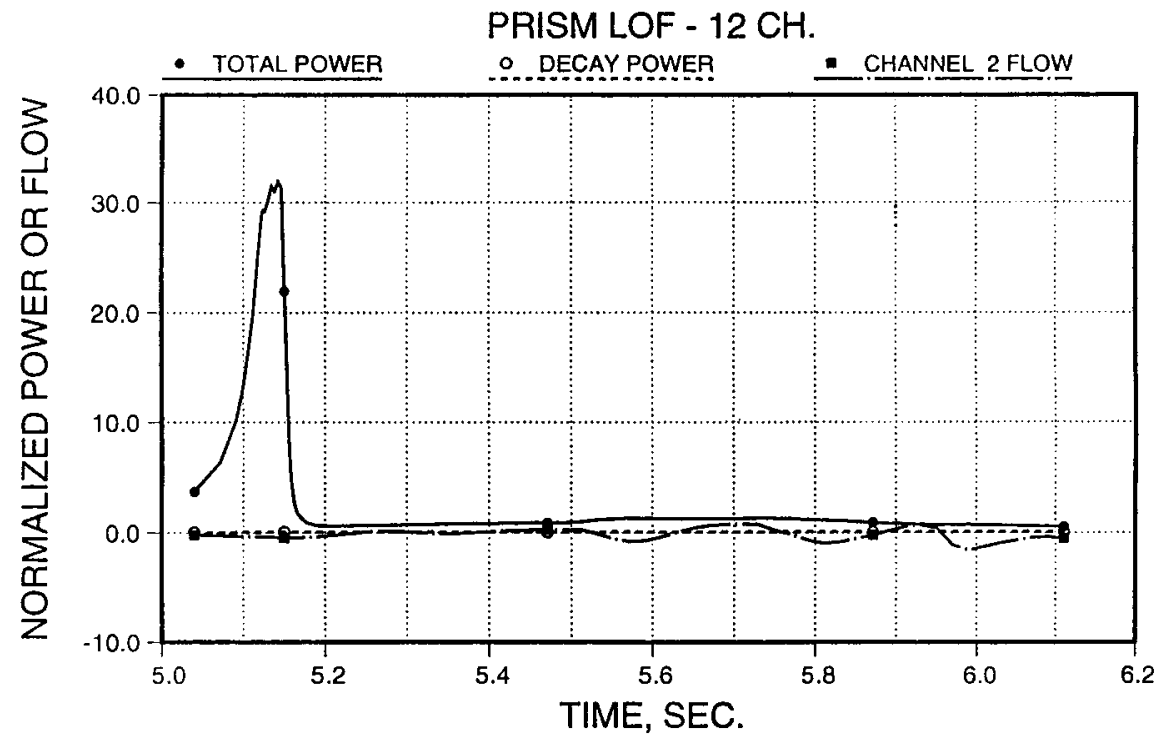

Fig. 71. Power and Flow During Case 1 for the PRISM Mod B/92

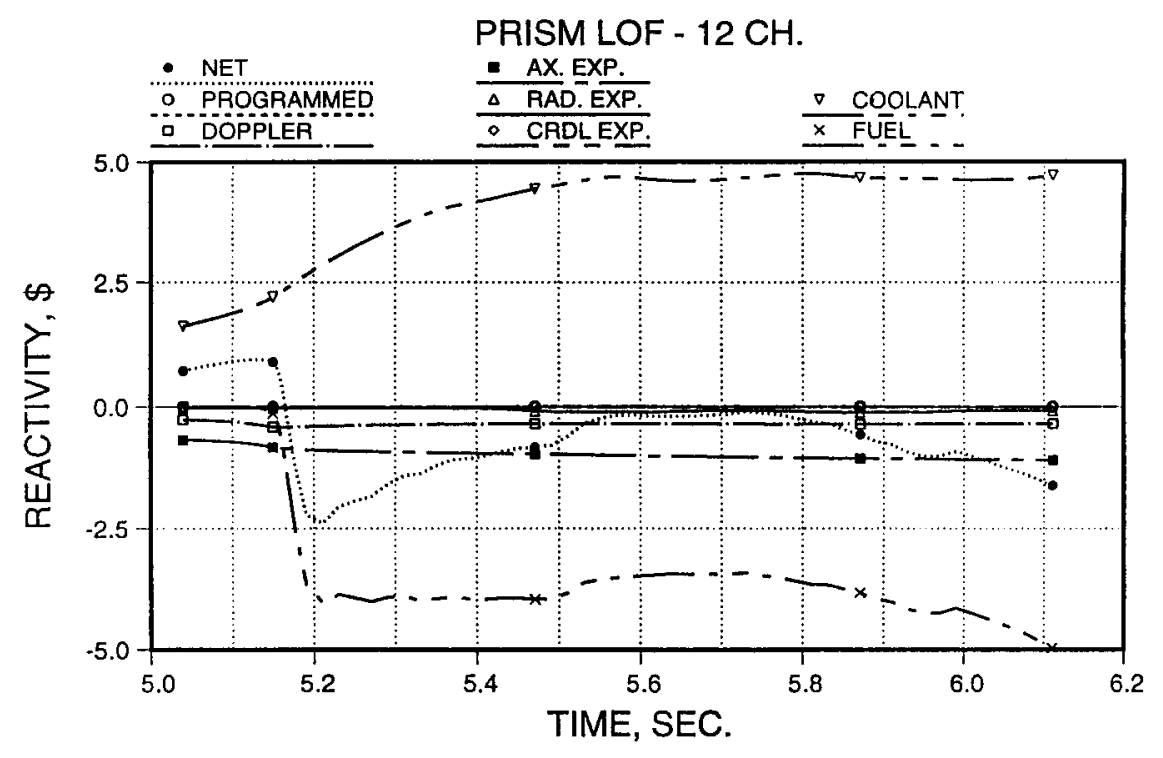

Fig. 72. Net and Component Reactivities During Case 1 for the PRISM Mod B/92 


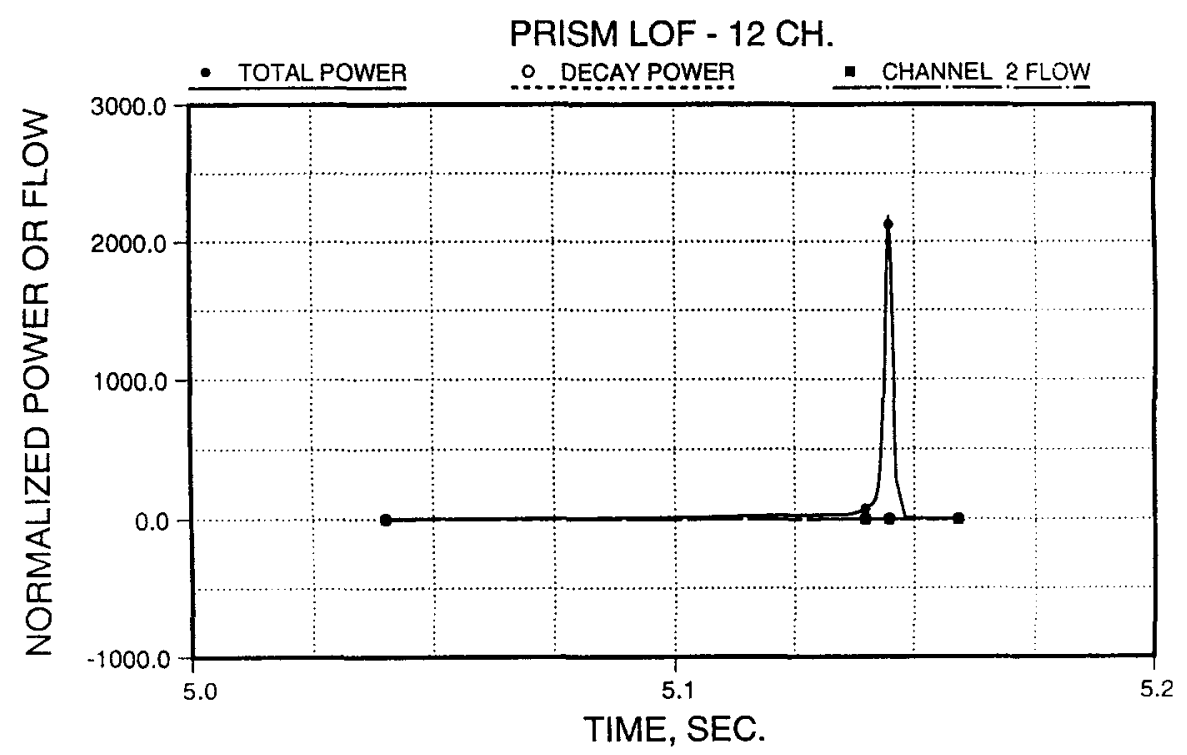

Fig. 73. Power and Flow During Case 2 for the PRISM Mod B/92

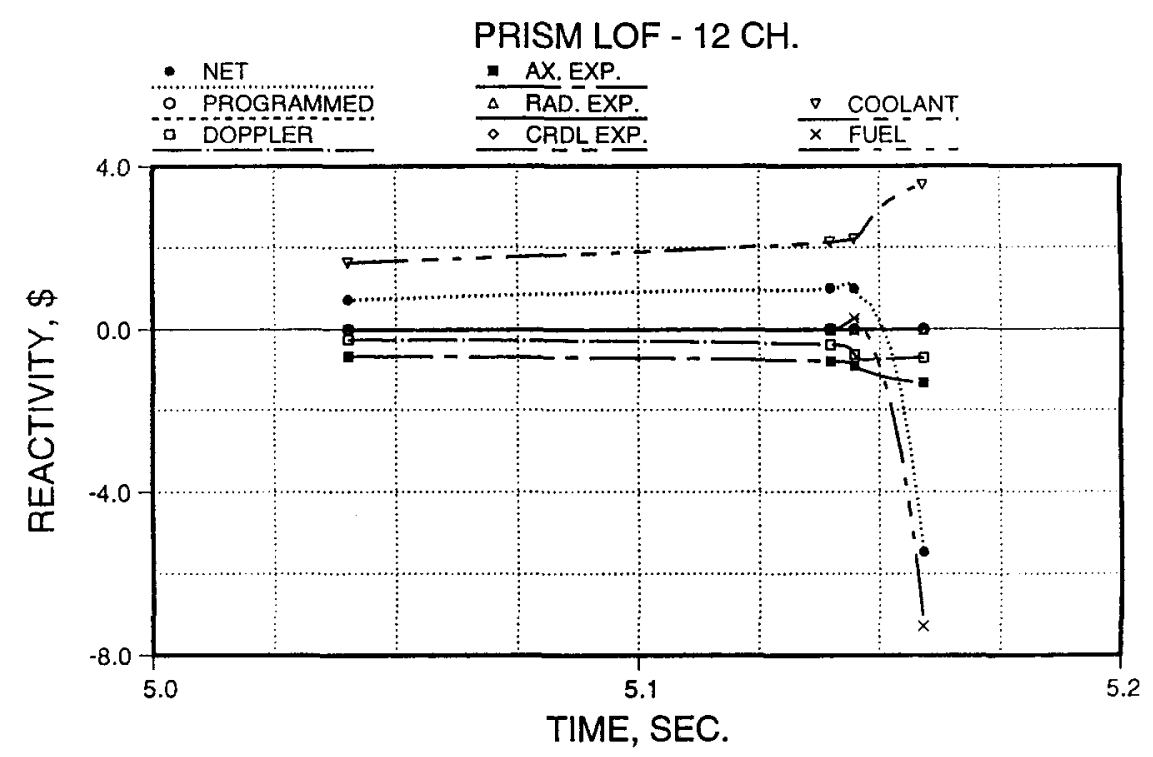

Fig. 74. Net and Component Reactivities During Case 2 for the PRISM Mod B/92 


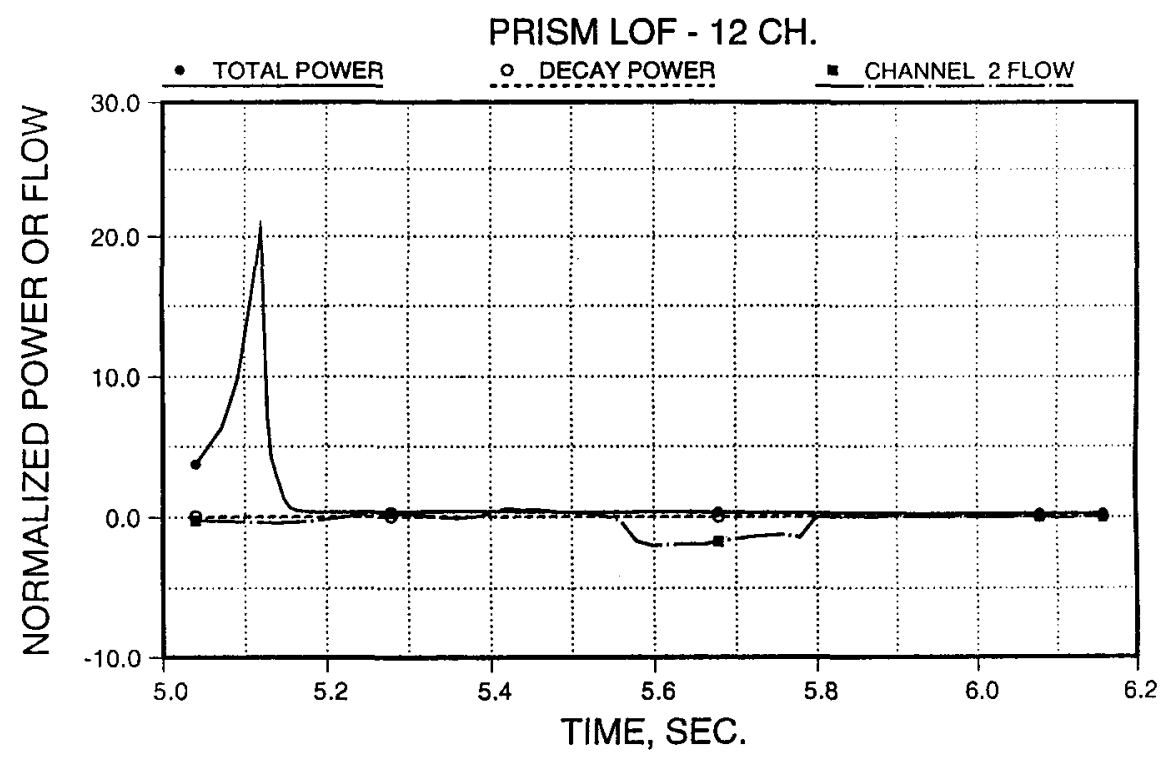

Fig. 75. Power and Flow During Case 3 for the PRISM Mod B/92 


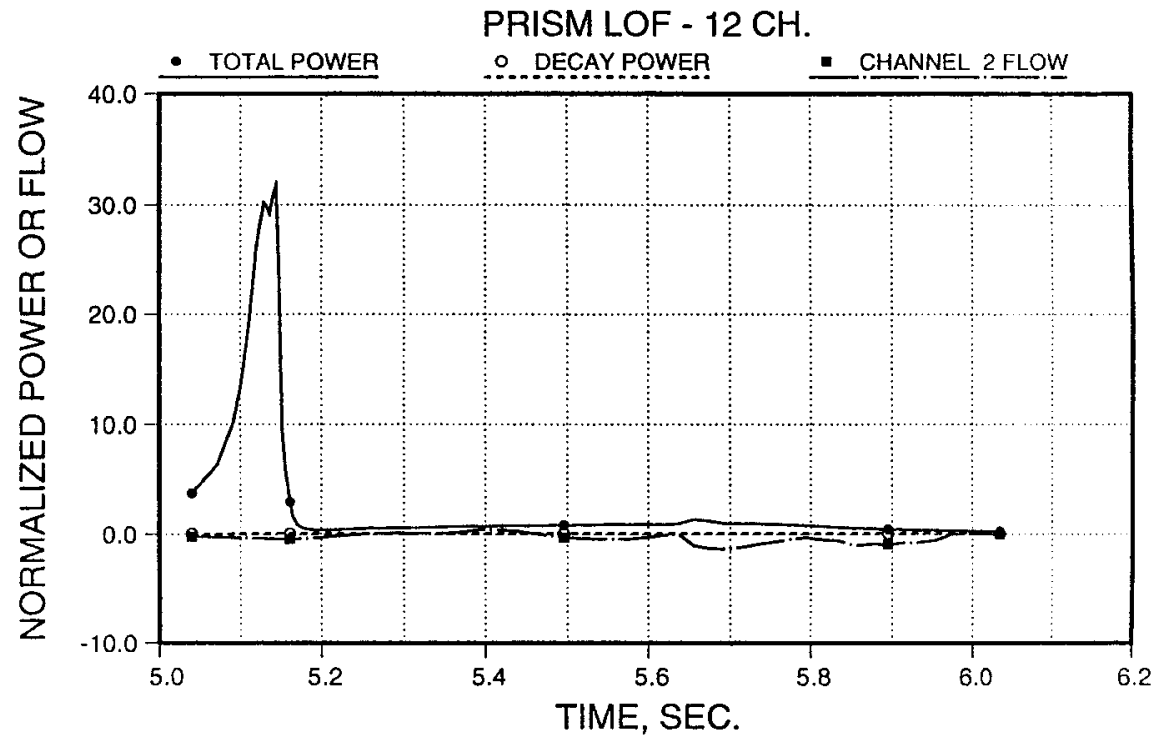

Fig. 76. Power and Flow During Case 4 for the PRISM Mod B/92

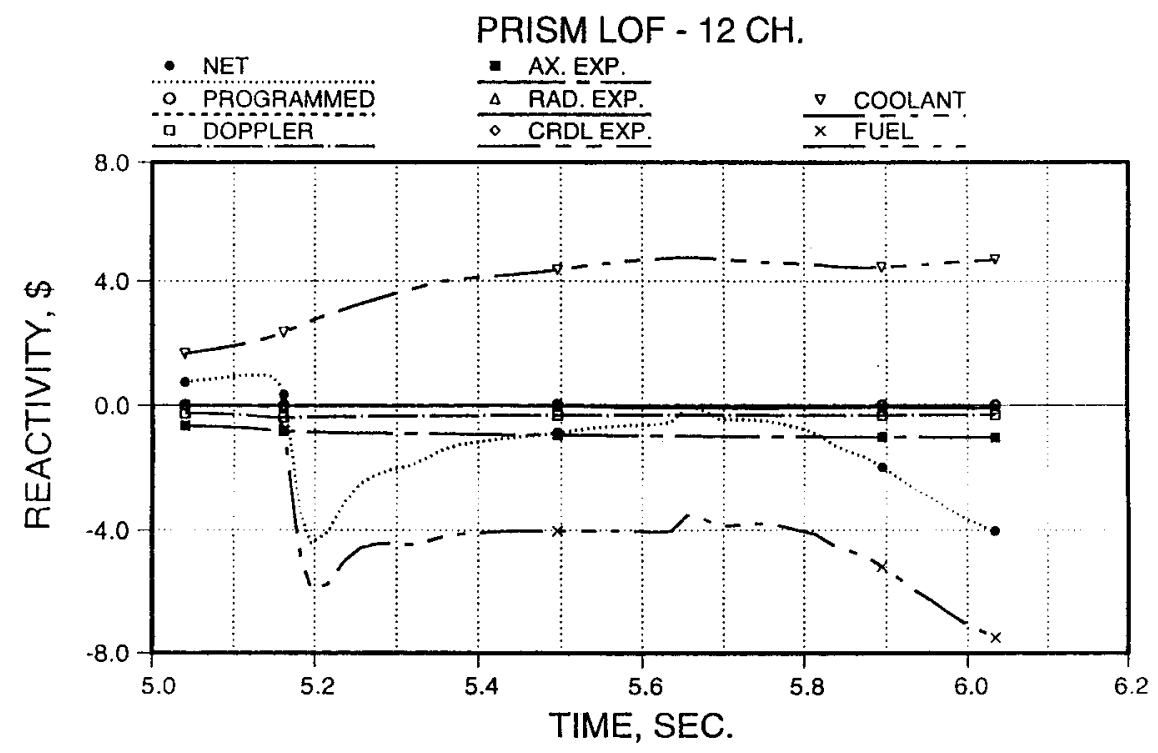

Fig. 77. Net and Component Reactivities During Case 4 for the PRISM Mod B/92 